\title{
Reaction of nitromethane with an iridium pincer complex. Multiple binding modes of the nitromethanate anion
}

\author{
Xiawei Zhang, Thomas J. Emge, Karsten Krogh-Jespersen* and Alan S. Goldman* \\ Department of Chemistry and Chemical Biology, \\ Rutgers-The State University of New Jersey, Piscataway, New Jersey, 08854
}

\section{Supporting Information}

I. X-ray Structure Determinations

Page \#

II. Structural Data for $\mathbf{1}$
(a) Figure S-1. ORTEP Diagram of 1
S3
(b) Table S-1. Crystal data and structure refinement for 1
S4
(c) Table S-2. Atomic coordinates for 1
S5
(d) Table S-3. Selected bond lengths and angles for $\mathbf{1}$
S6
(e) Table S-4. Torsion angles [ $\left.{ }^{\circ}\right]$ for $\mathbf{1}$
S8

III. Structural Data for $\mathbf{2}$
(a) Figure S-2. ORTEP Diagram of $\mathbf{2}$
S9
(b) Table S-5. Crystal data and structure refinement for $\mathbf{2}$
S10
(c) Table S-6. Atomic coordinates for $\mathbf{2}$
$\mathrm{S} 11$
(d) Table S-7. Selected bond lengths and angles for $\mathbf{2}$
$\mathrm{S} 12$
(e) Table S-8. Torsion angles $\left[{ }^{\circ}\right]$ for $\mathbf{2}$
S14

IV. Structural Data for 3
(a) Figure S-3. ORTEP Diagram of $\mathbf{3}$
S15
(b) Table S-9. Crystal data and structure refinement for $\mathbf{3}$
(c) Table S-10. Atomic coordinates for $\mathbf{3}$
(d) Table S-11. Selected bond lengths and angles for $\mathbf{3}$
S18
(e) Table S-12. Torsion angles $\left[{ }^{\circ}\right]$ for 3

V. Structural Data for $\mathbf{5}$
(a) Figure S-4. ORTEP Diagram of 5
(b) Table S-13. Crystal data and structure refinement for $\mathbf{5}$
(c) Table S-14. Atomic coordinates for 5
S24
(d) Table S-15. Selected bond lengths and angles for 5
S25
(e) Table S-16. Torsion angles $\left[{ }^{\circ}\right]$ for 5
S28 
I. X-ray Structure Determinations. Data were collected on a Bruker Smart APEX CCD diffractometer with graphite monochromatized Mo K $\alpha$ radiation $(\lambda=0.71073 \AA)$ at $100 \mathrm{~K}$. The data were corrected for Lorenz effects and polarization, and absorption, the latter by a multi-scan $(\mathrm{SADABS})^{1}$ method. The structures were solved by Patterson or direct methods (SHELXS86). ${ }^{2}$ All non-hydrogen atoms were refined (SHELXL97) $)^{3}$ based upon $\mathrm{F}_{\mathrm{obs}}{ }^{2}$. All hydrogen atom coordinates were calculated with idealized geometries (SHELXL97). Scattering factors $\left(f_{O}, f^{\prime}, f^{\prime \prime}\right)$ are as described in SHELXL97.

\section{References}

(1) Bruker-AXS. SADABS, Bruker Nonius area detector scaling and absorption correction, v2.05, Bruker-AXS Inc., Madison, Wisconsin, 2003.

(2) Sheldrick, G. M. SHELXS86, Program for the Solution of Crystal Structures, University of Göttingen, Germany, 1986.

(3) Sheldrick, G. M. SHELXL97, Program for Crystal Structure Refinement, University of Göttingen, Germany, 1997. 
II. Structural Data for 1

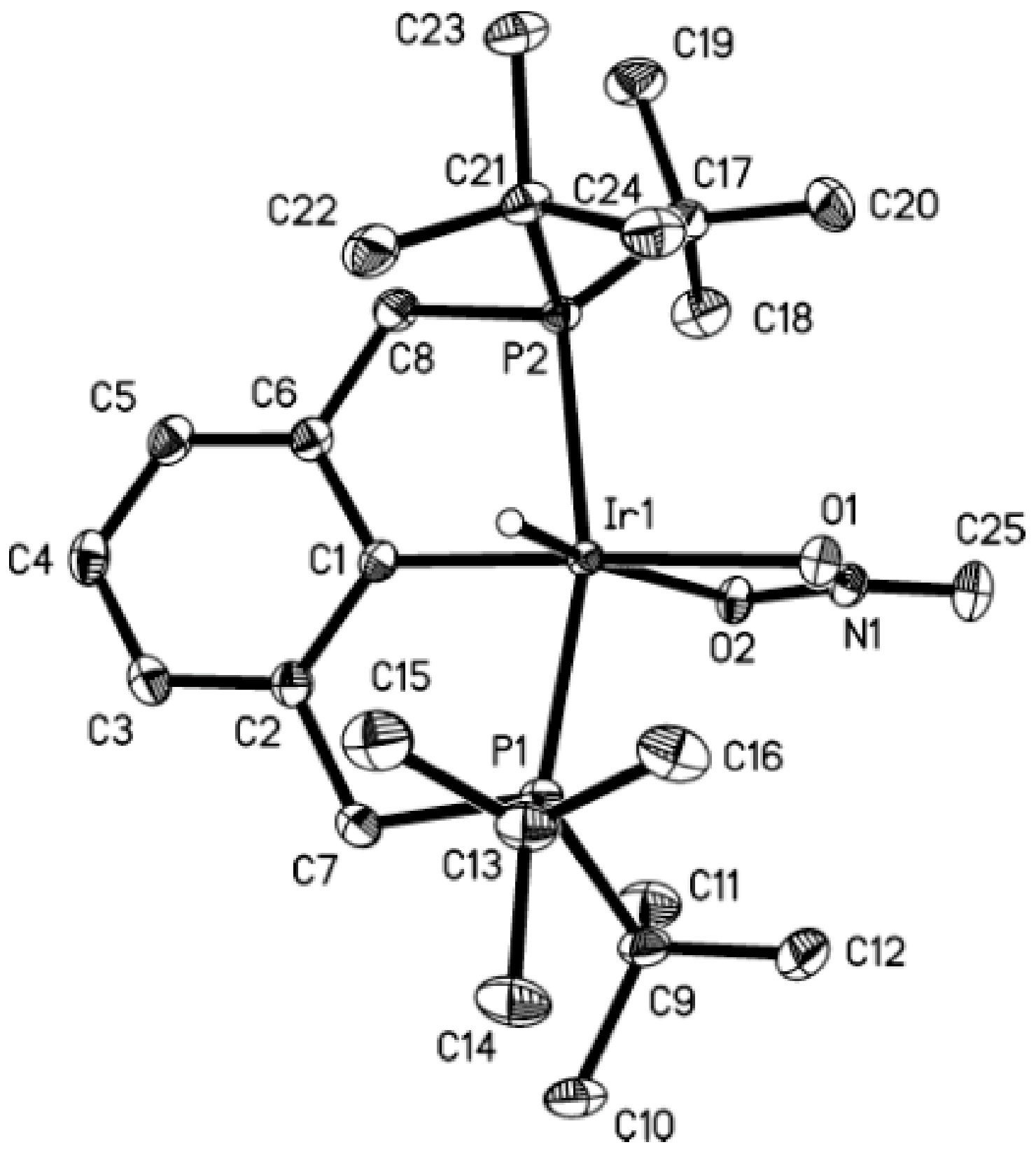

Figure S-1. ORTEP diagrams of $\mathbf{1}$. Hydrogen atoms omitted for clarity. Thermal ellipsoids are shown at $50 \%$ probability. 
Table S-1. Crystal data and structure refinement for $\mathbf{1}$.

\begin{tabular}{|c|c|c|}
\hline Identification code & \multicolumn{2}{|l|}{ irhno2ch2 } \\
\hline Empirical formula & \multicolumn{2}{|c|}{ C25 H46 Ir N O2 P2 } \\
\hline Formula weight & \multicolumn{2}{|l|}{646.77} \\
\hline Temperature & \multicolumn{2}{|l|}{$100(2) \mathrm{K}$} \\
\hline Wavelength & \multicolumn{2}{|l|}{$0.71073 \AA$} \\
\hline Crystal system & \multicolumn{2}{|l|}{ Monoclinic } \\
\hline Space group & \multicolumn{2}{|l|}{$\mathrm{P} 2(1) / \mathrm{n}$} \\
\hline \multirow[t]{3}{*}{ Unit cell dimensions } & $\mathrm{a}=7.8479(4) \AA$ & $\alpha=90^{\circ}$. \\
\hline & $\mathrm{b}=15.8896(8) \AA$ & $\beta=91.620(1)^{\circ}$. \\
\hline & $\mathrm{c}=21.9168(11) \AA$ & $\gamma=90^{\circ}$ \\
\hline Volume & \multicolumn{2}{|l|}{$2731.9(2) \AA^{3}$} \\
\hline $\mathrm{Z}$ & \multicolumn{2}{|l|}{4} \\
\hline Density (calculated) & \multicolumn{2}{|l|}{$1.572 \mathrm{Mg} / \mathrm{m}^{3}$} \\
\hline Absorption coefficient & \multicolumn{2}{|l|}{$5.025 \mathrm{~mm}^{-1}$} \\
\hline $\mathrm{F}(000)$ & \multicolumn{2}{|l|}{1304} \\
\hline Crystal size & \multicolumn{2}{|c|}{$0.20 \times 0.19 \times 0.18 \mathrm{~mm}^{3}$} \\
\hline Theta range for data collection & \multicolumn{2}{|l|}{2.26 to $30.51^{\circ}$} \\
\hline Index ranges & \multicolumn{2}{|c|}{$-11<=\mathrm{h}<=11,-22<=\mathrm{k}<=22,-31<=1<=31$} \\
\hline Reflections collected & \multicolumn{2}{|l|}{32004} \\
\hline Independent reflections & \multicolumn{2}{|c|}{$8323[\mathrm{R}(\mathrm{int})=0.0201]$} \\
\hline Completeness to theta $=30.51^{\circ}$ & \multicolumn{2}{|l|}{$99.7 \%$} \\
\hline Absorption correction & \multicolumn{2}{|l|}{ multi-scan } \\
\hline Max. and min. transmission & \multicolumn{2}{|l|}{0.4649 and 0.4331} \\
\hline Refinement method & \multicolumn{2}{|c|}{ Full-matrix least-squares on $\mathrm{F}^{2}$} \\
\hline Data / restraints / parameters & \multicolumn{2}{|l|}{$8323 / 1 / 464$} \\
\hline Goodness-of-fit on $\mathrm{F}^{2}$ & \multicolumn{2}{|l|}{1.049} \\
\hline Final $\mathrm{R}$ indices $[\mathrm{I}>2 \operatorname{sigma}(\mathrm{I})]$ & \multicolumn{2}{|c|}{$\mathrm{R} 1=0.0175, \mathrm{wR} 2=0.0380$} \\
\hline $\mathrm{R}$ indices (all data) & \multicolumn{2}{|c|}{$\mathrm{R} 1=0.0197, \mathrm{wR} 2=0.0386$} \\
\hline Largest diff. peak and hole & \multicolumn{2}{|c|}{1.808 and -0.677 e. $\AA^{-3}$} \\
\hline
\end{tabular}


Table S-2. Atomic coordinates ( $\times 10^{4}$ ) and equivalent isotropic displacement parameters $\left(\AA^{2} \times 10^{3}\right)$ for $\mathbf{1}$. $U(\mathrm{eq})$ is defined as one third of the trace of the orthogonalized $\mathrm{U}^{\mathrm{ij}}$ tensor.

\begin{tabular}{|c|c|c|c|c|}
\hline & $\mathrm{x}$ & $\mathrm{y}$ & $\mathrm{z}$ & $\mathrm{U}(\mathrm{eq})$ \\
\hline $\operatorname{Ir}(1)$ & $2474(1)$ & $6949(1)$ & 9095(1) & $11(1)$ \\
\hline $\mathrm{P}(1)$ & $3312(1)$ & $7849(1)$ & $9876(1)$ & $14(1)$ \\
\hline $\mathrm{P}(2)$ & 1751(1) & $6422(1)$ & $8136(1)$ & $13(1)$ \\
\hline $\mathrm{C}(1)$ & $1035(2)$ & $7942(1)$ & $8809(1)$ & $14(1)$ \\
\hline $\mathrm{C}(2)$ & $1018(2)$ & $8715(1)$ & $9135(1)$ & $17(1)$ \\
\hline $\mathrm{C}(3)$ & $168(3)$ & $9422(1)$ & $8904(1)$ & $21(1)$ \\
\hline$C(4)$ & $-721(2)$ & 9392(1) & $8348(1)$ & $22(1)$ \\
\hline $\mathrm{C}(5)$ & $-770(2)$ & $8642(1)$ & $8025(1)$ & $21(1)$ \\
\hline$C(6)$ & $87(2)$ & $7927(1)$ & $8246(1)$ & $17(1)$ \\
\hline$C(7)$ & 1889(3) & $8762(1)$ & 9758(1) & $21(1)$ \\
\hline $\mathrm{C}(8)$ & $-3(2)$ & $7119(1)$ & $7884(1)$ & $19(1)$ \\
\hline $\mathrm{C}(9)$ & 2966(3) & $7580(1)$ & $10702(1)$ & $21(1)$ \\
\hline$C(10)$ & $3114(3)$ & $8337(2)$ & 11141(1) & $26(1)$ \\
\hline $\mathrm{C}(11)$ & 1142(3) & $7234(2)$ & 10741(1) & $29(1)$ \\
\hline $\mathrm{C}(12)$ & $4234(3)$ & $6888(2)$ & $10908(1)$ & $30(1)$ \\
\hline $\mathrm{C}(13)$ & $5542(2)$ & $8252(1)$ & 9754(1) & $22(1)$ \\
\hline$C(14)$ & $6315(3)$ & $8775(2)$ & $10283(1)$ & $29(1)$ \\
\hline$C(15)$ & $5494(3)$ & $8814(2)$ & 9183(1) & $30(1)$ \\
\hline$C(16)$ & $6733(3)$ & $7498(1)$ & $9645(1)$ & $26(1)$ \\
\hline $\mathrm{C}(17)$ & $856(2)$ & $5325(1)$ & $8023(1)$ & $20(1)$ \\
\hline $\mathrm{C}(18)$ & $-542(3)$ & $5215(1)$ & $8495(1)$ & $27(1)$ \\
\hline $\mathrm{C}(19)$ & 18(3) & $5152(2)$ & 7392(1) & $30(1)$ \\
\hline $\mathrm{C}(20)$ & $2279(3)$ & $4685(1)$ & $8163(1)$ & $29(1)$ \\
\hline $\mathrm{C}(21)$ & $3504(2)$ & $6625(1)$ & $7580(1)$ & $18(1)$ \\
\hline $\mathrm{C}(22)$ & $3673(3)$ & $7583(1)$ & 7497(1) & $26(1)$ \\
\hline $\mathrm{C}(23)$ & $3161(3)$ & $6252(2)$ & 6942(1) & $25(1)$ \\
\hline $\mathrm{C}(24)$ & $5188(3)$ & $6273(2)$ & $7843(1)$ & $24(1)$ \\
\hline $\mathrm{N}(1)$ & $2504(2)$ & $5501(1)$ & $9708(1)$ & $16(1)$ \\
\hline $\mathrm{O}(1)$ & $3849(2)$ & $5840(1)$ & $9447(1)$ & $16(1)$ \\
\hline $\mathrm{O}(2)$ & $1128(2)$ & $5979(1)$ & $9656(1)$ & $16(1)$ \\
\hline $\mathrm{C}(25)$ & $2542(3)$ & $4778(1)$ & $9980(1)$ & $22(1)$ \\
\hline
\end{tabular}


Table S-3. Selected bond lengths $[\AA]$ and angles $\left[{ }^{\circ}\right]$ for $\mathbf{1}$.

\begin{tabular}{|c|c|c|c|}
\hline $\operatorname{Ir}(1)-C(1)$ & $2.0283(17)$ & $\mathrm{C}(13)-\mathrm{C}(15)$ & $1.537(3)$ \\
\hline $\operatorname{Ir}(1)-\mathrm{O}(1)$ & $2.1952(12)$ & $\mathrm{C}(13)-\mathrm{C}(16)$ & $1.543(3)$ \\
\hline $\operatorname{Ir}(1)-\mathrm{O}(2)$ & $2.2540(12)$ & $\mathrm{C}(14)-\mathrm{H}(14 \mathrm{~A})$ & $0.97(3)$ \\
\hline $\operatorname{Ir}(1)-\mathrm{P}(1)$ & $2.3117(5)$ & $\mathrm{C}(14)-\mathrm{H}(14 \mathrm{~B})$ & $0.97(3)$ \\
\hline $\operatorname{Ir}(1)-\mathrm{P}(2)$ & $2.3185(5)$ & $\mathrm{C}(14)-\mathrm{H}(14 \mathrm{C})$ & $0.94(3)$ \\
\hline $\operatorname{Ir}(1)-\mathrm{H}(1)$ & $1.518(16)$ & $\mathrm{C}(15)-\mathrm{H}(15 \mathrm{~A})$ & $1.01(3)$ \\
\hline $\mathrm{P}(1)-\mathrm{C}(7)$ & $1.8446(19)$ & $\mathrm{C}(15)-\mathrm{H}(15 \mathrm{~B})$ & $1.04(3)$ \\
\hline $\mathrm{P}(1)-\mathrm{C}(9)$ & $1.8876(19)$ & $\mathrm{C}(15)-\mathrm{H}(15 \mathrm{C})$ & $1.00(2)$ \\
\hline $\mathrm{P}(1)-\mathrm{C}(13)$ & $1.889(2)$ & $\mathrm{C}(16)-\mathrm{H}(16 \mathrm{~A})$ & $0.99(3)$ \\
\hline $\mathrm{P}(2)-\mathrm{C}(8)$ & $1.8392(19)$ & $\mathrm{C}(16)-\mathrm{H}(16 \mathrm{~B})$ & $1.01(3)$ \\
\hline $\mathrm{P}(2)-\mathrm{C}(21)$ & $1.8908(19)$ & $\mathrm{C}(16)-\mathrm{H}(16 \mathrm{C})$ & $0.95(3)$ \\
\hline $\mathrm{P}(2)-\mathrm{C}(17)$ & $1.8926(19)$ & $\mathrm{C}(17)-\mathrm{C}(20)$ & $1.535(3)$ \\
\hline$C(1)-C(2)$ & $1.422(2)$ & $C(17)-C(19)$ & $1.539(3)$ \\
\hline$C(1)-C(6)$ & $1.423(2)$ & $\mathrm{C}(17)-\mathrm{C}(18)$ & $1.539(3)$ \\
\hline$C(2)-C(3)$ & $1.396(3)$ & $\mathrm{C}(18)-\mathrm{H}(18 \mathrm{~A})$ & $0.97(3)$ \\
\hline $\mathrm{C}(2)-\mathrm{C}(7)$ & $1.510(3)$ & $\mathrm{C}(18)-\mathrm{H}(18 \mathrm{~B})$ & $0.97(3)$ \\
\hline$C(3)-C(4)$ & $1.387(3)$ & $\mathrm{C}(18)-\mathrm{H}(18 \mathrm{C})$ & $0.97(3)$ \\
\hline $\mathrm{C}(3)-\mathrm{H}(3)$ & $0.95(2)$ & $\mathrm{C}(19)-\mathrm{H}(19 \mathrm{~A})$ & $0.97(3)$ \\
\hline $\mathrm{C}(4)-\mathrm{C}(5)$ & $1.386(3)$ & $\mathrm{C}(19)-\mathrm{H}(19 \mathrm{~B})$ & $0.98(3)$ \\
\hline $\mathrm{C}(4)-\mathrm{H}(4)$ & $0.97(2)$ & $\mathrm{C}(19)-\mathrm{H}(19 \mathrm{C})$ & $0.99(3)$ \\
\hline$C(5)-C(6)$ & $1.400(2)$ & $\mathrm{C}(20)-\mathrm{H}(20 \mathrm{~A})$ & $0.92(3)$ \\
\hline $\mathrm{C}(5)-\mathrm{H}(5)$ & $0.94(2)$ & $\mathrm{C}(20)-\mathrm{H}(20 \mathrm{~B})$ & $0.97(3)$ \\
\hline $\mathrm{C}(6)-\mathrm{C}(8)$ & $1.510(3)$ & $\mathrm{C}(20)-\mathrm{H}(20 \mathrm{C})$ & $1.01(3)$ \\
\hline $\mathrm{C}(7)-\mathrm{H}(7 \mathrm{~A})$ & $0.99(2)$ & $\mathrm{C}(21)-\mathrm{C}(24)$ & $1.532(3)$ \\
\hline $\mathrm{C}(7)-\mathrm{H}(7 \mathrm{~B})$ & $0.97(3)$ & $\mathrm{C}(21)-\mathrm{C}(23)$ & $1.536(3)$ \\
\hline $\mathrm{C}(8)-\mathrm{H}(8 \mathrm{~A})$ & $0.94(3)$ & $\mathrm{C}(21)-\mathrm{C}(22)$ & $1.538(3)$ \\
\hline $\mathrm{C}(8)-\mathrm{H}(8 \mathrm{~B})$ & $1.02(3)$ & $\mathrm{C}(22)-\mathrm{H}(22 \mathrm{~A})$ & $0.99(3)$ \\
\hline $\mathrm{C}(9)-\mathrm{C}(11)$ & $1.538(3)$ & $\mathrm{C}(22)-\mathrm{H}(22 \mathrm{~B})$ & $0.96(3)$ \\
\hline $\mathrm{C}(9)-\mathrm{C}(12)$ & $1.541(3)$ & $\mathrm{C}(22)-\mathrm{H}(22 \mathrm{C})$ & $0.96(3)$ \\
\hline $\mathrm{C}(9)-\mathrm{C}(10)$ & $1.543(3)$ & $\mathrm{C}(23)-\mathrm{H}(23 \mathrm{~A})$ & $1.02(3)$ \\
\hline $\mathrm{C}(10)-\mathrm{H}(10 \mathrm{~A})$ & $0.96(3)$ & $\mathrm{C}(23)-\mathrm{H}(23 \mathrm{~B})$ & $1.00(3)$ \\
\hline $\mathrm{C}(10)-\mathrm{H}(10 \mathrm{~B})$ & $0.94(3)$ & $\mathrm{C}(23)-\mathrm{H}(23 \mathrm{C})$ & $0.95(3)$ \\
\hline $\mathrm{C}(10)-\mathrm{H}(10 \mathrm{C})$ & $0.96(3)$ & $\mathrm{C}(24)-\mathrm{H}(24 \mathrm{~A})$ & $0.95(3)$ \\
\hline $\mathrm{C}(11)-\mathrm{H}(11 \mathrm{~A})$ & $0.96(3)$ & $\mathrm{C}(24)-\mathrm{H}(24 \mathrm{~B})$ & $0.95(2)$ \\
\hline $\mathrm{C}(11)-\mathrm{H}(11 \mathrm{~B})$ & $1.07(3)$ & $\mathrm{C}(24)-\mathrm{H}(24 \mathrm{C})$ & $0.94(3)$ \\
\hline $\mathrm{C}(11)-\mathrm{H}(11 \mathrm{C})$ & $1.02(3)$ & $\mathrm{N}(1)-\mathrm{C}(25)$ & $1.294(2)$ \\
\hline $\mathrm{C}(12)-\mathrm{H}(12 \mathrm{~A})$ & $1.00(3)$ & $\mathrm{N}(1)-\mathrm{O}(2)$ & $1.3235(18)$ \\
\hline $\mathrm{C}(12)-\mathrm{H}(12 \mathrm{~B})$ & $1.07(3)$ & $\mathrm{N}(1)-\mathrm{O}(1)$ & $1.3288(19)$ \\
\hline $\mathrm{C}(12)-\mathrm{H}(12 \mathrm{C})$ & $0.99(3)$ & $\mathrm{C}(25)-\mathrm{H}(25 \mathrm{~A})$ & $0.96(3)$ \\
\hline $\mathrm{C}(13)-\mathrm{C}(14)$ & $1.537(3)$ & $\mathrm{C}(25)-\mathrm{H}(25 \mathrm{~B})$ & $0.90(3)$ \\
\hline $\mathrm{C}(1)-\operatorname{Ir}(1)-\mathrm{O}(1)$ & $175.20(6)$ & $\mathrm{C}(21)-\mathrm{P}(2)-\mathrm{C}(17)$ & $110.35(9)$ \\
\hline $\mathrm{C}(1)-\operatorname{Ir}(1)-\mathrm{O}(2)$ & $115.73(6)$ & $\mathrm{C}(8)-\mathrm{P}(2)-\operatorname{Ir}(1)$ & $102.49(6)$ \\
\hline $\mathrm{O}(1)-\operatorname{Ir}(1)-\mathrm{O}(2)$ & $59.49(4)$ & $\mathrm{C}(21)-\mathrm{P}(2)-\operatorname{Ir}(1)$ & $111.00(6)$ \\
\hline$C(1)-\operatorname{Ir}(1)-P(1)$ & $83.79(5)$ & $\mathrm{C}(17)-\mathrm{P}(2)-\operatorname{Ir}(1)$ & $122.11(6)$ \\
\hline $\mathrm{O}(1)-\operatorname{Ir}(1)-\mathrm{P}(1)$ & $96.30(4)$ & $C(2)-C(1)-C(6)$ & $116.00(15)$ \\
\hline $\mathrm{O}(2)-\operatorname{Ir}(1)-\mathrm{P}(1)$ & $98.43(3)$ & $\mathrm{C}(2)-\mathrm{C}(1)-\operatorname{Ir}(1)$ & $122.00(13)$ \\
\hline $\mathrm{C}(1)-\operatorname{Ir}(1)-\mathrm{P}(2)$ & $83.20(5)$ & $C(6)-C(1)-\operatorname{Ir}(1)$ & $121.82(13)$ \\
\hline $\mathrm{O}(1)-\operatorname{Ir}(1)-\mathrm{P}(2)$ & $97.68(4)$ & $\mathrm{C}(3)-\mathrm{C}(2)-\mathrm{C}(1)$ & $121.64(17)$ \\
\hline $\mathrm{O}(2)-\operatorname{Ir}(1)-\mathrm{P}(2)$ & $98.11(3)$ & $C(3)-C(2)-C(7)$ & $119.22(17)$ \\
\hline $\mathrm{P}(1)-\operatorname{Ir}(1)-\mathrm{P}(2)$ & $162.218(16)$ & $C(1)-C(2)-C(7)$ & $119.11(15)$ \\
\hline $\mathrm{C}(1)-\operatorname{Ir}(1)-\mathrm{H}(1)$ & $78.6(10)$ & $\mathrm{C}(4)-\mathrm{C}(3)-\mathrm{C}(2)$ & $120.95(18)$ \\
\hline $\mathrm{O}(1)-\operatorname{Ir}(1)-\mathrm{H}(1)$ & $106.1(10)$ & $\mathrm{C}(4)-\mathrm{C}(3)-\mathrm{H}(3)$ & $120.0(14)$ \\
\hline $\mathrm{O}(2)-\operatorname{Ir}(1)-\mathrm{H}(1)$ & $165.6(10)$ & $\mathrm{C}(2)-\mathrm{C}(3)-\mathrm{H}(3)$ & $119.0(15)$ \\
\hline $\mathrm{P}(1)-\operatorname{Ir}(1)-\mathrm{H}(1)$ & $82.9(10)$ & $C(5)-C(4)-C(3)$ & $119.01(17)$ \\
\hline $\mathrm{P}(2)-\operatorname{Ir}(1)-\mathrm{H}(1)$ & $82.7(10)$ & $\mathrm{C}(5)-\mathrm{C}(4)-\mathrm{H}(4)$ & $119.9(14)$ \\
\hline $\mathrm{C}(7)-\mathrm{P}(1)-\mathrm{C}(9)$ & $102.11(9)$ & $\mathrm{C}(3)-\mathrm{C}(4)-\mathrm{H}(4)$ & $121.1(14)$ \\
\hline $\mathrm{C}(7)-\mathrm{P}(1)-\mathrm{C}(13)$ & $105.88(10)$ & $\mathrm{C}(4)-\mathrm{C}(5)-\mathrm{C}(6)$ & $120.99(18)$ \\
\hline $\mathrm{C}(9)-\mathrm{P}(1)-\mathrm{C}(13)$ & $111.77(9)$ & $\mathrm{C}(4)-\mathrm{C}(5)-\mathrm{H}(5)$ & $118.6(14)$ \\
\hline $\mathrm{C}(7)-\mathrm{P}(1)-\operatorname{Ir}(1)$ & $102.96(6)$ & $\mathrm{C}(6)-\mathrm{C}(5)-\mathrm{H}(5)$ & $120.3(15)$ \\
\hline $\mathrm{C}(9)-\mathrm{P}(1)-\operatorname{Ir}(1)$ & $121.63(6)$ & $C(5)-C(6)-C(1)$ & $121.38(17)$ \\
\hline $\mathrm{C}(13)-\mathrm{P}(1)-\operatorname{Ir}(1)$ & $110.52(6)$ & $C(5)-C(6)-C(8)$ & $119.57(16)$ \\
\hline $\mathrm{C}(8)-\mathrm{P}(2)-\mathrm{C}(21)$ & $104.80(9)$ & $\mathrm{C}(1)-\mathrm{C}(6)-\mathrm{C}(8)$ & $119.05(15)$ \\
\hline $\mathrm{C}(8)-\mathrm{P}(2)-\mathrm{C}(17)$ & $104.09(9)$ & $\mathrm{C}(2)-\mathrm{C}(7)-\mathrm{P}(1)$ & $110.15(13)$ \\
\hline
\end{tabular}




\begin{tabular}{|c|c|}
\hline $\mathrm{C}(2)-\mathrm{C}(7)-\mathrm{H}(7 \mathrm{~A})$ & $108.7(14)$ \\
\hline $\mathrm{P}(1)-\mathrm{C}(7)-\mathrm{H}(7 \mathrm{~A})$ & $107.9(14)$ \\
\hline $\mathrm{C}(2)-\mathrm{C}(7)-\mathrm{H}(7 \mathrm{~B})$ & $114.6(15)$ \\
\hline $\mathrm{P}(1)-\mathrm{C}(7)-\mathrm{H}(7 \mathrm{~B})$ & $109.2(15)$ \\
\hline $\mathrm{H}(7 \mathrm{~A})-\mathrm{C}(7)-\mathrm{H}(7 \mathrm{~B})$ & $106(2)$ \\
\hline$C(6)-C(8)-P(2)$ & $109.31(12)$ \\
\hline $\mathrm{C}(6)-\mathrm{C}(8)-\mathrm{H}(8 \mathrm{~A})$ & $110.2(16)$ \\
\hline $\mathrm{P}(2)-\mathrm{C}(8)-\mathrm{H}(8 \mathrm{~A})$ & $113.1(16)$ \\
\hline $\mathrm{C}(6)-\mathrm{C}(8)-\mathrm{H}(8 \mathrm{~B})$ & $110.9(16)$ \\
\hline $\mathrm{P}(2)-\mathrm{C}(8)-\mathrm{H}(8 \mathrm{~B})$ & $104.2(16)$ \\
\hline $\mathrm{H}(8 \mathrm{~A})-\mathrm{C}(8)-\mathrm{H}(8 \mathrm{~B})$ & $109(2)$ \\
\hline $\mathrm{C}(11)-\mathrm{C}(9)-\mathrm{C}(12)$ & $108.87(19)$ \\
\hline $\mathrm{C}(11)-\mathrm{C}(9)-\mathrm{C}(10)$ & $107.29(17)$ \\
\hline$C(12)-C(9)-C(10)$ & $109.65(17)$ \\
\hline $\mathrm{C}(11)-\mathrm{C}(9)-\mathrm{P}(1)$ & $107.09(14)$ \\
\hline $\mathrm{C}(12)-\mathrm{C}(9)-\mathrm{P}(1)$ & $109.49(14)$ \\
\hline $\mathrm{C}(10)-\mathrm{C}(9)-\mathrm{P}(1)$ & $114.29(14)$ \\
\hline $\mathrm{C}(9)-\mathrm{C}(10)-\mathrm{H}(10 \mathrm{~A})$ & $108.4(15)$ \\
\hline $\mathrm{C}(9)-\mathrm{C}(10)-\mathrm{H}(10 \mathrm{~B})$ & $112.4(16)$ \\
\hline $\mathrm{H}(10 \mathrm{~A})-\mathrm{C}(10)-\mathrm{H}(10 \mathrm{~B})$ & $107(2)$ \\
\hline $\mathrm{C}(9)-\mathrm{C}(10)-\mathrm{H}(10 \mathrm{C})$ & $113.4(15)$ \\
\hline $\mathrm{H}(10 \mathrm{~A})-\mathrm{C}(10)-\mathrm{H}(10 \mathrm{C})$ & $106(2)$ \\
\hline $\mathrm{H}(10 \mathrm{~B})-\mathrm{C}(10)-\mathrm{H}(10 \mathrm{C})$ & $109(2)$ \\
\hline $\mathrm{C}(9)-\mathrm{C}(11)-\mathrm{H}(11 \mathrm{~A})$ & $112.1(19)$ \\
\hline $\mathrm{C}(9)-\mathrm{C}(11)-\mathrm{H}(11 \mathrm{~B})$ & $108.0(15)$ \\
\hline $\mathrm{H}(11 \mathrm{~A})-\mathrm{C}(11)-\mathrm{H}(11 \mathrm{~B})$ & $111(2)$ \\
\hline $\mathrm{C}(9)-\mathrm{C}(11)-\mathrm{H}(11 \mathrm{C})$ & $107.9(17)$ \\
\hline $\mathrm{H}(11 \mathrm{~A})-\mathrm{C}(11)-\mathrm{H}(11 \mathrm{C})$ & $107(2)$ \\
\hline $\mathrm{H}(11 \mathrm{~B})-\mathrm{C}(11)-\mathrm{H}(11 \mathrm{C})$ & $110(2)$ \\
\hline $\mathrm{C}(9)-\mathrm{C}(12)-\mathrm{H}(12 \mathrm{~A})$ & $108.6(17)$ \\
\hline $\mathrm{C}(9)-\mathrm{C}(12)-\mathrm{H}(12 \mathrm{~B})$ & $112.8(15)$ \\
\hline $\mathrm{H}(12 \mathrm{~A})-\mathrm{C}(12)-\mathrm{H}(12 \mathrm{~B})$ & $108(2)$ \\
\hline $\mathrm{C}(9)-\mathrm{C}(12)-\mathrm{H}(12 \mathrm{C})$ & $113.3(15)$ \\
\hline $\mathrm{H}(12 \mathrm{~A})-\mathrm{C}(12)-\mathrm{H}(12 \mathrm{C})$ & $107(2)$ \\
\hline $\mathrm{H}(12 \mathrm{~B})-\mathrm{C}(12)-\mathrm{H}(12 \mathrm{C})$ & $106(2)$ \\
\hline$C(14)-C(13)-C(15)$ & $107.47(17)$ \\
\hline$C(14)-C(13)-C(16)$ & $108.06(17)$ \\
\hline$C(15)-C(13)-C(16)$ & $108.96(18)$ \\
\hline $\mathrm{C}(14)-\mathrm{C}(13)-\mathrm{P}(1)$ & $115.10(15)$ \\
\hline $\mathrm{C}(15)-\mathrm{C}(13)-\mathrm{P}(1)$ & $108.04(14)$ \\
\hline $\mathrm{C}(16)-\mathrm{C}(13)-\mathrm{P}(1)$ & $109.08(13)$ \\
\hline $\mathrm{C}(13)-\mathrm{C}(14)-\mathrm{H}(14 \mathrm{~A})$ & $114.7(16)$ \\
\hline $\mathrm{C}(13)-\mathrm{C}(14)-\mathrm{H}(14 \mathrm{~B})$ & $111.3(15)$ \\
\hline $\mathrm{H}(14 \mathrm{~A})-\mathrm{C}(14)-\mathrm{H}(14 \mathrm{~B})$ & $106(2)$ \\
\hline $\mathrm{C}(13)-\mathrm{C}(14)-\mathrm{H}(14 \mathrm{C})$ & $108.8(17)$ \\
\hline $\mathrm{H}(14 \mathrm{~A})-\mathrm{C}(14)-\mathrm{H}(14 \mathrm{C})$ & $110(2)$ \\
\hline $\mathrm{H}(14 \mathrm{~B})-\mathrm{C}(14)-\mathrm{H}(14 \mathrm{C})$ & $106(2)$ \\
\hline $\mathrm{C}(13)-\mathrm{C}(15)-\mathrm{H}(15 \mathrm{~A})$ & $109.6(14)$ \\
\hline $\mathrm{C}(13)-\mathrm{C}(15)-\mathrm{H}(15 \mathrm{~B})$ & $111.7(16)$ \\
\hline $\mathrm{H}(15 \mathrm{~A})-\mathrm{C}(15)-\mathrm{H}(15 \mathrm{~B})$ & $106(2)$ \\
\hline $\mathrm{C}(13)-\mathrm{C}(15)-\mathrm{H}(15 \mathrm{C})$ & $114.0(14)$ \\
\hline $\mathrm{H}(15 \mathrm{~A})-\mathrm{C}(15)-\mathrm{H}(15 \mathrm{C})$ & $107(2)$ \\
\hline $\mathrm{H}(15 \mathrm{~B})-\mathrm{C}(15)-\mathrm{H}(15 \mathrm{C})$ & $109(2)$ \\
\hline $\mathrm{C}(13)-\mathrm{C}(16)-\mathrm{H}(16 \mathrm{~A})$ & $109.5(15)$ \\
\hline $\mathrm{C}(13)-\mathrm{C}(16)-\mathrm{H}(16 \mathrm{~B})$ & $109.2(17)$ \\
\hline $\mathrm{H}(16 \mathrm{~A})-\mathrm{C}(16)-\mathrm{H}(16 \mathrm{~B})$ & $112(2)$ \\
\hline $\mathrm{C}(13)-\mathrm{C}(16)-\mathrm{H}(16 \mathrm{C})$ & $108.9(15)$ \\
\hline $\mathrm{H}(16 \mathrm{~A})-\mathrm{C}(16)-\mathrm{H}(16 \mathrm{C})$ & $107(2)$ \\
\hline
\end{tabular}

\begin{tabular}{|c|c|}
\hline $\mathrm{H}(16 \mathrm{~B})-\mathrm{C}(16)-\mathrm{H}(16 \mathrm{C})$ & $110(2)$ \\
\hline$C(20)-C(17)-C(19)$ & $110.62(18)$ \\
\hline $\mathrm{C}(20)-\mathrm{C}(17)-\mathrm{C}(18)$ & $108.57(18)$ \\
\hline$C(19)-C(17)-C(18)$ & $106.78(17)$ \\
\hline $\mathrm{C}(20)-\mathrm{C}(17)-\mathrm{P}(2)$ & $108.59(13)$ \\
\hline C(19)-C(17)-P(2) & $115.39(14)$ \\
\hline $\mathrm{C}(18)-\mathrm{C}(17)-\mathrm{P}(2)$ & $106.63(13)$ \\
\hline $\mathrm{C}(17)-\mathrm{C}(18)-\mathrm{H}(18 \mathrm{~A})$ & $108.5(17)$ \\
\hline $\mathrm{C}(17)-\mathrm{C}(18)-\mathrm{H}(18 \mathrm{~B})$ & $114.8(16)$ \\
\hline $\mathrm{H}(18 \mathrm{~A})-\mathrm{C}(18)-\mathrm{H}(18 \mathrm{~B})$ & $104(2)$ \\
\hline $\mathrm{C}(17)-\mathrm{C}(18)-\mathrm{H}(18 \mathrm{C})$ & $114.3(15)$ \\
\hline $\mathrm{H}(18 \mathrm{~A})-\mathrm{C}(18)-\mathrm{H}(18 \mathrm{C})$ & $109(2)$ \\
\hline $\mathrm{H}(18 \mathrm{~B})-\mathrm{C}(18)-\mathrm{H}(18 \mathrm{C})$ & $105(2)$ \\
\hline $\mathrm{C}(17)-\mathrm{C}(19)-\mathrm{H}(19 \mathrm{~A})$ & $113.4(16)$ \\
\hline $\mathrm{C}(17)-\mathrm{C}(19)-\mathrm{H}(19 \mathrm{~B})$ & $112.2(15)$ \\
\hline $\mathrm{H}(19 \mathrm{~A})-\mathrm{C}(19)-\mathrm{H}(19 \mathrm{~B})$ & $109(2)$ \\
\hline $\mathrm{C}(17)-\mathrm{C}(19)-\mathrm{H}(19 \mathrm{C})$ & $109.1(17)$ \\
\hline $\mathrm{H}(19 \mathrm{~A})-\mathrm{C}(19)-\mathrm{H}(19 \mathrm{C})$ & $106(2)$ \\
\hline $\mathrm{H}(19 \mathrm{~B})-\mathrm{C}(19)-\mathrm{H}(19 \mathrm{C})$ & $107(2)$ \\
\hline $\mathrm{C}(17)-\mathrm{C}(20)-\mathrm{H}(20 \mathrm{~A})$ & $111.5(16)$ \\
\hline $\mathrm{C}(17)-\mathrm{C}(20)-\mathrm{H}(20 \mathrm{~B})$ & $113.6(15)$ \\
\hline $\mathrm{H}(20 \mathrm{~A})-\mathrm{C}(20)-\mathrm{H}(20 \mathrm{~B})$ & $104(2)$ \\
\hline $\mathrm{C}(17)-\mathrm{C}(20)-\mathrm{H}(20 \mathrm{C})$ & $111.4(15)$ \\
\hline $\mathrm{H}(20 \mathrm{~A})-\mathrm{C}(20)-\mathrm{H}(20 \mathrm{C})$ & $107(2)$ \\
\hline $\mathrm{H}(20 \mathrm{~B})-\mathrm{C}(20)-\mathrm{H}(20 \mathrm{C})$ & $109(2)$ \\
\hline$C(24)-C(21)-C(23)$ & $109.14(16)$ \\
\hline $\mathrm{C}(24)-\mathrm{C}(21)-\mathrm{C}(22)$ & $109.23(17)$ \\
\hline $\mathrm{C}(23)-\mathrm{C}(21)-\mathrm{C}(22)$ & $106.74(16)$ \\
\hline $\mathrm{C}(24)-\mathrm{C}(21)-\mathrm{P}(2)$ & $109.31(13)$ \\
\hline $\mathrm{C}(23)-\mathrm{C}(21)-\mathrm{P}(2)$ & $114.12(14)$ \\
\hline $\mathrm{C}(22)-\mathrm{C}(21)-\mathrm{P}(2)$ & $108.20(13)$ \\
\hline $\mathrm{C}(21)-\mathrm{C}(22)-\mathrm{H}(22 \mathrm{~A})$ & $108.4(16)$ \\
\hline $\mathrm{C}(21)-\mathrm{C}(22)-\mathrm{H}(22 \mathrm{~B})$ & $112.7(15)$ \\
\hline $\mathrm{H}(22 \mathrm{~A})-\mathrm{C}(22)-\mathrm{H}(22 \mathrm{~B})$ & $107(2)$ \\
\hline $\mathrm{C}(21)-\mathrm{C}(22)-\mathrm{H}(22 \mathrm{C})$ & $112.9(17)$ \\
\hline $\mathrm{H}(22 \mathrm{~A})-\mathrm{C}(22)-\mathrm{H}(22 \mathrm{C})$ & $106(2)$ \\
\hline $\mathrm{H}(22 \mathrm{~B})-\mathrm{C}(22)-\mathrm{H}(22 \mathrm{C})$ & $110(2)$ \\
\hline $\mathrm{C}(21)-\mathrm{C}(23)-\mathrm{H}(23 \mathrm{~A})$ & $110.3(16)$ \\
\hline $\mathrm{C}(21)-\mathrm{C}(23)-\mathrm{H}(23 \mathrm{~B})$ & $111.7(14)$ \\
\hline $\mathrm{H}(23 \mathrm{~A})-\mathrm{C}(23)-\mathrm{H}(23 \mathrm{~B})$ & $104(2)$ \\
\hline $\mathrm{C}(21)-\mathrm{C}(23)-\mathrm{H}(23 \mathrm{C})$ & $110.7(15)$ \\
\hline $\mathrm{H}(23 \mathrm{~A})-\mathrm{C}(23)-\mathrm{H}(23 \mathrm{C})$ & $110(2)$ \\
\hline $\mathrm{H}(23 \mathrm{~B})-\mathrm{C}(23)-\mathrm{H}(23 \mathrm{C})$ & $110(2)$ \\
\hline $\mathrm{C}(21)-\mathrm{C}(24)-\mathrm{H}(24 \mathrm{~A})$ & $113.2(16)$ \\
\hline $\mathrm{C}(21)-\mathrm{C}(24)-\mathrm{H}(24 \mathrm{~B})$ & $111.5(15)$ \\
\hline $\mathrm{H}(24 \mathrm{~A})-\mathrm{C}(24)-\mathrm{H}(24 \mathrm{~B})$ & $113(2)$ \\
\hline $\mathrm{C}(21)-\mathrm{C}(24)-\mathrm{H}(24 \mathrm{C})$ & $108.2(16)$ \\
\hline $\mathrm{H}(24 \mathrm{~A})-\mathrm{C}(24)-\mathrm{H}(24 \mathrm{C})$ & $106(2)$ \\
\hline $\mathrm{H}(24 \mathrm{~B})-\mathrm{C}(24)-\mathrm{H}(24 \mathrm{C})$ & $104(2)$ \\
\hline $\mathrm{C}(25)-\mathrm{N}(1)-\mathrm{O}(2)$ & $123.88(16)$ \\
\hline $\mathrm{C}(25)-\mathrm{N}(1)-\mathrm{O}(1)$ & $123.41(16)$ \\
\hline $\mathrm{O}(2)-\mathrm{N}(1)-\mathrm{O}(1)$ & $112.72(13)$ \\
\hline $\mathrm{N}(1)-\mathrm{O}(1)-\operatorname{Ir}(1)$ & $95.10(9)$ \\
\hline $\mathrm{N}(1)-\mathrm{O}(2)-\operatorname{Ir}(1)$ & $92.60(9)$ \\
\hline $\mathrm{N}(1)-\mathrm{C}(25)-\mathrm{H}(25 \mathrm{~A})$ & $116.1(15)$ \\
\hline $\mathrm{N}(1)-\mathrm{C}(25)-\mathrm{H}(25 \mathrm{~B})$ & $118.4(16)$ \\
\hline $\mathrm{H}(25 \mathrm{~A})-\mathrm{C}(25)-\mathrm{H}(25 \mathrm{~B})$ & $125(2)$ \\
\hline
\end{tabular}


Table S-4. Torsion angles $\left[{ }^{\circ}\right]$ for $\mathbf{1}$.

\begin{tabular}{|c|c|c|c|}
\hline $\mathrm{C}(1)-\operatorname{Ir}(1)-\mathrm{P}(1)-\mathrm{C}(7)$ & $7.68(9)$ & $\mathrm{C}(1)-\mathrm{C}(6)-\mathrm{C}(8)-\mathrm{P}(2)$ & $-19.2(2)$ \\
\hline $\mathrm{O}(1)-\operatorname{Ir}(1)-\mathrm{P}(1)-\mathrm{C}(7)$ & $-167.50(8)$ & $\mathrm{C}(21)-\mathrm{P}(2)-\mathrm{C}(8)-\mathrm{C}(6)$ & $-95.30(14)$ \\
\hline $\mathrm{O}(2)-\operatorname{Ir}(1)-\mathrm{P}(1)-\mathrm{C}(7)$ & $-107.50(8)$ & $\mathrm{C}(17)-\mathrm{P}(2)-\mathrm{C}(8)-\mathrm{C}(6)$ & $148.78(13)$ \\
\hline$P(2)-\operatorname{Ir}(1)-P(1)-C(7)$ & $50.84(9)$ & $\operatorname{Ir}(1)-\mathrm{P}(2)-\mathrm{C}(8)-\mathrm{C}(6)$ & $20.69(14)$ \\
\hline $\mathrm{C}(1)-\operatorname{Ir}(1)-\mathrm{P}(1)-\mathrm{C}(9)$ & $120.91(9)$ & $\mathrm{C}(7)-\mathrm{P}(1)-\mathrm{C}(9)-\mathrm{C}(11)$ & $69.06(16)$ \\
\hline $\mathrm{O}(1)-\operatorname{Ir}(1)-\mathrm{P}(1)-\mathrm{C}(9)$ & $-54.26(8)$ & $\mathrm{C}(13)-\mathrm{P}(1)-\mathrm{C}(9)-\mathrm{C}(11)$ & $-178.17(14)$ \\
\hline $\mathrm{O}(2)-\operatorname{Ir}(1)-\mathrm{P}(1)-\mathrm{C}(9)$ & $5.74(8)$ & $\operatorname{Ir}(1)-\mathrm{P}(1)-\mathrm{C}(9)-\mathrm{C}(11)$ & $-44.61(16)$ \\
\hline $\mathrm{P}(2)-\operatorname{Ir}(1)-\mathrm{P}(1)-\mathrm{C}(9)$ & $164.07(8)$ & $\mathrm{C}(7)-\mathrm{P}(1)-\mathrm{C}(9)-\mathrm{C}(12)$ & $-173.06(15)$ \\
\hline $\mathrm{C}(1)-\operatorname{Ir}(1)-\mathrm{P}(1)-\mathrm{C}(13)$ & $-105.02(9)$ & $\mathrm{C}(13)-\mathrm{P}(1)-\mathrm{C}(9)-\mathrm{C}(12)$ & $-60.29(17)$ \\
\hline $\mathrm{O}(1)-\operatorname{Ir}(1)-\mathrm{P}(1)-\mathrm{C}(13)$ & $79.80(8)$ & $\operatorname{Ir}(1)-\mathrm{P}(1)-\mathrm{C}(9)-\mathrm{C}(12)$ & $73.28(16)$ \\
\hline $\mathrm{O}(2)-\operatorname{Ir}(1)-\mathrm{P}(1)-\mathrm{C}(13)$ & $139.81(8)$ & $\mathrm{C}(7)-\mathrm{P}(1)-\mathrm{C}(9)-\mathrm{C}(10)$ & $-49.62(17)$ \\
\hline $\mathrm{P}(2)-\operatorname{Ir}(1)-\mathrm{P}(1)-\mathrm{C}(13)$ & $-61.86(9)$ & $\mathrm{C}(13)-\mathrm{P}(1)-\mathrm{C}(9)-\mathrm{C}(10)$ & $63.15(17)$ \\
\hline $\mathrm{C}(1)-\operatorname{Ir}(1)-\mathrm{P}(2)-\mathrm{C}(8)$ & $-14.01(8)$ & $\operatorname{Ir}(1)-\mathrm{P}(1)-\mathrm{C}(9)-\mathrm{C}(10)$ & $-163.29(12)$ \\
\hline $\mathrm{O}(1)-\operatorname{Ir}(1)-\mathrm{P}(2)-\mathrm{C}(8)$ & $161.24(8)$ & $\mathrm{C}(7)-\mathrm{P}(1)-\mathrm{C}(13)-\mathrm{C}(14)$ & 75.94(18) \\
\hline $\mathrm{O}(2)-\operatorname{Ir}(1)-\mathrm{P}(2)-\mathrm{C}(8)$ & 101.12(8) & $\mathrm{C}(9)-\mathrm{P}(1)-\mathrm{C}(13)-\mathrm{C}(14)$ & $-34.45(19)$ \\
\hline $\mathrm{P}(1)-\operatorname{Ir}(1)-\mathrm{P}(2)-\mathrm{C}(8)$ & $-57.24(9)$ & $\operatorname{Ir}(1)-\mathrm{P}(1)-\mathrm{C}(13)-\mathrm{C}(14)$ & $-173.25(14)$ \\
\hline $\mathrm{C}(1)-\operatorname{Ir}(1)-\mathrm{P}(2)-\mathrm{C}(21)$ & $97.42(8)$ & $\mathrm{C}(7)-\mathrm{P}(1)-\mathrm{C}(13)-\mathrm{C}(15)$ & $-44.14(16)$ \\
\hline $\mathrm{O}(1)-\operatorname{Ir}(1)-\mathrm{P}(2)-\mathrm{C}(21)$ & $-87.34(7)$ & $\mathrm{C}(9)-\mathrm{P}(1)-\mathrm{C}(13)-\mathrm{C}(15)$ & $-154.53(14)$ \\
\hline $\mathrm{O}(2)-\operatorname{Ir}(1)-\mathrm{P}(2)-\mathrm{C}(21)$ & $-147.46(7)$ & $\operatorname{Ir}(1)-\mathrm{P}(1)-\mathrm{C}(13)-\mathrm{C}(15)$ & $66.67(15)$ \\
\hline $\mathrm{P}(1)-\operatorname{Ir}(1)-\mathrm{P}(2)-\mathrm{C}(21)$ & $54.19(9)$ & $\mathrm{C}(7)-\mathrm{P}(1)-\mathrm{C}(13)-\mathrm{C}(16)$ & $-162.45(14)$ \\
\hline $\mathrm{C}(1)-\operatorname{Ir}(1)-\mathrm{P}(2)-\mathrm{C}(17)$ & $-129.69(9)$ & $\mathrm{C}(9)-\mathrm{P}(1)-\mathrm{C}(13)-\mathrm{C}(16)$ & $87.16(15)$ \\
\hline $\mathrm{O}(1)-\operatorname{Ir}(1)-\mathrm{P}(2)-\mathrm{C}(17)$ & $45.55(8)$ & $\operatorname{Ir}(1)-\mathrm{P}(1)-\mathrm{C}(13)-\mathrm{C}(16)$ & $-51.63(15)$ \\
\hline $\mathrm{O}(2)-\operatorname{Ir}(1)-\mathrm{P}(2)-\mathrm{C}(17)$ & $-14.57(8)$ & $\mathrm{C}(8)-\mathrm{P}(2)-\mathrm{C}(17)-\mathrm{C}(20)$ & $174.73(15)$ \\
\hline $\mathrm{P}(1)-\operatorname{Ir}(1)-\mathrm{P}(2)-\mathrm{C}(17)$ & $-172.92(8)$ & $\mathrm{C}(21)-\mathrm{P}(2)-\mathrm{C}(17)-\mathrm{C}(20)$ & $62.76(16)$ \\
\hline $\mathrm{O}(1)-\operatorname{Ir}(1)-\mathrm{C}(1)-\mathrm{C}(2)$ & $90.5(7)$ & $\operatorname{Ir}(1)-P(2)-C(17)-C(20)$ & $-70.39(15)$ \\
\hline $\mathrm{O}(2)-\operatorname{Ir}(1)-\mathrm{C}(1)-\mathrm{C}(2)$ & $95.66(14)$ & $\mathrm{C}(8)-\mathrm{P}(2)-\mathrm{C}(17)-\mathrm{C}(19)$ & $49.92(18)$ \\
\hline $\mathrm{P}(1)-\operatorname{Ir}(1)-\mathrm{C}(1)-\mathrm{C}(2)$ & $-0.73(14)$ & $\mathrm{C}(21)-\mathrm{P}(2)-\mathrm{C}(17)-\mathrm{C}(19)$ & $-62.05(18)$ \\
\hline$P(2)-\operatorname{Ir}(1)-C(1)-C(2)$ & $-168.58(14)$ & $\operatorname{Ir}(1)-P(2)-C(17)-C(19)$ & $164.80(14)$ \\
\hline $\mathrm{O}(1)-\operatorname{Ir}(1)-\mathrm{C}(1)-\mathrm{C}(6)$ & $-94.5(7)$ & $\mathrm{C}(8)-\mathrm{P}(2)-\mathrm{C}(17)-\mathrm{C}(18)$ & $-68.46(15)$ \\
\hline $\mathrm{O}(2)-\operatorname{Ir}(1)-\mathrm{C}(1)-\mathrm{C}(6)$ & $-89.39(15)$ & $\mathrm{C}(21)-\mathrm{P}(2)-\mathrm{C}(17)-\mathrm{C}(18)$ & $179.58(13)$ \\
\hline $\mathrm{P}(1)-\operatorname{Ir}(1)-\mathrm{C}(1)-\mathrm{C}(6)$ & $174.22(14)$ & $\operatorname{Ir}(1)-P(2)-C(17)-C(18)$ & $46.43(15)$ \\
\hline$P(2)-\operatorname{Ir}(1)-C(1)-C(6)$ & $6.37(13)$ & $\mathrm{C}(8)-\mathrm{P}(2)-\mathrm{C}(21)-\mathrm{C}(24)$ & $164.31(14)$ \\
\hline $\mathrm{C}(6)-\mathrm{C}(1)-\mathrm{C}(2)-\mathrm{C}(3)$ & $-2.1(3)$ & $\mathrm{C}(17)-\mathrm{P}(2)-\mathrm{C}(21)-\mathrm{C}(24)$ & $-84.19(15)$ \\
\hline $\operatorname{Ir}(1)-\mathrm{C}(1)-\mathrm{C}(2)-\mathrm{C}(3)$ & $173.15(14)$ & $\operatorname{Ir}(1)-\mathrm{P}(2)-\mathrm{C}(21)-\mathrm{C}(24)$ & $54.36(15)$ \\
\hline $\mathrm{C}(6)-\mathrm{C}(1)-\mathrm{C}(2)-\mathrm{C}(7)$ & $175.70(17)$ & $\mathrm{C}(8)-\mathrm{P}(2)-\mathrm{C}(21)-\mathrm{C}(23)$ & $-73.18(16)$ \\
\hline $\operatorname{Ir}(1)-C(1)-C(2)-C(7)$ & $-9.1(2)$ & $\mathrm{C}(17)-\mathrm{P}(2)-\mathrm{C}(21)-\mathrm{C}(23)$ & $38.32(17)$ \\
\hline $\mathrm{C}(1)-\mathrm{C}(2)-\mathrm{C}(3)-\mathrm{C}(4)$ & $1.1(3)$ & $\operatorname{Ir}(1)-\mathrm{P}(2)-\mathrm{C}(21)-\mathrm{C}(23)$ & $176.87(13)$ \\
\hline $\mathrm{C}(7)-\mathrm{C}(2)-\mathrm{C}(3)-\mathrm{C}(4)$ & $-176.68(18)$ & $\mathrm{C}(8)-\mathrm{P}(2)-\mathrm{C}(21)-\mathrm{C}(22)$ & $45.46(15)$ \\
\hline $\mathrm{C}(2)-\mathrm{C}(3)-\mathrm{C}(4)-\mathrm{C}(5)$ & $0.6(3)$ & $\mathrm{C}(17)-\mathrm{P}(2)-\mathrm{C}(21)-\mathrm{C}(22)$ & $156.96(13)$ \\
\hline $\mathrm{C}(3)-\mathrm{C}(4)-\mathrm{C}(5)-\mathrm{C}(6)$ & $-1.2(3)$ & $\operatorname{Ir}(1)-\mathrm{P}(2)-\mathrm{C}(21)-\mathrm{C}(22)$ & $-64.48(14)$ \\
\hline $\mathrm{C}(4)-\mathrm{C}(5)-\mathrm{C}(6)-\mathrm{C}(1)$ & $0.2(3)$ & $\mathrm{C}(25)-\mathrm{N}(1)-\mathrm{O}(1)-\operatorname{Ir}(1)$ & $176.90(16)$ \\
\hline$C(4)-C(5)-C(6)-C(8)$ & 179.60(18) & $\mathrm{O}(2)-\mathrm{N}(1)-\mathrm{O}(1)-\operatorname{Ir}(1)$ & $-2.81(14)$ \\
\hline $\mathrm{C}(2)-\mathrm{C}(1)-\mathrm{C}(6)-\mathrm{C}(5)$ & $1.5(3)$ & $\mathrm{C}(1)-\operatorname{Ir}(1)-\mathrm{O}(1)-\mathrm{N}(1)$ & $7.1(7)$ \\
\hline $\operatorname{Ir}(1)-C(1)-C(6)-C(5)$ & $-173.78(14)$ & $\mathrm{O}(2)-\operatorname{Ir}(1)-\mathrm{O}(1)-\mathrm{N}(1)$ & $1.76(9)$ \\
\hline $\mathrm{C}(2)-\mathrm{C}(1)-\mathrm{C}(6)-\mathrm{C}(8)$ & $-177.99(16)$ & $\mathrm{P}(1)-\operatorname{Ir}(1)-\mathrm{O}(1)-\mathrm{N}(1)$ & $97.86(9)$ \\
\hline $\operatorname{Ir}(1)-C(1)-C(6)-C(8)$ & $6.8(2)$ & $\mathrm{P}(2)-\operatorname{Ir}(1)-\mathrm{O}(1)-\mathrm{N}(1)$ & $-93.16(9)$ \\
\hline $\mathrm{C}(3)-\mathrm{C}(2)-\mathrm{C}(7)-\mathrm{P}(1)$ & $-166.81(15)$ & $\mathrm{C}(25)-\mathrm{N}(1)-\mathrm{O}(2)-\operatorname{Ir}(1)$ & $-176.98(17)$ \\
\hline $\mathrm{C}(1)-\mathrm{C}(2)-\mathrm{C}(7)-\mathrm{P}(1)$ & $15.4(2)$ & $\mathrm{O}(1)-\mathrm{N}(1)-\mathrm{O}(2)-\operatorname{Ir}(1)$ & $2.72(13)$ \\
\hline $\mathrm{C}(9)-\mathrm{P}(1)-\mathrm{C}(7)-\mathrm{C}(2)$ & $-140.59(14)$ & $\mathrm{C}(1)-\operatorname{Ir}(1)-\mathrm{O}(2)-\mathrm{N}(1)$ & 178.73(9) \\
\hline $\mathrm{C}(13)-\mathrm{P}(1)-\mathrm{C}(7)-\mathrm{C}(2)$ & $102.32(15)$ & $\mathrm{O}(1)-\operatorname{Ir}(1)-\mathrm{O}(2)-\mathrm{N}(1)$ & $-1.76(9)$ \\
\hline $\operatorname{Ir}(1)-\mathrm{P}(1)-\mathrm{C}(7)-\mathrm{C}(2)$ & $-13.74(15)$ & $\mathrm{P}(1)-\operatorname{Ir}(1)-\mathrm{O}(2)-\mathrm{N}(1)$ & $-94.14(9)$ \\
\hline$C(5)-C(6)-C(8)-P(2)$ & $161.32(15)$ & $\mathrm{P}(2)-\operatorname{Ir}(1)-\mathrm{O}(2)-\mathrm{N}(1)$ & $92.40(9)$ \\
\hline
\end{tabular}




\section{Structural Data for 2}

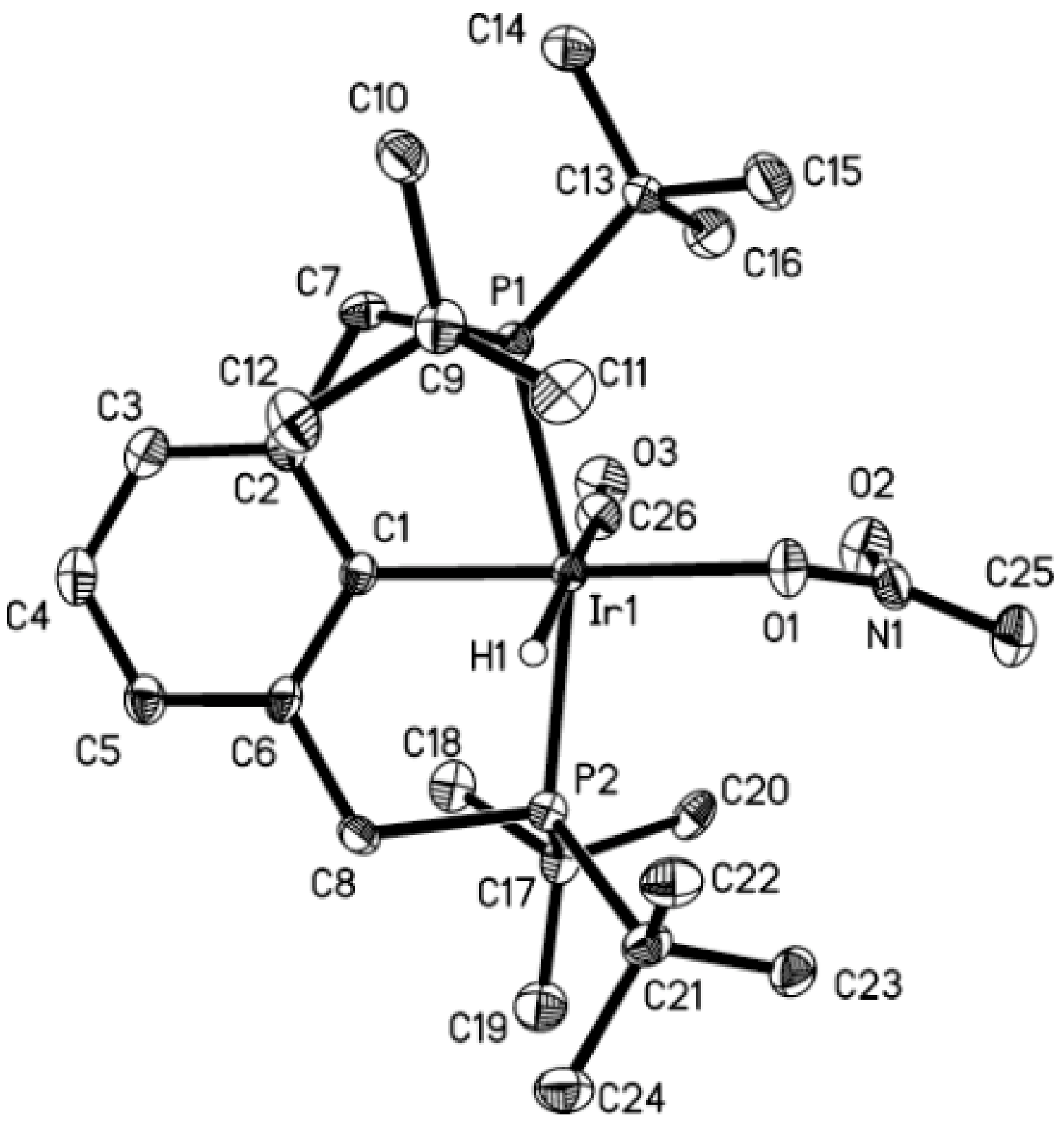

Figure S-2. ORTEP diagram of 2. Hydrogen atoms omitted for clarity. Thermal ellipsoids are shown at $50 \%$ probability. 
Table S-5. Crystal data and structure refinement for 2 .

\begin{tabular}{|c|c|c|}
\hline Identification code & \multicolumn{2}{|l|}{ ir_new } \\
\hline Empirical formula & \multicolumn{2}{|c|}{ C26 H46 Ir N O3 P2 } \\
\hline Formula weight & \multicolumn{2}{|l|}{674.78} \\
\hline Temperature & \multicolumn{2}{|l|}{$100(2) \mathrm{K}$} \\
\hline Wavelength & \multicolumn{2}{|l|}{$0.63225 \AA$} \\
\hline Crystal system & \multicolumn{2}{|l|}{ Monoclinic } \\
\hline Space group & \multicolumn{2}{|l|}{$\mathrm{P} 2(1) / \mathrm{n}$} \\
\hline \multirow[t]{3}{*}{ Unit cell dimensions } & $\mathrm{a}=11.4360(7) \AA$ & $\alpha=90^{\circ}$ \\
\hline & $\mathrm{b}=21.0884(13) \AA$ & $\beta=95.925(1)^{\circ}$. \\
\hline & $\mathrm{c}=11.7539(7) \AA$ & $\gamma=90^{\circ}$ \\
\hline Volume & \multicolumn{2}{|l|}{$2819.5(3) \AA^{3}$} \\
\hline $\mathrm{Z}$ & \multicolumn{2}{|l|}{4} \\
\hline Density (calculated) & \multicolumn{2}{|l|}{$1.590 \mathrm{Mg} / \mathrm{m}^{3}$} \\
\hline Absorption coefficient & \multicolumn{2}{|l|}{$3.455 \mathrm{~mm}^{-1}$} \\
\hline $\mathrm{F}(000)$ & \multicolumn{2}{|l|}{1360} \\
\hline Crystal size & \multicolumn{2}{|c|}{$0.11 \times 0.10 \times 0.03 \mathrm{~mm}^{3}$} \\
\hline Theta range for data collection & \multicolumn{2}{|l|}{1.77 to $26.83^{\circ}$. } \\
\hline Index ranges & \multicolumn{2}{|c|}{$-16<=\mathrm{h}<=16,-30<=\mathrm{k}<=30,-16<=1<=16$} \\
\hline Reflections collected & \multicolumn{2}{|l|}{36619} \\
\hline Independent reflections & \multicolumn{2}{|c|}{$8581[\mathrm{R}(\mathrm{int})=0.0783]$} \\
\hline Completeness to theta $=26.83^{\circ}$ & \multicolumn{2}{|l|}{$99.7 \%$} \\
\hline Absorption correction & \multicolumn{2}{|c|}{ Semi-empirical from equivalents } \\
\hline Max. and min. transmission & \multicolumn{2}{|l|}{0.9034 and 0.7024} \\
\hline Refinement method & \multicolumn{2}{|c|}{ Full-matrix least-squares on $\mathrm{F}^{2}$} \\
\hline Data / restraints / parameters & \multicolumn{2}{|l|}{$8581 / 1 / 316$} \\
\hline Goodness-of-fit on $\mathrm{F}^{2}$ & \multicolumn{2}{|l|}{1.003} \\
\hline Final $\mathrm{R}$ indices $[\mathrm{I}>2 \operatorname{sigma}(\mathrm{I})]$ & \multicolumn{2}{|c|}{$\mathrm{R} 1=0.0587, \mathrm{wR} 2=0.1161$} \\
\hline $\mathrm{R}$ indices (all data) & \multicolumn{2}{|c|}{$\mathrm{R} 1=0.0773, \mathrm{wR} 2=0.1239$} \\
\hline Largest diff. peak and hole & \multicolumn{2}{|c|}{3.126 and -4.806 e. $\AA^{-3}$} \\
\hline
\end{tabular}


Table S-6. Atomic coordinates ( x $\left.10^{4}\right)$ and equivalent isotropic displacement parameters $\left(\AA^{2} \times 10^{3}\right)$ for 2 . $U(e q)$ is defined as one third of the trace of the orthogonalized $U^{i j}$ tensor.

\begin{tabular}{|c|c|c|c|c|}
\hline & $\mathrm{x}$ & $\mathrm{y}$ & $\mathrm{z}$ & $\mathrm{U}(\mathrm{eq})$ \\
\hline $\operatorname{Ir}(1)$ & $3621(1)$ & $1210(1)$ & 2233(1) & $12(1)$ \\
\hline $\mathrm{P}(1)$ & $5146(1)$ & 1950(1) & $2378(1)$ & $14(1)$ \\
\hline $\mathrm{P}(2)$ & $2522(1)$ & $328(1)$ & 2678(1) & $15(1)$ \\
\hline$C(1)$ & $3852(5)$ & 1317(3) & $3969(5)$ & $14(1)$ \\
\hline$C(2)$ & $4348(6)$ & 1878(3) & $4470(5)$ & $17(1)$ \\
\hline$C(3)$ & $4461(6)$ & 1950(3) & $5658(6)$ & $22(1)$ \\
\hline$C(4)$ & $4116(6)$ & 1473(4) & $6366(6)$ & $23(1)$ \\
\hline$C(5)$ & $3672(6)$ & $908(3)$ & $5877(6)$ & $20(1)$ \\
\hline$C(6)$ & $3556(5)$ & $823(3)$ & $4700(5)$ & $17(1)$ \\
\hline$C(7)$ & $4815(6)$ & $2368(3)$ & $3678(6)$ & $18(1)$ \\
\hline$C(8)$ & $3173(6)$ & $195(3)$ & $4164(5)$ & $17(1)$ \\
\hline $\mathrm{C}(9)$ & $6646(5)$ & $1587(3)$ & $2714(6)$ & $19(1)$ \\
\hline$C(10)$ & $7642(6)$ & 2088(4) & 2783(6) & $24(1)$ \\
\hline$C(11)$ & $6868(6)$ & 1098(3) & $1772(6)$ & $25(2)$ \\
\hline$C(12)$ & $6704(6)$ & $1244(4)$ & $3866(6)$ & $24(1)$ \\
\hline$C(13)$ & $5187(6)$ & 2577(3) & $1245(6)$ & $19(1)$ \\
\hline$C(14)$ & $5834(7)$ & $3179(3)$ & $1708(6)$ & $26(2)$ \\
\hline$C(15)$ & $5739(7)$ & 2319(4) & $198(6)$ & $26(2)$ \\
\hline$C(16)$ & $3905(6)$ & 2761(3) & $842(6)$ & $25(1)$ \\
\hline$C(17)$ & $902(6)$ & $451(3)$ & 2821(5) & $18(1)$ \\
\hline$C(18)$ & $823(6)$ & $943(3)$ & $3775(6)$ & $22(1)$ \\
\hline$C(19)$ & $252(7)$ & $-140(4)$ & $3157(7)$ & $27(2)$ \\
\hline$C(20)$ & $292(6)$ & $725(3)$ & $1684(6)$ & $23(1)$ \\
\hline$C(21)$ & $2738(6)$ & $-431(3)$ & 1893(6) & $20(1)$ \\
\hline$C(22)$ & $3997(6)$ & $-440(3)$ & 1529(7) & $24(1)$ \\
\hline$C(23)$ & $1876(6)$ & $-476(4)$ & $812(6)$ & $24(1)$ \\
\hline$C(24)$ & $2603(7)$ & $-1020(3)$ & 2651(7) & $26(2)$ \\
\hline $\mathrm{N}(1)$ & $2752(5)$ & 1123(3) & $-329(5)$ & $21(1)$ \\
\hline $\mathrm{O}(1)$ & $3704(4)$ & $1027(2)$ & $446(4)$ & $22(1)$ \\
\hline $\mathrm{O}(2)$ & $2000(5)$ & 1533(3) & $-122(5)$ & $28(1)$ \\
\hline$C(25)$ & $2716(7)$ & $782(4)$ & $-1261(6)$ & $26(2)$ \\
\hline $\mathrm{O}(3)$ & $1687(4)$ & $2219(2)$ & $2155(5)$ & $26(1)$ \\
\hline$C(26)$ & $2398(6)$ & 1834(3) & 2114(6) & $20(1)$ \\
\hline
\end{tabular}


Table S-7. Selected bond lengths $[\AA]$ and angles $\left[{ }^{\circ}\right]$ for 2.

\begin{tabular}{|c|c|c|c|}
\hline $\operatorname{Ir}(1)-C(26)$ & $1.914(6)$ & $C(13)-C(16)$ & $1.543(10)$ \\
\hline $\operatorname{Ir}(1)-C(1)$ & $2.042(6)$ & $\mathrm{C}(14)-\mathrm{H}(14 \mathrm{~A})$ & 0.9800 \\
\hline $\operatorname{Ir}(1)-\mathrm{O}(1)$ & $2.148(5)$ & $\mathrm{C}(14)-\mathrm{H}(14 \mathrm{~B})$ & 0.9800 \\
\hline $\operatorname{Ir}(1)-\mathrm{P}(1)$ & $2.3325(16)$ & $\mathrm{C}(14)-\mathrm{H}(14 \mathrm{C})$ & 0.9800 \\
\hline $\operatorname{Ir}(1)-\mathrm{P}(2)$ & $2.3349(16)$ & $\mathrm{C}(15)-\mathrm{H}(15 \mathrm{~A})$ & 0.9800 \\
\hline $\operatorname{Ir}(1)-\mathrm{H}(1)$ & $1.78(2)$ & $\mathrm{C}(15)-\mathrm{H}(15 \mathrm{~B})$ & 0.9800 \\
\hline $\mathrm{P}(1)-\mathrm{C}(7)$ & $1.836(7)$ & $\mathrm{C}(15)-\mathrm{H}(15 \mathrm{C})$ & 0.9800 \\
\hline $\mathrm{P}(1)-\mathrm{C}(13)$ & $1.880(6)$ & $\mathrm{C}(16)-\mathrm{H}(16 \mathrm{~A})$ & 0.9800 \\
\hline $\mathrm{P}(1)-\mathrm{C}(9)$ & $1.883(6)$ & $\mathrm{C}(16)-\mathrm{H}(16 \mathrm{~B})$ & 0.9800 \\
\hline $\mathrm{P}(2)-\mathrm{C}(8)$ & $1.848(6)$ & $\mathrm{C}(16)-\mathrm{H}(16 \mathrm{C})$ & 0.9800 \\
\hline $\mathrm{P}(2)-\mathrm{C}(21)$ & $1.878(7)$ & $\mathrm{C}(17)-\mathrm{C}(19)$ & $1.525(10)$ \\
\hline $\mathrm{P}(2)-\mathrm{C}(17)$ & $1.895(6)$ & $\mathrm{C}(17)-\mathrm{C}(18)$ & $1.537(9)$ \\
\hline$C(1)-C(6)$ & $1.413(9)$ & $\mathrm{C}(17)-\mathrm{C}(20)$ & $1.554(9)$ \\
\hline $\mathrm{C}(1)-\mathrm{C}(2)$ & $1.415(9)$ & $\mathrm{C}(18)-\mathrm{H}(18 \mathrm{~A})$ & 0.9800 \\
\hline $\mathrm{C}(2)-\mathrm{C}(3)$ & $1.397(9)$ & $\mathrm{C}(18)-\mathrm{H}(18 \mathrm{~B})$ & 0.9800 \\
\hline $\mathrm{C}(2)-\mathrm{C}(7)$ & $1.524(9)$ & $\mathrm{C}(18)-\mathrm{H}(18 \mathrm{C})$ & 0.9800 \\
\hline $\mathrm{C}(3)-\mathrm{C}(4)$ & $1.388(10)$ & $\mathrm{C}(19)-\mathrm{H}(19 \mathrm{~A})$ & 0.9800 \\
\hline $\mathrm{C}(3)-\mathrm{H}(3)$ & 0.9500 & $\mathrm{C}(19)-\mathrm{H}(19 \mathrm{~B})$ & 0.9800 \\
\hline$C(4)-C(5)$ & $1.397(10)$ & $\mathrm{C}(19)-\mathrm{H}(19 \mathrm{C})$ & 0.9800 \\
\hline $\mathrm{C}(4)-\mathrm{H}(4)$ & 0.9500 & $\mathrm{C}(20)-\mathrm{H}(20 \mathrm{~A})$ & 0.9800 \\
\hline$C(5)-C(6)$ & $1.388(9)$ & $\mathrm{C}(20)-\mathrm{H}(20 \mathrm{~B})$ & 0.9800 \\
\hline $\mathrm{C}(5)-\mathrm{H}(5)$ & 0.9500 & $\mathrm{C}(20)-\mathrm{H}(20 \mathrm{C})$ & 0.9800 \\
\hline $\mathrm{C}(6)-\mathrm{C}(8)$ & $1.512(9)$ & $\mathrm{C}(21)-\mathrm{C}(23)$ & $1.529(10)$ \\
\hline $\mathrm{C}(7)-\mathrm{H}(7 \mathrm{~A})$ & 0.9900 & $\mathrm{C}(21)-\mathrm{C}(22)$ & $1.543(10)$ \\
\hline $\mathrm{C}(7)-\mathrm{H}(7 \mathrm{~B})$ & 0.9900 & $\mathrm{C}(21)-\mathrm{C}(24)$ & $1.545(10)$ \\
\hline $\mathrm{C}(8)-\mathrm{H}(8 \mathrm{~A})$ & 0.9900 & $\mathrm{C}(22)-\mathrm{H}(22 \mathrm{~A})$ & 0.9800 \\
\hline $\mathrm{C}(8)-\mathrm{H}(8 \mathrm{~B})$ & 0.9900 & $\mathrm{C}(22)-\mathrm{H}(22 \mathrm{~B})$ & 0.9800 \\
\hline $\mathrm{C}(9)-\mathrm{C}(12)$ & $1.530(9)$ & $\mathrm{C}(22)-\mathrm{H}(22 \mathrm{C})$ & 0.9800 \\
\hline C(9)-C(10) & $1.550(9)$ & $\mathrm{C}(23)-\mathrm{H}(23 \mathrm{~A})$ & 0.9800 \\
\hline $\mathrm{C}(9)-\mathrm{C}(11)$ & $1.553(9)$ & $\mathrm{C}(23)-\mathrm{H}(23 \mathrm{~B})$ & 0.9800 \\
\hline $\mathrm{C}(10)-\mathrm{H}(10 \mathrm{~A})$ & 0.9800 & $\mathrm{C}(23)-\mathrm{H}(23 \mathrm{C})$ & 0.9800 \\
\hline $\mathrm{C}(10)-\mathrm{H}(10 \mathrm{~B})$ & 0.9800 & $\mathrm{C}(24)-\mathrm{H}(24 \mathrm{~A})$ & 0.9800 \\
\hline $\mathrm{C}(10)-\mathrm{H}(10 \mathrm{C})$ & 0.9800 & $\mathrm{C}(24)-\mathrm{H}(24 \mathrm{~B})$ & 0.9800 \\
\hline $\mathrm{C}(11)-\mathrm{H}(11 \mathrm{~A})$ & 0.9800 & $\mathrm{C}(24)-\mathrm{H}(24 \mathrm{C})$ & 0.9800 \\
\hline $\mathrm{C}(11)-\mathrm{H}(11 \mathrm{~B})$ & 0.9800 & $\mathrm{~N}(1)-\mathrm{O}(2)$ & $1.261(8)$ \\
\hline $\mathrm{C}(11)-\mathrm{H}(11 \mathrm{C})$ & 0.9800 & $\mathrm{~N}(1)-\mathrm{C}(25)$ & $1.307(9)$ \\
\hline $\mathrm{C}(12)-\mathrm{H}(12 \mathrm{~A})$ & 0.9800 & $\mathrm{~N}(1)-\mathrm{O}(1)$ & $1.361(7)$ \\
\hline $\mathrm{C}(12)-\mathrm{H}(12 \mathrm{~B})$ & 0.9800 & $\mathrm{C}(25)-\mathrm{H}(25 \mathrm{~A})$ & 0.9500 \\
\hline $\mathrm{C}(12)-\mathrm{H}(12 \mathrm{C})$ & 0.9800 & $\mathrm{C}(25)-\mathrm{H}(25 \mathrm{~B})$ & 0.9500 \\
\hline$C(13)-C(15)$ & $1.539(10)$ & $\mathrm{O}(3)-\mathrm{C}(26)$ & $1.154(8)$ \\
\hline \multirow[t]{2}{*}{$\mathrm{C}(13)-\mathrm{C}(14)$} & $1.541(9)$ & & \\
\hline & & $\mathrm{C}(13)-\mathrm{P}(1)-\operatorname{Ir}(1)$ & $119.4(2)$ \\
\hline$C(26)-\operatorname{Ir}(1)-C(1)$ & $90.9(3)$ & $\mathrm{C}(9)-\mathrm{P}(1)-\operatorname{Ir}(1)$ & $113.6(2)$ \\
\hline \multirow[t]{2}{*}{$\mathrm{C}(26)-\operatorname{Ir}(1)-\mathrm{O}(1)$} & $99.1(2)$ & $\mathrm{C}(8)-\mathrm{P}(2)-\mathrm{C}(21)$ & $105.9(3)$ \\
\hline & & $\mathrm{C}(8)-\mathrm{P}(2)-\mathrm{C}(17)$ & $103.8(3)$ \\
\hline $\mathrm{C}(1)-\operatorname{Ir}(1)-\mathrm{O}(1)$ & $169.3(2)$ & $\mathrm{C}(21)-\mathrm{P}(2)-\mathrm{C}(17)$ & $109.9(3)$ \\
\hline $\mathrm{C}(26)-\operatorname{Ir}(1)-\mathrm{P}(1)$ & $94.6(2)$ & $\mathrm{C}(8)-\mathrm{P}(2)-\operatorname{Ir}(1)$ & $99.2(2)$ \\
\hline $\mathrm{C}(1)-\operatorname{Ir}(1)-\mathrm{P}(1)$ & $80.51(17)$ & $\mathrm{C}(21)-\mathrm{P}(2)-\operatorname{Ir}(1)$ & $117.9(2)$ \\
\hline $\mathrm{O}(1)-\operatorname{Ir}(1)-\mathrm{P}(1)$ & $94.84(14)$ & $\mathrm{C}(17)-\mathrm{P}(2)-\operatorname{Ir}(1)$ & $117.7(2)$ \\
\hline$C(26)-\operatorname{Ir}(1)-P(2)$ & $99.1(2)$ & $\mathrm{C}(6)-\mathrm{C}(1)-\mathrm{C}(2)$ & $118.3(5)$ \\
\hline $\mathrm{C}(1)-\operatorname{Ir}(1)-\mathrm{P}(2)$ & $83.14(17)$ & $\mathrm{C}(6)-\mathrm{C}(1)-\operatorname{Ir}(1)$ & $120.8(4)$ \\
\hline $\mathrm{O}(1)-\operatorname{Ir}(1)-\mathrm{P}(2)$ & $98.88(14)$ & $\mathrm{C}(2)-\mathrm{C}(1)-\operatorname{Ir}(1)$ & $120.8(4)$ \\
\hline $\mathrm{P}(1)-\operatorname{Ir}(1)-\mathrm{P}(2)$ & $158.78(6)$ & $\mathrm{C}(3)-\mathrm{C}(2)-\mathrm{C}(1)$ & $119.9(6)$ \\
\hline $\mathrm{C}(26)-\operatorname{Ir}(1)-\mathrm{H}(1)$ & $173(3)$ & $\mathrm{C}(3)-\mathrm{C}(2)-\mathrm{C}(7)$ & $122.4(6)$ \\
\hline $\mathrm{C}(1)-\operatorname{Ir}(1)-\mathrm{H}(1)$ & $87(3)$ & $C(1)-C(2)-C(7)$ & $117.6(5)$ \\
\hline $\mathrm{O}(1)-\operatorname{Ir}(1)-\mathrm{H}(1)$ & $84(3)$ & $C(4)-C(3)-C(2)$ & $121.2(6)$ \\
\hline $\mathrm{P}(1)-\operatorname{Ir}(1)-\mathrm{H}(1)$ & $92(3)$ & $\mathrm{C}(4)-\mathrm{C}(3)-\mathrm{H}(3)$ & 119.4 \\
\hline $\mathrm{P}(2)-\operatorname{Ir}(1)-\mathrm{H}(1)$ & $74(3)$ & $\mathrm{C}(2)-\mathrm{C}(3)-\mathrm{H}(3)$ & 119.4 \\
\hline $\mathrm{C}(7)-\mathrm{P}(1)-\mathrm{C}(13)$ & $106.0(3)$ & $\mathrm{C}(3)-\mathrm{C}(4)-\mathrm{C}(5)$ & $119.1(6)$ \\
\hline $\mathrm{C}(7)-\mathrm{P}(1)-\mathrm{C}(9)$ & $106.4(3)$ & $\mathrm{C}(3)-\mathrm{C}(4)-\mathrm{H}(4)$ & 120.5 \\
\hline $\mathrm{C}(13)-\mathrm{P}(1)-\mathrm{C}(9)$ & $110.2(3)$ & $\mathrm{C}(5)-\mathrm{C}(4)-\mathrm{H}(4)$ & 120.5 \\
\hline $\mathrm{C}(7)-\mathrm{P}(1)-\operatorname{Ir}(1)$ & $99.5(2)$ & $C(6)-C(5)-C(4)$ & $120.9(6)$ \\
\hline
\end{tabular}




\begin{tabular}{|c|c|}
\hline $\mathrm{C}(6)-\mathrm{C}(5)-\mathrm{H}(5)$ & 119.6 \\
\hline $\mathrm{C}(4)-\mathrm{C}(5)-\mathrm{H}(5)$ & 119.6 \\
\hline $\mathrm{C}(5)-\mathrm{C}(6)-\mathrm{C}(1)$ & $120.5(6)$ \\
\hline $\mathrm{C}(5)-\mathrm{C}(6)-\mathrm{C}(8)$ & $121.4(6)$ \\
\hline$C(1)-C(6)-C(8)$ & $118.0(5)$ \\
\hline $\mathrm{C}(2)-\mathrm{C}(7)-\mathrm{P}(1)$ & $107.4(4)$ \\
\hline $\mathrm{C}(2)-\mathrm{C}(7)-\mathrm{H}(7 \mathrm{~A})$ & 110.2 \\
\hline $\mathrm{P}(1)-\mathrm{C}(7)-\mathrm{H}(7 \mathrm{~A})$ & 110.2 \\
\hline $\mathrm{C}(2)-\mathrm{C}(7)-\mathrm{H}(7 \mathrm{~B})$ & 110.2 \\
\hline $\mathrm{P}(1)-\mathrm{C}(7)-\mathrm{H}(7 \mathrm{~B})$ & 110.2 \\
\hline $\mathrm{H}(7 \mathrm{~A})-\mathrm{C}(7)-\mathrm{H}(7 \mathrm{~B})$ & 108.5 \\
\hline $\mathrm{C}(6)-\mathrm{C}(8)-\mathrm{P}(2)$ & $109.3(4)$ \\
\hline $\mathrm{C}(6)-\mathrm{C}(8)-\mathrm{H}(8 \mathrm{~A})$ & 109.8 \\
\hline $\mathrm{P}(2)-\mathrm{C}(8)-\mathrm{H}(8 \mathrm{~A})$ & 109.8 \\
\hline $\mathrm{C}(6)-\mathrm{C}(8)-\mathrm{H}(8 \mathrm{~B})$ & 109.8 \\
\hline $\mathrm{P}(2)-\mathrm{C}(8)-\mathrm{H}(8 \mathrm{~B})$ & 109.8 \\
\hline $\mathrm{H}(8 \mathrm{~A})-\mathrm{C}(8)-\mathrm{H}(8 \mathrm{~B})$ & 108.3 \\
\hline$C(12)-C(9)-C(10)$ & $108.1(5)$ \\
\hline $\mathrm{C}(12)-\mathrm{C}(9)-\mathrm{C}(11)$ & $108.8(6)$ \\
\hline$C(10)-C(9)-C(11)$ & $108.4(6)$ \\
\hline $\mathrm{C}(12)-\mathrm{C}(9)-\mathrm{P}(1)$ & $109.5(4)$ \\
\hline $\mathrm{C}(10)-\mathrm{C}(9)-\mathrm{P}(1)$ & $112.5(5)$ \\
\hline $\mathrm{C}(11)-\mathrm{C}(9)-\mathrm{P}(1)$ & $109.5(4)$ \\
\hline $\mathrm{C}(9)-\mathrm{C}(10)-\mathrm{H}(10 \mathrm{~A})$ & 109.5 \\
\hline $\mathrm{C}(9)-\mathrm{C}(10)-\mathrm{H}(10 \mathrm{~B})$ & 109.5 \\
\hline $\mathrm{H}(10 \mathrm{~A})-\mathrm{C}(10)-\mathrm{H}(10 \mathrm{~B})$ & 109.5 \\
\hline $\mathrm{C}(9)-\mathrm{C}(10)-\mathrm{H}(10 \mathrm{C})$ & 109.5 \\
\hline $\mathrm{H}(10 \mathrm{~A})-\mathrm{C}(10)-\mathrm{H}(10 \mathrm{C})$ & 109.5 \\
\hline $\mathrm{H}(10 \mathrm{~B})-\mathrm{C}(10)-\mathrm{H}(10 \mathrm{C})$ & 109.5 \\
\hline $\mathrm{C}(9)-\mathrm{C}(11)-\mathrm{H}(11 \mathrm{~A})$ & 109.5 \\
\hline $\mathrm{C}(9)-\mathrm{C}(11)-\mathrm{H}(11 \mathrm{~B})$ & 109.5 \\
\hline $\mathrm{H}(11 \mathrm{~A})-\mathrm{C}(11)-\mathrm{H}(11 \mathrm{~B})$ & 109.5 \\
\hline $\mathrm{C}(9)-\mathrm{C}(11)-\mathrm{H}(11 \mathrm{C})$ & 109.5 \\
\hline $\mathrm{H}(11 \mathrm{~A})-\mathrm{C}(11)-\mathrm{H}(11 \mathrm{C})$ & 109.5 \\
\hline $\mathrm{H}(11 \mathrm{~B})-\mathrm{C}(11)-\mathrm{H}(11 \mathrm{C})$ & 109.5 \\
\hline $\mathrm{C}(9)-\mathrm{C}(12)-\mathrm{H}(12 \mathrm{~A})$ & 109.5 \\
\hline $\mathrm{C}(9)-\mathrm{C}(12)-\mathrm{H}(12 \mathrm{~B})$ & 109.5 \\
\hline $\mathrm{H}(12 \mathrm{~A})-\mathrm{C}(12)-\mathrm{H}(12 \mathrm{~B})$ & 109.5 \\
\hline $\mathrm{C}(9)-\mathrm{C}(12)-\mathrm{H}(12 \mathrm{C})$ & 109.5 \\
\hline $\mathrm{H}(12 \mathrm{~A})-\mathrm{C}(12)-\mathrm{H}(12 \mathrm{C})$ & 109.5 \\
\hline $\mathrm{H}(12 \mathrm{~B})-\mathrm{C}(12)-\mathrm{H}(12 \mathrm{C})$ & 109.5 \\
\hline$C(15)-C(13)-C(14)$ & $110.6(6)$ \\
\hline$C(15)-C(13)-C(16)$ & $107.4(6)$ \\
\hline$C(14)-C(13)-C(16)$ & $107.9(6)$ \\
\hline $\mathrm{C}(15)-\mathrm{C}(13)-\mathrm{P}(1)$ & $111.1(5)$ \\
\hline $\mathrm{C}(14)-\mathrm{C}(13)-\mathrm{P}(1)$ & $112.0(5)$ \\
\hline $\mathrm{C}(16)-\mathrm{C}(13)-\mathrm{P}(1)$ & $107.6(5)$ \\
\hline $\mathrm{C}(13)-\mathrm{C}(14)-\mathrm{H}(14 \mathrm{~A})$ & 109.5 \\
\hline $\mathrm{C}(13)-\mathrm{C}(14)-\mathrm{H}(14 \mathrm{~B})$ & 109.5 \\
\hline $\mathrm{H}(14 \mathrm{~A})-\mathrm{C}(14)-\mathrm{H}(14 \mathrm{~B})$ & 109.5 \\
\hline $\mathrm{C}(13)-\mathrm{C}(14)-\mathrm{H}(14 \mathrm{C})$ & 109.5 \\
\hline $\mathrm{H}(14 \mathrm{~A})-\mathrm{C}(14)-\mathrm{H}(14 \mathrm{C})$ & 109.5 \\
\hline $\mathrm{H}(14 \mathrm{~B})-\mathrm{C}(14)-\mathrm{H}(14 \mathrm{C})$ & 109.5 \\
\hline $\mathrm{C}(13)-\mathrm{C}(15)-\mathrm{H}(15 \mathrm{~A})$ & 109.5 \\
\hline $\mathrm{C}(13)-\mathrm{C}(15)-\mathrm{H}(15 \mathrm{~B})$ & 109.5 \\
\hline $\mathrm{H}(15 \mathrm{~A})-\mathrm{C}(15)-\mathrm{H}(15 \mathrm{~B})$ & 109.5 \\
\hline $\mathrm{C}(13)-\mathrm{C}(15)-\mathrm{H}(15 \mathrm{C})$ & 109.5 \\
\hline $\mathrm{H}(15 \mathrm{~A})-\mathrm{C}(15)-\mathrm{H}(15 \mathrm{C})$ & 109.5 \\
\hline $\mathrm{H}(15 \mathrm{~B})-\mathrm{C}(15)-\mathrm{H}(15 \mathrm{C})$ & 109.5 \\
\hline $\mathrm{C}(13)-\mathrm{C}(16)-\mathrm{H}(16 \mathrm{~A})$ & 109.5 \\
\hline $\mathrm{C}(13)-\mathrm{C}(16)-\mathrm{H}(16 \mathrm{~B})$ & 109.5 \\
\hline
\end{tabular}

\begin{tabular}{|c|c|}
\hline $\mathrm{H}(16 \mathrm{~A})-\mathrm{C}(16)-\mathrm{H}(16 \mathrm{~B})$ & 109.5 \\
\hline $\mathrm{C}(13)-\mathrm{C}(16)-\mathrm{H}(16 \mathrm{C})$ & 109.5 \\
\hline $\mathrm{H}(16 \mathrm{~A})-\mathrm{C}(16)-\mathrm{H}(16 \mathrm{C})$ & 109.5 \\
\hline $\mathrm{H}(16 \mathrm{~B})-\mathrm{C}(16)-\mathrm{H}(16 \mathrm{C})$ & 109.5 \\
\hline$C(19)-C(17)-C(18)$ & $107.2(6)$ \\
\hline$C(19)-C(17)-C(20)$ & $109.8(6)$ \\
\hline$C(18)-C(17)-C(20)$ & $108.7(6)$ \\
\hline $\mathrm{C}(19)-\mathrm{C}(17)-\mathrm{P}(2)$ & $114.8(5)$ \\
\hline $\mathrm{C}(18)-\mathrm{C}(17)-\mathrm{P}(2)$ & $106.8(4)$ \\
\hline$C(20)-C(17)-P(2)$ & $109.3(4)$ \\
\hline $\mathrm{C}(17)-\mathrm{C}(18)-\mathrm{H}(18 \mathrm{~A})$ & 109.5 \\
\hline $\mathrm{C}(17)-\mathrm{C}(18)-\mathrm{H}(18 \mathrm{~B})$ & 109.5 \\
\hline $\mathrm{H}(18 \mathrm{~A})-\mathrm{C}(18)-\mathrm{H}(18 \mathrm{~B})$ & 109.5 \\
\hline $\mathrm{C}(17)-\mathrm{C}(18)-\mathrm{H}(18 \mathrm{C})$ & 109.5 \\
\hline $\mathrm{H}(18 \mathrm{~A})-\mathrm{C}(18)-\mathrm{H}(18 \mathrm{C})$ & 109.5 \\
\hline $\mathrm{H}(18 \mathrm{~B})-\mathrm{C}(18)-\mathrm{H}(18 \mathrm{C})$ & 109.5 \\
\hline $\mathrm{C}(17)-\mathrm{C}(19)-\mathrm{H}(19 \mathrm{~A})$ & 109.5 \\
\hline $\mathrm{C}(17)-\mathrm{C}(19)-\mathrm{H}(19 \mathrm{~B})$ & 109.5 \\
\hline $\mathrm{H}(19 \mathrm{~A})-\mathrm{C}(19)-\mathrm{H}(19 \mathrm{~B})$ & 109.5 \\
\hline $\mathrm{C}(17)-\mathrm{C}(19)-\mathrm{H}(19 \mathrm{C})$ & 109.5 \\
\hline $\mathrm{H}(19 \mathrm{~A})-\mathrm{C}(19)-\mathrm{H}(19 \mathrm{C})$ & 109.5 \\
\hline $\mathrm{H}(19 \mathrm{~B})-\mathrm{C}(19)-\mathrm{H}(19 \mathrm{C})$ & 109.5 \\
\hline $\mathrm{C}(17)-\mathrm{C}(20)-\mathrm{H}(20 \mathrm{~A})$ & 109.5 \\
\hline $\mathrm{C}(17)-\mathrm{C}(20)-\mathrm{H}(20 \mathrm{~B})$ & 109.5 \\
\hline $\mathrm{H}(20 \mathrm{~A})-\mathrm{C}(20)-\mathrm{H}(20 \mathrm{~B})$ & 109.5 \\
\hline $\mathrm{C}(17)-\mathrm{C}(20)-\mathrm{H}(20 \mathrm{C})$ & 109.5 \\
\hline$H(20 A)-C(20)-H(20 C)$ & 109.5 \\
\hline $\mathrm{H}(20 \mathrm{~B})-\mathrm{C}(20)-\mathrm{H}(20 \mathrm{C})$ & 109.5 \\
\hline $\mathrm{C}(23)-\mathrm{C}(21)-\mathrm{C}(22)$ & $108.0(6)$ \\
\hline $\mathrm{C}(23)-\mathrm{C}(21)-\mathrm{C}(24)$ & $109.7(6)$ \\
\hline $\mathrm{C}(22)-\mathrm{C}(21)-\mathrm{C}(24)$ & $107.6(6)$ \\
\hline $\mathrm{C}(23)-\mathrm{C}(21)-\mathrm{P}(2)$ & $110.8(5)$ \\
\hline $\mathrm{C}(22)-\mathrm{C}(21)-\mathrm{P}(2)$ & $108.7(4)$ \\
\hline $\mathrm{C}(24)-\mathrm{C}(21)-\mathrm{P}(2)$ & $112.0(5)$ \\
\hline $\mathrm{C}(21)-\mathrm{C}(22)-\mathrm{H}(22 \mathrm{~A})$ & 109.5 \\
\hline $\mathrm{C}(21)-\mathrm{C}(22)-\mathrm{H}(22 \mathrm{~B})$ & 109.5 \\
\hline $\mathrm{H}(22 \mathrm{~A})-\mathrm{C}(22)-\mathrm{H}(22 \mathrm{~B})$ & 109.5 \\
\hline $\mathrm{C}(21)-\mathrm{C}(22)-\mathrm{H}(22 \mathrm{C})$ & 109.5 \\
\hline $\mathrm{H}(22 \mathrm{~A})-\mathrm{C}(22)-\mathrm{H}(22 \mathrm{C})$ & 109.5 \\
\hline $\mathrm{H}(22 \mathrm{~B})-\mathrm{C}(22)-\mathrm{H}(22 \mathrm{C})$ & 109.5 \\
\hline $\mathrm{C}(21)-\mathrm{C}(23)-\mathrm{H}(23 \mathrm{~A})$ & 109.5 \\
\hline $\mathrm{C}(21)-\mathrm{C}(23)-\mathrm{H}(23 \mathrm{~B})$ & 109.5 \\
\hline $\mathrm{H}(23 \mathrm{~A})-\mathrm{C}(23)-\mathrm{H}(23 \mathrm{~B})$ & 109.5 \\
\hline $\mathrm{C}(21)-\mathrm{C}(23)-\mathrm{H}(23 \mathrm{C})$ & 109.5 \\
\hline $\mathrm{H}(23 \mathrm{~A})-\mathrm{C}(23)-\mathrm{H}(23 \mathrm{C})$ & 109.5 \\
\hline $\mathrm{H}(23 \mathrm{~B})-\mathrm{C}(23)-\mathrm{H}(23 \mathrm{C})$ & 109.5 \\
\hline $\mathrm{C}(21)-\mathrm{C}(24)-\mathrm{H}(24 \mathrm{~A})$ & 109.5 \\
\hline $\mathrm{C}(21)-\mathrm{C}(24)-\mathrm{H}(24 \mathrm{~B})$ & 109.5 \\
\hline $\mathrm{H}(24 \mathrm{~A})-\mathrm{C}(24)-\mathrm{H}(24 \mathrm{~B})$ & 109.5 \\
\hline $\mathrm{C}(21)-\mathrm{C}(24)-\mathrm{H}(24 \mathrm{C})$ & 109.5 \\
\hline $\mathrm{H}(24 \mathrm{~A})-\mathrm{C}(24)-\mathrm{H}(24 \mathrm{C})$ & 109.5 \\
\hline $\mathrm{H}(24 \mathrm{~B})-\mathrm{C}(24)-\mathrm{H}(24 \mathrm{C})$ & 109.5 \\
\hline $\mathrm{O}(2)-\mathrm{N}(1)-\mathrm{C}(25)$ & $125.2(6)$ \\
\hline $\mathrm{O}(2)-\mathrm{N}(1)-\mathrm{O}(1)$ & $119.2(5)$ \\
\hline $\mathrm{C}(25)-\mathrm{N}(1)-\mathrm{O}(1)$ & $115.6(6)$ \\
\hline $\mathrm{N}(1)-\mathrm{O}(1)-\operatorname{Ir}(1)$ & $121.0(4)$ \\
\hline $\mathrm{N}(1)-\mathrm{C}(25)-\mathrm{H}(25 \mathrm{~A})$ & 120.0 \\
\hline $\mathrm{N}(1)-\mathrm{C}(25)-\mathrm{H}(25 \mathrm{~B})$ & 120.0 \\
\hline $\mathrm{H}(25 \mathrm{~A})-\mathrm{C}(25)-\mathrm{H}(25 \mathrm{~B})$ & 120.0 \\
\hline $\mathrm{O}(3)-\mathrm{C}(26)-\operatorname{Ir}(1)$ & $173.3(6)$ \\
\hline
\end{tabular}


Table S-8. Torsion angles $\left[{ }^{\circ}\right]$ for $\mathbf{2}$.

\begin{tabular}{|c|c|c|c|}
\hline $\mathrm{C}(26)-\operatorname{Ir}(1)-\mathrm{P}(1)-\mathrm{C}(7)$ & $59.9(3)$ & $\mathrm{C}(5)-\mathrm{C}(6)-\mathrm{C}(8)-\mathrm{P}(2)$ & $156.4(5)$ \\
\hline $\mathrm{C}(1)-\operatorname{Ir}(1)-\mathrm{P}(1)-\mathrm{C}(7)$ & $-30.3(3)$ & $\mathrm{C}(1)-\mathrm{C}(6)-\mathrm{C}(8)-\mathrm{P}(2)$ & $-26.7(7)$ \\
\hline $\mathrm{O}(1)-\operatorname{Ir}(1)-\mathrm{P}(1)-\mathrm{C}(7)$ & $159.4(3)$ & $\mathrm{C}(21)-\mathrm{P}(2)-\mathrm{C}(8)-\mathrm{C}(6)$ & $153.8(4)$ \\
\hline $\mathrm{P}(2)-\operatorname{Ir}(1)-\mathrm{P}(1)-\mathrm{C}(7)$ & $-70.3(3)$ & $\mathrm{C}(17)-\mathrm{P}(2)-\mathrm{C}(8)-\mathrm{C}(6)$ & $-90.5(5)$ \\
\hline$C(26)-\operatorname{Ir}(1)-P(1)-C(13)$ & $-54.6(3)$ & $\operatorname{Ir}(1)-\mathrm{P}(2)-\mathrm{C}(8)-\mathrm{C}(6)$ & $31.1(5)$ \\
\hline $\mathrm{C}(1)-\operatorname{Ir}(1)-\mathrm{P}(1)-\mathrm{C}(13)$ & $-144.8(3)$ & $\mathrm{C}(7)-\mathrm{P}(1)-\mathrm{C}(9)-\mathrm{C}(12)$ & $47.6(5)$ \\
\hline $\mathrm{O}(1)-\operatorname{Ir}(1)-\mathrm{P}(1)-\mathrm{C}(13)$ & $44.9(3)$ & $\mathrm{C}(13)-\mathrm{P}(1)-\mathrm{C}(9)-\mathrm{C}(12)$ & $162.1(5)$ \\
\hline$P(2)-\operatorname{Ir}(1)-P(1)-C(13)$ & $175.2(3)$ & $\operatorname{Ir}(1)-\mathrm{P}(1)-\mathrm{C}(9)-\mathrm{C}(12)$ & $-60.8(5)$ \\
\hline $\mathrm{C}(26)-\operatorname{Ir}(1)-\mathrm{P}(1)-\mathrm{C}(9)$ & $172.5(3)$ & $\mathrm{C}(7)-\mathrm{P}(1)-\mathrm{C}(9)-\mathrm{C}(10)$ & $-72.6(5)$ \\
\hline $\mathrm{C}(1)-\operatorname{Ir}(1)-\mathrm{P}(1)-\mathrm{C}(9)$ & $82.4(3)$ & $\mathrm{C}(13)-\mathrm{P}(1)-\mathrm{C}(9)-\mathrm{C}(10)$ & $41.8(5)$ \\
\hline $\mathrm{O}(1)-\operatorname{Ir}(1)-\mathrm{P}(1)-\mathrm{C}(9)$ & $-87.9(3)$ & $\operatorname{Ir}(1)-\mathrm{P}(1)-\mathrm{C}(9)-\mathrm{C}(10)$ & $178.9(4)$ \\
\hline $\mathrm{P}(2)-\operatorname{Ir}(1)-\mathrm{P}(1)-\mathrm{C}(9)$ & $42.4(3)$ & $\mathrm{C}(7)-\mathrm{P}(1)-\mathrm{C}(9)-\mathrm{C}(11)$ & $166.8(5)$ \\
\hline $\mathrm{C}(26)-\operatorname{Ir}(1)-\mathrm{P}(2)-\mathrm{C}(8)$ & $-112.2(3)$ & $\mathrm{C}(13)-\mathrm{P}(1)-\mathrm{C}(9)-\mathrm{C}(11)$ & $-78.8(5)$ \\
\hline $\mathrm{C}(1)-\operatorname{Ir}(1)-\mathrm{P}(2)-\mathrm{C}(8)$ & $-22.4(3)$ & $\operatorname{Ir}(1)-\mathrm{P}(1)-\mathrm{C}(9)-\mathrm{C}(11)$ & $58.3(5)$ \\
\hline $\mathrm{O}(1)-\operatorname{Ir}(1)-\mathrm{P}(2)-\mathrm{C}(8)$ & $147.0(3)$ & $\mathrm{C}(7)-\mathrm{P}(1)-\mathrm{C}(13)-\mathrm{C}(15)$ & $166.5(5)$ \\
\hline $\mathrm{P}(1)-\operatorname{Ir}(1)-\mathrm{P}(2)-\mathrm{C}(8)$ & $17.3(3)$ & $\mathrm{C}(9)-\mathrm{P}(1)-\mathrm{C}(13)-\mathrm{C}(15)$ & $51.8(6)$ \\
\hline$C(26)-\operatorname{Ir}(1)-P(2)-C(21)$ & $134.2(3)$ & $\operatorname{Ir}(1)-\mathrm{P}(1)-\mathrm{C}(13)-\mathrm{C}(15)$ & $-82.4(5)$ \\
\hline $\mathrm{C}(1)-\operatorname{Ir}(1)-\mathrm{P}(2)-\mathrm{C}(21)$ & $-136.0(3)$ & $\mathrm{C}(7)-\mathrm{P}(1)-\mathrm{C}(13)-\mathrm{C}(14)$ & $42.3(6)$ \\
\hline $\mathrm{O}(1)-\operatorname{Ir}(1)-\mathrm{P}(2)-\mathrm{C}(21)$ & $33.4(3)$ & $\mathrm{C}(9)-\mathrm{P}(1)-\mathrm{C}(13)-\mathrm{C}(14)$ & $-72.4(6)$ \\
\hline$P(1)-\operatorname{Ir}(1)-P(2)-C(21)$ & $-96.2(3)$ & $\operatorname{Ir}(1)-\mathrm{P}(1)-\mathrm{C}(13)-\mathrm{C}(14)$ & $153.3(4)$ \\
\hline$C(26)-\operatorname{Ir}(1)-P(2)-C(17)$ & $-1.2(3)$ & $\mathrm{C}(7)-\mathrm{P}(1)-\mathrm{C}(13)-\mathrm{C}(16)$ & $-76.2(5)$ \\
\hline $\mathrm{C}(1)-\operatorname{Ir}(1)-\mathrm{P}(2)-\mathrm{C}(17)$ & $88.6(3)$ & $\mathrm{C}(9)-\mathrm{P}(1)-\mathrm{C}(13)-\mathrm{C}(16)$ & $169.1(4)$ \\
\hline $\mathrm{O}(1)-\mathrm{Ir}(1)-\mathrm{P}(2)-\mathrm{C}(17)$ & $-102.0(3)$ & $\operatorname{Ir}(1)-\mathrm{P}(1)-\mathrm{C}(13)-\mathrm{C}(16)$ & $34.9(5)$ \\
\hline $\mathrm{P}(1)-\operatorname{Ir}(1)-\mathrm{P}(2)-\mathrm{C}(17)$ & $128.3(3)$ & $\mathrm{C}(8)-\mathrm{P}(2)-\mathrm{C}(17)-\mathrm{C}(19)$ & $-69.4(5)$ \\
\hline$C(26)-\operatorname{Ir}(1)-C(1)-C(6)$ & $112.2(5)$ & $\mathrm{C}(21)-\mathrm{P}(2)-\mathrm{C}(17)-\mathrm{C}(19)$ & $43.5(6)$ \\
\hline $\mathrm{O}(1)-\operatorname{Ir}(1)-\mathrm{C}(1)-\mathrm{C}(6)$ & $-88.5(13)$ & $\operatorname{Ir}(1)-\mathrm{P}(2)-\mathrm{C}(17)-\mathrm{C}(19)$ & $-177.8(4)$ \\
\hline $\mathrm{P}(1)-\operatorname{Ir}(1)-\mathrm{C}(1)-\mathrm{C}(6)$ & $-153.3(5)$ & $\mathrm{C}(8)-\mathrm{P}(2)-\mathrm{C}(17)-\mathrm{C}(18)$ & $49.2(5)$ \\
\hline$P(2)-\operatorname{Ir}(1)-C(1)-C(6)$ & $13.2(5)$ & $\mathrm{C}(21)-\mathrm{P}(2)-\mathrm{C}(17)-\mathrm{C}(18)$ & $162.1(5)$ \\
\hline$C(26)-\operatorname{Ir}(1)-C(1)-C(2)$ & $-70.0(5)$ & $\operatorname{Ir}(1)-\mathrm{P}(2)-\mathrm{C}(17)-\mathrm{C}(18)$ & $-59.2(5)$ \\
\hline $\mathrm{O}(1)-\operatorname{Ir}(1)-\mathrm{C}(1)-\mathrm{C}(2)$ & 89.3(13) & $\mathrm{C}(8)-\mathrm{P}(2)-\mathrm{C}(17)-\mathrm{C}(20)$ & $166.7(4)$ \\
\hline $\mathrm{P}(1)-\operatorname{Ir}(1)-\mathrm{C}(1)-\mathrm{C}(2)$ & $24.5(5)$ & $\mathrm{C}(21)-\mathrm{P}(2)-\mathrm{C}(17)-\mathrm{C}(20)$ & $-80.4(5)$ \\
\hline $\mathrm{P}(2)-\operatorname{Ir}(1)-\mathrm{C}(1)-\mathrm{C}(2)$ & $-169.0(5)$ & $\operatorname{Ir}(1)-\mathrm{P}(2)-\mathrm{C}(17)-\mathrm{C}(20)$ & $58.3(5)$ \\
\hline$C(6)-C(1)-C(2)-C(3)$ & $-4.3(9)$ & $\mathrm{C}(8)-\mathrm{P}(2)-\mathrm{C}(21)-\mathrm{C}(23)$ & $159.3(5)$ \\
\hline $\operatorname{Ir}(1)-C(1)-C(2)-C(3)$ & 177.9(5) & $\mathrm{C}(17)-\mathrm{P}(2)-\mathrm{C}(21)-\mathrm{C}(23)$ & $47.8(5)$ \\
\hline$C(6)-C(1)-C(2)-C(7)$ & 171.8(6) & $\operatorname{Ir}(1)-\mathrm{P}(2)-\mathrm{C}(21)-\mathrm{C}(23)$ & $-90.9(5)$ \\
\hline $\operatorname{Ir}(1)-C(1)-C(2)-C(7)$ & $-6.0(8)$ & $\mathrm{C}(8)-\mathrm{P}(2)-\mathrm{C}(21)-\mathrm{C}(22)$ & $-82.2(5)$ \\
\hline$C(1)-C(2)-C(3)-C(4)$ & $1.3(10)$ & $\mathrm{C}(17)-\mathrm{P}(2)-\mathrm{C}(21)-\mathrm{C}(22)$ & $166.2(5)$ \\
\hline$C(7)-C(2)-C(3)-C(4)$ & $-174.6(6)$ & $\operatorname{Ir}(1)-\mathrm{P}(2)-\mathrm{C}(21)-\mathrm{C}(22)$ & $27.6(5)$ \\
\hline$C(2)-C(3)-C(4)-C(5)$ & $1.5(11)$ & $\mathrm{C}(8)-\mathrm{P}(2)-\mathrm{C}(21)-\mathrm{C}(24)$ & $36.5(6)$ \\
\hline$C(3)-C(4)-C(5)-C(6)$ & $-1.1(10)$ & $\mathrm{C}(17)-\mathrm{P}(2)-\mathrm{C}(21)-\mathrm{C}(24)$ & $-75.0(6)$ \\
\hline$C(4)-C(5)-C(6)-C(1)$ & $-2.0(10)$ & $\operatorname{Ir}(1)-\mathrm{P}(2)-\mathrm{C}(21)-\mathrm{C}(24)$ & $146.3(4)$ \\
\hline$C(4)-C(5)-C(6)-C(8)$ & 174.9(6) & $\mathrm{O}(2)-\mathrm{N}(1)-\mathrm{O}(1)-\operatorname{Ir}(1)$ & $27.5(8)$ \\
\hline$C(2)-C(1)-C(6)-C(5)$ & $4.7(9)$ & $\mathrm{C}(25)-\mathrm{N}(1)-\mathrm{O}(1)-\operatorname{Ir}(1)$ & $-154.1(5)$ \\
\hline $\operatorname{Ir}(1)-C(1)-C(6)-C(5)$ & $-177.5(5)$ & $\mathrm{C}(26)-\mathrm{Ir}(1)-\mathrm{O}(1)-\mathrm{N}(1)$ & $-26.0(5)$ \\
\hline$C(2)-C(1)-C(6)-C(8)$ & $-172.3(6)$ & $\mathrm{C}(1)-\operatorname{Ir}(1)-\mathrm{O}(1)-\mathrm{N}(1)$ & $175.0(10)$ \\
\hline $\operatorname{Ir}(1)-\mathrm{C}(1)-\mathrm{C}(6)-\mathrm{C}(8)$ & $5.5(8)$ & $\mathrm{P}(1)-\operatorname{Ir}(1)-\mathrm{O}(1)-\mathrm{N}(1)$ & $-121.4(4)$ \\
\hline $\mathrm{C}(3)-\mathrm{C}(2)-\mathrm{C}(7)-\mathrm{P}(1)$ & $152.9(6)$ & $\mathrm{P}(2)-\operatorname{Ir}(1)-\mathrm{O}(1)-\mathrm{N}(1)$ & $74.8(4)$ \\
\hline $\mathrm{C}(1)-\mathrm{C}(2)-\mathrm{C}(7)-\mathrm{P}(1)$ & $-23.1(7)$ & $\mathrm{C}(1)-\operatorname{Ir}(1)-\mathrm{C}(26)-\mathrm{O}(3)$ & $5(5)$ \\
\hline $\mathrm{C}(13)-\mathrm{P}(1)-\mathrm{C}(7)-\mathrm{C}(2)$ & $160.2(4)$ & $\mathrm{O}(1)-\operatorname{Ir}(1)-\mathrm{C}(26)-\mathrm{O}(3)$ & $-171(5)$ \\
\hline $\mathrm{C}(9)-\mathrm{P}(1)-\mathrm{C}(7)-\mathrm{C}(2)$ & $-82.5(5)$ & $\mathrm{P}(1)-\operatorname{Ir}(1)-\mathrm{C}(26)-\mathrm{O}(3)$ & $-75(5)$ \\
\hline $\operatorname{Ir}(1)-\mathrm{P}(1)-\mathrm{C}(7)-\mathrm{C}(2)$ & $35.7(4)$ & $\mathrm{P}(2)-\operatorname{Ir}(1)-\mathrm{C}(26)-\mathrm{O}(3)$ & $88(5)$ \\
\hline
\end{tabular}


IV. Structural Data for (PCP) $\operatorname{IrH}(\mathrm{CO})\left(\mathrm{CH}_{2} \mathrm{NO}_{2}\right) 3$.

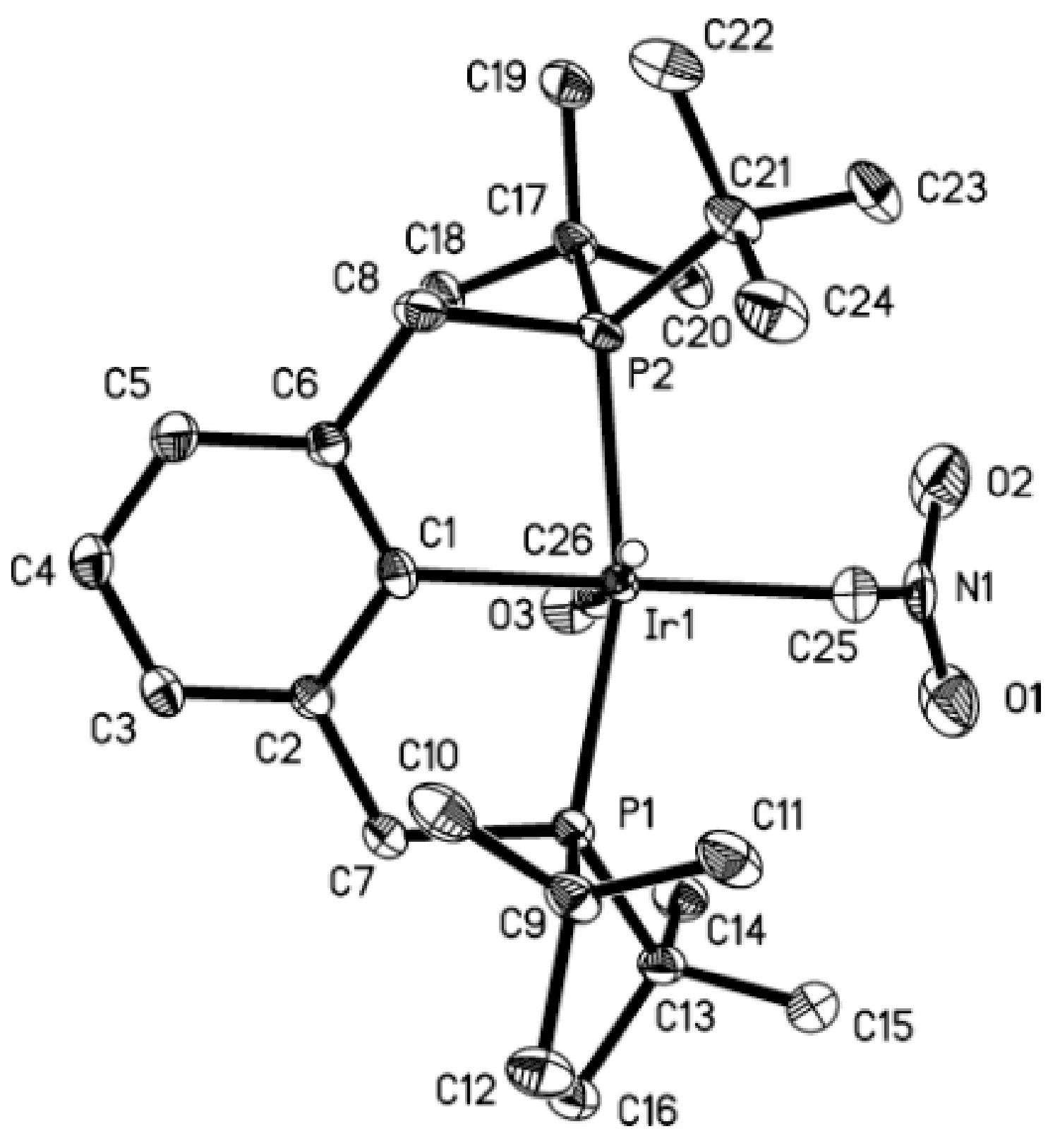

Figure S-3. ORTEP diagrams of 3. Hydrogen atoms omitted for clarity. Thermal ellipsoids are shown at $50 \%$ probability. 
Table S-9. Crystal data and structure refinement for 3.

\begin{tabular}{|c|c|c|}
\hline Identification code & \multicolumn{2}{|l|}{ irhcoc3 } \\
\hline Empirical formula & \multicolumn{2}{|c|}{$\mathrm{C} 26 \mathrm{H} 46 \mathrm{Ir} N \mathrm{O} 3 \mathrm{P} 2$} \\
\hline Formula weight & \multicolumn{2}{|l|}{674.78} \\
\hline Temperature & \multicolumn{2}{|l|}{$100(2) \mathrm{K}$} \\
\hline Wavelength & \multicolumn{2}{|l|}{$0.71073 \AA$} \\
\hline Crystal system & \multicolumn{2}{|l|}{ Monoclinic } \\
\hline Space group & \multicolumn{2}{|l|}{$\mathrm{Pn}$} \\
\hline \multirow[t]{3}{*}{ Unit cell dimensions } & $a=8.6883(5) \AA$ & $\alpha=90^{\circ}$. \\
\hline & $\mathrm{b}=16.0224(9) \AA$ & $\beta=104.699(1)^{\circ}$ \\
\hline & $\mathrm{c}=10.3949(6) \AA$ & $\gamma=90^{\circ}$ \\
\hline Volume & \multicolumn{2}{|l|}{$1399.69(14) \AA^{3}$} \\
\hline $\mathrm{Z}$ & \multicolumn{2}{|l|}{2} \\
\hline Density (calculated) & \multicolumn{2}{|l|}{$1.601 \mathrm{Mg} / \mathrm{m}^{3}$} \\
\hline Absorption coefficient & \multicolumn{2}{|l|}{$4.910 \mathrm{~mm}^{-1}$} \\
\hline $\mathrm{F}(000)$ & \multicolumn{2}{|l|}{680} \\
\hline Crystal size & \multicolumn{2}{|c|}{$0.26 \times 0.18 \times 0.10 \mathrm{~mm}^{3}$} \\
\hline Theta range for data collection & \multicolumn{2}{|l|}{2.39 to $30.47^{\circ}$. } \\
\hline Index ranges & \multicolumn{2}{|c|}{$-12<=\mathrm{h}<=12,-22<=\mathrm{k}<=22,-14<=1<=14$} \\
\hline Reflections collected & \multicolumn{2}{|l|}{16646} \\
\hline Independent reflections & \multicolumn{2}{|c|}{$8256[\mathrm{R}(\mathrm{int})=0.0244]$} \\
\hline Completeness to theta $=30.47^{\circ}$ & \multicolumn{2}{|l|}{$99.6 \%$} \\
\hline Absorption correction & \multicolumn{2}{|c|}{ Semi-empirical from equivalents } \\
\hline Refinement method & \multicolumn{2}{|c|}{ Full-matrix least-squares on $\mathrm{F}^{2}$} \\
\hline Data / restraints / parameters & \multicolumn{2}{|l|}{$8256 / 3 / 437$} \\
\hline Goodness-of-fit on $\mathrm{F}^{2}$ & \multicolumn{2}{|l|}{0.915} \\
\hline Final $R$ indices $[\mathrm{I}>2 \operatorname{sigma}(\mathrm{I})]$ & \multicolumn{2}{|c|}{$\mathrm{R} 1=0.0238, \mathrm{wR} 2=0.0518$} \\
\hline $\mathrm{R}$ indices (all data) & \multicolumn{2}{|c|}{$\mathrm{R} 1=0.0250, \mathrm{wR} 2=0.0522$} \\
\hline Absolute structure parameter & \multicolumn{2}{|l|}{$0.016(5)$} \\
\hline Largest diff. peak and hole & \multicolumn{2}{|c|}{2.859 and -1.017 e. $\AA^{-3}$} \\
\hline
\end{tabular}


Table S-10. Atomic coordinates ( $\left.\times 10^{4}\right)$ and equivalent isotropic displacement parameters $\left(\AA^{2} \times 10^{3}\right)$ for $3 . U(e q)$ is defined as one third of the trace of the orthogonalized $U^{i j}$ tensor.

\begin{tabular}{|c|c|c|c|c|}
\hline & $\mathrm{x}$ & $\mathrm{y}$ & $\mathrm{z}$ & $\mathrm{U}(\mathrm{eq})$ \\
\hline $\operatorname{Ir}(1)$ & $4266(1)$ & $2575(1)$ & $3206(1)$ & $14(1)$ \\
\hline $\mathrm{P}(1)$ & $2965(1)$ & $3348(1)$ & $1328(1)$ & $16(1)$ \\
\hline $\mathrm{P}(2)$ & $6170(1)$ & $1688(1)$ & $4542(1)$ & $16(1)$ \\
\hline $\mathrm{C}(1)$ & $4547(4)$ & 1761(2) & $1710(3)$ & $18(1)$ \\
\hline$C(2)$ & $3554(4)$ & 1821(2) & $410(3)$ & $17(1)$ \\
\hline$C(3)$ & $3740(5)$ & $1282(2)$ & $-583(4)$ & $22(1)$ \\
\hline$C(4)$ & 4921(5) & $675(3)$ & $-316(4)$ & $25(1)$ \\
\hline$C(5)$ & $5945(5)$ & $627(2)$ & $946(4)$ & $25(1)$ \\
\hline$C(6)$ & 5774(4) & 1171(2) & 1944(3) & $18(1)$ \\
\hline$C(7)$ & $2312(5)$ & $2504(2)$ & $108(4)$ & $19(1)$ \\
\hline$C(8)$ & 6986(4) & $1178(3)$ & $3274(3)$ & $21(1)$ \\
\hline $\mathrm{C}(9)$ & 4352(4) & $4016(2)$ & $629(3)$ & $22(1)$ \\
\hline$C(10)$ & $5536(5)$ & $3441(3)$ & $189(4)$ & $26(1)$ \\
\hline $\mathrm{C}(11)$ & $5288(5)$ & $4602(3)$ & $1705(4)$ & $29(1)$ \\
\hline$C(12)$ & $3516(5)$ & $4526(3)$ & $-598(4)$ & $27(1)$ \\
\hline$C(13)$ & 1073(4) & $3941(2)$ & $1275(3)$ & $21(1)$ \\
\hline$C(14)$ & $106(5)$ & $3457(3)$ & 2067(4) & $25(1)$ \\
\hline$C(15)$ & $1431(6)$ & $4807(2)$ & 1935(4) & $27(1)$ \\
\hline$C(16)$ & 19(5) & $4038(3)$ & $-151(4)$ & $26(1)$ \\
\hline$C(17)$ & $5372(4)$ & $796(2)$ & $5354(3)$ & 19(1) \\
\hline$C(18)$ & $4380(5)$ & $243(2)$ & 4231(4) & $23(1)$ \\
\hline$C(19)$ & $6651(5)$ & $242(3)$ & $6236(4)$ & $26(1)$ \\
\hline$C(20)$ & $4303(5)$ & $1126(3)$ & 6193(4) & $23(1)$ \\
\hline$C(21)$ & 7981(4) & $2146(2)$ & $5739(4)$ & $24(1)$ \\
\hline$C(22)$ & $9424(5)$ & $1557(3)$ & $6024(4)$ & $30(1)$ \\
\hline$C(23)$ & $7618(6)$ & 2392(3) & 7053(4) & $30(1)$ \\
\hline$C(24)$ & $8487(5)$ & 2934(3) & $5082(5)$ & $31(1)$ \\
\hline $\mathrm{N}(1)$ & $3240(4)$ & $3515(2)$ & $5504(3)$ & $27(1)$ \\
\hline $\mathrm{O}(1)$ & 2001(4) & $3920(2)$ & $5162(3)$ & $47(1)$ \\
\hline $\mathrm{O}(2)$ & $3529(5)$ & $3075(2)$ & $6500(3)$ & $47(1)$ \\
\hline$C(25)$ & $4371(5)$ & $3558(2)$ & $4696(4)$ & $24(1)$ \\
\hline $\mathrm{O}(3)$ & $1240(3)$ & $1660(2)$ & $3367(3)$ & $28(1)$ \\
\hline$C(26)$ & 2369(4) & $2022(2)$ & $3354(3)$ & 19(1) \\
\hline
\end{tabular}


Table S-11. Bond lengths $[\AA]$ and angles $\left[{ }^{\circ}\right]$ for 3 .

\begin{tabular}{|c|c|c|c|}
\hline$\overline{\operatorname{Ir}(1)-C(26)}$ & $1.911(4)$ & $\mathrm{C}(13)-\mathrm{C}(15)$ & $1.544(5)$ \\
\hline $\operatorname{Ir}(1)-C(1)$ & $2.091(3)$ & $\mathrm{C}(14)-\mathrm{H}(14 \mathrm{~A})$ & $0.97(5)$ \\
\hline $\operatorname{Ir}(1)-C(25)$ & $2.194(4)$ & $\mathrm{C}(14)-\mathrm{H}(14 \mathrm{~B})$ & $0.89(7)$ \\
\hline $\operatorname{Ir}(1)-\mathrm{P}(1)$ & $2.3447(9)$ & $\mathrm{C}(14)-\mathrm{H}(14 \mathrm{C})$ & $0.96(5)$ \\
\hline $\operatorname{Ir}(1)-\mathrm{P}(2)$ & $2.3499(9)$ & $\mathrm{C}(15)-\mathrm{H}(15 \mathrm{~A})$ & $0.96(5)$ \\
\hline $\operatorname{Ir}(1)-\mathrm{H}(1)$ & $1.531(18)$ & $\mathrm{C}(15)-\mathrm{H}(15 \mathrm{~B})$ & $0.87(6)$ \\
\hline $\mathrm{P}(1)-\mathrm{C}(7)$ & $1.842(4)$ & $\mathrm{C}(15)-\mathrm{H}(15 \mathrm{C})$ & $0.96(5)$ \\
\hline $\mathrm{P}(1)-\mathrm{C}(13)$ & $1.888(3)$ & $\mathrm{C}(16)-\mathrm{H}(16 \mathrm{~A})$ & $1.01(5)$ \\
\hline $\mathrm{P}(1)-\mathrm{C}(9)$ & $1.890(3)$ & $\mathrm{C}(16)-\mathrm{H}(16 \mathrm{~B})$ & $0.97(5)$ \\
\hline $\mathrm{P}(2)-\mathrm{C}(8)$ & $1.839(4)$ & $\mathrm{C}(16)-\mathrm{H}(16 \mathrm{C})$ & $0.92(5)$ \\
\hline $\mathrm{P}(2)-\mathrm{C}(17)$ & $1.880(3)$ & $\mathrm{C}(17)-\mathrm{C}(20)$ & $1.521(5)$ \\
\hline $\mathrm{P}(2)-\mathrm{C}(21)$ & $1.890(4)$ & $C(17)-C(19)$ & $1.531(5)$ \\
\hline$C(1)-C(6)$ & $1.400(5)$ & $\mathrm{C}(17)-\mathrm{C}(18)$ & $1.542(5)$ \\
\hline$C(1)-C(2)$ & $1.410(5)$ & $\mathrm{C}(18)-\mathrm{H}(18 \mathrm{~A})$ & $0.90(5)$ \\
\hline $\mathrm{C}(2)-\mathrm{C}(3)$ & $1.386(5)$ & $\mathrm{C}(18)-\mathrm{H}(18 \mathrm{~B})$ & $0.95(5)$ \\
\hline $\mathrm{C}(2)-\mathrm{C}(7)$ & $1.513(5)$ & $\mathrm{C}(18)-\mathrm{H}(18 \mathrm{C})$ & $0.95(5)$ \\
\hline $\mathrm{C}(3)-\mathrm{C}(4)$ & $1.389(6)$ & $\mathrm{C}(19)-\mathrm{H}(19 \mathrm{~A})$ & $1.01(5)$ \\
\hline $\mathrm{C}(3)-\mathrm{H}(3)$ & $0.96(4)$ & $\mathrm{C}(19)-\mathrm{H}(19 \mathrm{~B})$ & $0.88(5)$ \\
\hline $\mathrm{C}(4)-\mathrm{C}(5)$ & $1.388(5)$ & $\mathrm{C}(19)-\mathrm{H}(19 \mathrm{C})$ & $0.89(5)$ \\
\hline $\mathrm{C}(4)-\mathrm{H}(4)$ & $0.98(4)$ & $\mathrm{C}(20)-\mathrm{H}(20 \mathrm{~A})$ & $0.97(6)$ \\
\hline$C(5)-C(6)$ & $1.391(5)$ & $\mathrm{C}(20)-\mathrm{H}(20 \mathrm{~B})$ & $0.93(5)$ \\
\hline $\mathrm{C}(5)-\mathrm{H}(5)$ & $0.96(4)$ & $\mathrm{C}(20)-\mathrm{H}(20 \mathrm{C})$ & $0.86(6)$ \\
\hline $\mathrm{C}(6)-\mathrm{C}(8)$ & $1.511(5)$ & $\mathrm{C}(21)-\mathrm{C}(23)$ & $1.529(6)$ \\
\hline $\mathrm{C}(7)-\mathrm{H}(7 \mathrm{~A})$ & $1.03(5)$ & $C(21)-C(22)$ & $1.537(6)$ \\
\hline $\mathrm{C}(7)-\mathrm{H}(7 \mathrm{~B})$ & $0.95(6)$ & $\mathrm{C}(21)-\mathrm{C}(24)$ & $1.551(6)$ \\
\hline $\mathrm{C}(8)-\mathrm{H}(8 \mathrm{~A})$ & $0.99(4)$ & $\mathrm{C}(22)-\mathrm{H}(22 \mathrm{~A})$ & $0.95(5)$ \\
\hline $\mathrm{C}(8)-\mathrm{H}(8 \mathrm{~B})$ & $1.00(4)$ & $\mathrm{C}(22)-\mathrm{H}(22 \mathrm{~B})$ & $1.04(5)$ \\
\hline $\mathrm{C}(9)-\mathrm{C}(11)$ & $1.528(5)$ & $\mathrm{C}(22)-\mathrm{H}(22 \mathrm{C})$ & $0.91(5)$ \\
\hline $\mathrm{C}(9)-\mathrm{C}(12)$ & $1.533(5)$ & $\mathrm{C}(23)-\mathrm{H}(23 \mathrm{~A})$ & $0.95(5)$ \\
\hline $\mathrm{C}(9)-\mathrm{C}(10)$ & $1.535(6)$ & $\mathrm{C}(23)-\mathrm{H}(23 \mathrm{~B})$ & $1.00(5)$ \\
\hline $\mathrm{C}(10)-\mathrm{H}(10 \mathrm{~A})$ & $0.89(5)$ & $\mathrm{C}(23)-\mathrm{H}(23 \mathrm{C})$ & $1.08(6)$ \\
\hline $\mathrm{C}(10)-\mathrm{H}(10 \mathrm{~B})$ & $0.93(5)$ & $\mathrm{C}(24)-\mathrm{H}(24 \mathrm{~A})$ & $0.93(6)$ \\
\hline $\mathrm{C}(10)-\mathrm{H}(10 \mathrm{C})$ & $1.02(5)$ & $\mathrm{C}(24)-\mathrm{H}(24 \mathrm{~B})$ & $0.91(6)$ \\
\hline $\mathrm{C}(11)-\mathrm{H}(11 \mathrm{~A})$ & $0.91(5)$ & $\mathrm{C}(24)-\mathrm{H}(24 \mathrm{C})$ & $0.94(6)$ \\
\hline $\mathrm{C}(11)-\mathrm{H}(11 \mathrm{~B})$ & $0.94(5)$ & $\mathrm{N}(1)-\mathrm{O}(2)$ & $1.225(5)$ \\
\hline $\mathrm{C}(11)-\mathrm{H}(11 \mathrm{C})$ & $1.01(5)$ & $\mathrm{N}(1)-\mathrm{O}(1)$ & $1.229(5)$ \\
\hline $\mathrm{C}(12)-\mathrm{H}(12 \mathrm{~A})$ & $0.88(6)$ & $\mathrm{N}(1)-\mathrm{C}(25)$ & $1.448(5)$ \\
\hline $\mathrm{C}(12)-\mathrm{H}(12 \mathrm{~B})$ & $0.94(5)$ & $\mathrm{C}(25)-\mathrm{H}(25 \mathrm{~A})$ & $0.94(5)$ \\
\hline $\mathrm{C}(12)-\mathrm{H}(12 \mathrm{C})$ & $0.94(5)$ & $\mathrm{C}(25)-\mathrm{H}(25 \mathrm{~B})$ & $0.99(4)$ \\
\hline C(13)-C(14) & $1.528(5)$ & $\mathrm{O}(3)-\mathrm{C}(26)$ & $1.144(4)$ \\
\hline$C(13)-C(16)$ & $1.540(5)$ & & \\
\hline$C(26)-\operatorname{Ir}(1)-C(1)$ & $92.06(14)$ & $\mathrm{P}(2)-\operatorname{Ir}(1)-\mathrm{H}(1)$ & $74.6(14)$ \\
\hline$C(26)-\operatorname{Ir}(1)-C(25)$ & $99.13(14)$ & $\mathrm{C}(7)-\mathrm{P}(1)-\mathrm{C}(13)$ & $103.64(17)$ \\
\hline $\mathrm{C}(1)-\operatorname{Ir}(1)-\mathrm{C}(25)$ & $168.77(14)$ & $\mathrm{C}(7)-\mathrm{P}(1)-\mathrm{C}(9)$ & $105.42(17)$ \\
\hline $\mathrm{C}(26)-\operatorname{Ir}(1)-\mathrm{P}(1)$ & 93.93(10) & $\mathrm{C}(13)-\mathrm{P}(1)-\mathrm{C}(9)$ & $109.83(16)$ \\
\hline $\mathrm{C}(1)-\operatorname{Ir}(1)-\mathrm{P}(1)$ & $80.39(10)$ & $C(7)-P(1)-\operatorname{Ir}(1)$ & $100.65(12)$ \\
\hline $\mathrm{C}(25)-\operatorname{Ir}(1)-\mathrm{P}(1)$ & 97.71(11) & $\mathrm{C}(13)-\mathrm{P}(1)-\operatorname{Ir}(1)$ & $121.48(11)$ \\
\hline $\mathrm{C}(26)-\operatorname{Ir}(1)-\mathrm{P}(2)$ & $99.42(10)$ & $\mathrm{C}(9)-\mathrm{P}(1)-\operatorname{Ir}(1)$ & $113.54(12)$ \\
\hline$C(1)-\operatorname{Ir}(1)-\mathrm{P}(2)$ & $82.19(10)$ & $\mathrm{C}(8)-\mathrm{P}(2)-\mathrm{C}(17)$ & $103.73(17)$ \\
\hline $\mathrm{C}(25)-\operatorname{Ir}(1)-\mathrm{P}(2)$ & $96.88(11)$ & $\mathrm{C}(8)-\mathrm{P}(2)-\mathrm{C}(21)$ & $103.68(18)$ \\
\hline $\mathrm{P}(1)-\operatorname{Ir}(1)-\mathrm{P}(2)$ & 158.37(3) & $\mathrm{C}(17)-\mathrm{P}(2)-\mathrm{C}(21)$ & $109.89(16)$ \\
\hline $\mathrm{C}(26)-\operatorname{Ir}(1)-\mathrm{H}(1)$ & $173.5(14)$ & C(8)-P(2)-Ir(1) & $100.78(12)$ \\
\hline $\mathrm{C}(1)-\operatorname{Ir}(1)-\mathrm{H}(1)$ & $84.6(14)$ & $\mathrm{C}(17)-\mathrm{P}(2)-\operatorname{Ir}(1)$ & $116.17(11)$ \\
\hline $\mathrm{C}(25)-\operatorname{Ir}(1)-\mathrm{H}(1)$ & $84.4(14)$ & $\mathrm{C}(21)-\mathrm{P}(2)-\operatorname{Ir}(1)$ & $119.85(13)$ \\
\hline $\mathrm{P}(1)-\operatorname{Ir}(1)-\mathrm{H}(1)$ & $91.0(14)$ & $\mathrm{C}(6)-\mathrm{C}(1)-\mathrm{C}(2)$ & $117.8(3)$ \\
\hline
\end{tabular}




$\begin{array}{lc} & \\ \text { C(6)-C(1)-Ir(1) } & 121.3(2) \\ \text { C(2)-C(1)-Ir(1) } & 120.8(2) \\ \text { C(3)-C(2)-C(1) } & 120.9(3) \\ \text { C(3)-C(2)-C(7) } & 120.5(3) \\ \text { C(1)-C(2)-C(7) } & 118.6(3) \\ \text { C(2)-C(3)-C(4) } & 120.5(3) \\ \text { C(2)-C(3)-H(3) } & 118(3) \\ \text { C(4)-C(3)-H(3) } & 122(3) \\ \text { C(5)-C(4)-C(3) } & 119.4(4) \\ \text { C(5)-C(4)-H(4) } & 117(3) \\ \text { C(3)-C(4)-H(4) } & 124(3) \\ \text { C(4)-C(5)-C(6) } & 120.4(3) \\ \text { C(4)-C(5)-H(5) } & 122(3) \\ \text { C(6)-C(5)-H(5) } & 117(3) \\ \text { C(5)-C(6)-C(1) } & 120.9(3) \\ \text { C(5)-C(6)-C(8) } & 120.4(3) \\ \text { C(1)-C(6)-C(8) } & 118.5(3) \\ \text { C(2)-C(7)-P(1) } & 108.0(3) \\ \text { C(2)-C(7)-H(7A) } & 112(2) \\ \text { P(1)-C(7)-H(7A) } & 104(3) \\ \text { C(2)-C(7)-H(7B) } & 112(3) \\ \text { P(1)-C(7)-H(7B) } & 115(3) \\ \text { H(7A)-C(7)-H(7) } & 105(4) \\ \text { C(6)-C(8)-P(2) } & 110.7(2) \\ \text { C(6)-C(8)-H(8A) } & 110(2) \\ \text { P(2)-C(8)-H(8A) } & 109(2) \\ \text { C(6)-C(8)-H(8B) } & 112(2) \\ \text { P(2)-C(8)-H(8B) } & 115(2) \\ \text { H(8A)-C(8)-H(8B) } & 100(3) \\ \text { C(11)-C(9)-C(12) } & 109.4(3) \\ \text { C(11)-C(9)-C(10) } & 108.3(3) \\ \text { C(12)-C(9)-C(10) } & 106.6(3) \\ \text { C(11)-C(9)-P(1) } & 109.8(3) \\ \text { C(12)-C(9)-P(1) } & 114.1(3) \\ \text { C(10)-C(9)-P(1) } & 108.4(3) \\ \text { C(9)-C(10)-H(10A) } & 118(3) \\ \text { C(9)-C(10)-H(10B) } & 116(3) \\ \text { H(10A)-C(10)-H(10B) } & 104(5) \\ \text { C(9)-C(10)-H(10C) } & 112(3) \\ \text { H(10A)-C(10)-H(10C) } & 107(4) \\ \text { H(10B)-C(10)-H(10C) } & 96(4) \\ \text { C(9)-C(11)-H(11A) } & 112(3) \\ \text { C(9)-C(11)-H(11B) } & 115(3) \\ \text { H(11A)-C(11)-H(11B) } & 99(4) \\ \text { C(9)-C(11)-H(11C) } & 111(3) \\ \text { H(11A)-C(11)-H(11C) } & 109(4) \\ \text { H(11B)-C(11)-H(11C) } & 110(4) \\ \text { C(9)-C(12)-H(12A) } & 110(3) \\ \text { C(9)-C(12)-H(12B) } & 112(3) \\ \text { H(12A)-C(12)-H(12B) } & 106(4) \\ \text { C(9)-C(12)-H(12C) } & 107(3) \\ \text { H(12A)-C(12)-H(12C) } & 110(5) \\ \text { H(12B)-C(12)-H(12C) } & 112(4) \\ \text { C(14)-C(13)-C(16) } & 107.2(3) \\ \text { C(14)-C(13)-C(15) } & 107.1(3) \\ \text { C(16)-C(13)-C(15) } & 109.9(3) \\ \text { C(14)-C(13)-P(1) } & 108.8(2) \\ \text { C(16)-C(13)-P(1) } & 112.3(2) \\ & \\ & \end{array}$

\begin{tabular}{|c|c|}
\hline$C(15)-C(13)-P(1)$ & $111.3(3)$ \\
\hline $\mathrm{C}(13)-\mathrm{C}(14)-\mathrm{H}(14 \mathrm{~A})$ & $114(3)$ \\
\hline $\mathrm{C}(13)-\mathrm{C}(14)-\mathrm{H}(14 \mathrm{~B})$ & $112(3)$ \\
\hline $\mathrm{H}(14 \mathrm{~A})-\mathrm{C}(14)-\mathrm{H}(14 \mathrm{~B})$ & $107(4)$ \\
\hline $\mathrm{C}(13)-\mathrm{C}(14)-\mathrm{H}(14 \mathrm{C})$ & $107(3)$ \\
\hline $\mathrm{H}(14 \mathrm{~A})-\mathrm{C}(14)-\mathrm{H}(14 \mathrm{C})$ & $107(4)$ \\
\hline $\mathrm{H}(14 \mathrm{~B})-\mathrm{C}(14)-\mathrm{H}(14 \mathrm{C})$ & $109(5)$ \\
\hline $\mathrm{C}(13)-\mathrm{C}(15)-\mathrm{H}(15 \mathrm{~A})$ & $104(3)$ \\
\hline $\mathrm{C}(13)-\mathrm{C}(15)-\mathrm{H}(15 \mathrm{~B})$ & 107(3) \\
\hline $\mathrm{H}(15 \mathrm{~A})-\mathrm{C}(15)-\mathrm{H}(15 \mathrm{~B})$ & $113(5)$ \\
\hline $\mathrm{C}(13)-\mathrm{C}(15)-\mathrm{H}(15 \mathrm{C})$ & $108(3)$ \\
\hline $\mathrm{H}(15 \mathrm{~A})-\mathrm{C}(15)-\mathrm{H}(15 \mathrm{C})$ & $120(4)$ \\
\hline $\mathrm{H}(15 \mathrm{~B})-\mathrm{C}(15)-\mathrm{H}(15 \mathrm{C})$ & $104(4)$ \\
\hline $\mathrm{C}(13)-\mathrm{C}(16)-\mathrm{H}(16 \mathrm{~A})$ & $106(3)$ \\
\hline $\mathrm{C}(13)-\mathrm{C}(16)-\mathrm{H}(16 \mathrm{~B})$ & $115(3)$ \\
\hline $\mathrm{H}(16 \mathrm{~A})-\mathrm{C}(16)-\mathrm{H}(16 \mathrm{~B})$ & $111(4)$ \\
\hline $\mathrm{C}(13)-\mathrm{C}(16)-\mathrm{H}(16 \mathrm{C})$ & $106(3)$ \\
\hline $\mathrm{H}(16 \mathrm{~A})-\mathrm{C}(16)-\mathrm{H}(16 \mathrm{C})$ & $107(4)$ \\
\hline $\mathrm{H}(16 \mathrm{~B})-\mathrm{C}(16)-\mathrm{H}(16 \mathrm{C})$ & $112(4)$ \\
\hline C(20)-C(17)-C(19) & $108.3(3)$ \\
\hline $\mathrm{C}(20)-\mathrm{C}(17)-\mathrm{C}(18)$ & 109.2(3) \\
\hline C(19)-C(17)-C(18) & $107.5(3)$ \\
\hline $\mathrm{C}(20)-\mathrm{C}(17)-\mathrm{P}(2)$ & $110.0(2)$ \\
\hline C(19)-C(17)-P(2) & $114.5(3)$ \\
\hline $\mathrm{C}(18)-\mathrm{C}(17)-\mathrm{P}(2)$ & $107.2(2)$ \\
\hline $\mathrm{C}(17)-\mathrm{C}(18)-\mathrm{H}(18 \mathrm{~A})$ & $114(3)$ \\
\hline $\mathrm{C}(17)-\mathrm{C}(18)-\mathrm{H}(18 \mathrm{~B})$ & $110(3)$ \\
\hline H(18A)-C(18)-H(18B) & $102(4)$ \\
\hline $\mathrm{C}(17)-\mathrm{C}(18)-\mathrm{H}(18 \mathrm{C})$ & $106(3)$ \\
\hline H(18A)-C(18)-H(18C) & $106(4)$ \\
\hline $\mathrm{H}(18 \mathrm{~B})-\mathrm{C}(18)-\mathrm{H}(18 \mathrm{C})$ & $118(4)$ \\
\hline $\mathrm{C}(17)-\mathrm{C}(19)-\mathrm{H}(19 \mathrm{~A})$ & $108(3)$ \\
\hline $\mathrm{C}(17)-\mathrm{C}(19)-\mathrm{H}(19 \mathrm{~B})$ & $112(4)$ \\
\hline H(19A)-C(19)-H(19B) & $119(4)$ \\
\hline $\mathrm{C}(17)-\mathrm{C}(19)-\mathrm{H}(19 \mathrm{C})$ & $107(3)$ \\
\hline H(19A)-C(19)-H(19C) & $111(4)$ \\
\hline $\mathrm{H}(19 \mathrm{~B})-\mathrm{C}(19)-\mathrm{H}(19 \mathrm{C})$ & $99(5)$ \\
\hline $\mathrm{C}(17)-\mathrm{C}(20)-\mathrm{H}(20 \mathrm{~A})$ & $110(3)$ \\
\hline $\mathrm{C}(17)-\mathrm{C}(20)-\mathrm{H}(20 \mathrm{~B})$ & $118(3)$ \\
\hline $\mathrm{H}(20 \mathrm{~A})-\mathrm{C}(20)-\mathrm{H}(20 \mathrm{~B})$ & $108(4)$ \\
\hline $\mathrm{C}(17)-\mathrm{C}(20)-\mathrm{H}(20 \mathrm{C})$ & $110(3)$ \\
\hline $\mathrm{H}(20 \mathrm{~A})-\mathrm{C}(20)-\mathrm{H}(20 \mathrm{C})$ & $110(4)$ \\
\hline $\mathrm{H}(20 \mathrm{~B})-\mathrm{C}(20)-\mathrm{H}(20 \mathrm{C})$ & $101(5)$ \\
\hline $\mathrm{C}(23)-\mathrm{C}(21)-\mathrm{C}(22)$ & 109.3(3) \\
\hline $\mathrm{C}(23)-\mathrm{C}(21)-\mathrm{C}(24)$ & 109.2(4) \\
\hline$C(22)-C(21)-C(24)$ & $106.0(3)$ \\
\hline $\mathrm{C}(23)-\mathrm{C}(21)-\mathrm{P}(2)$ & $111.2(3)$ \\
\hline $\mathrm{C}(22)-\mathrm{C}(21)-\mathrm{P}(2)$ & $113.0(3)$ \\
\hline $\mathrm{C}(24)-\mathrm{C}(21)-\mathrm{P}(2)$ & 107.9(3) \\
\hline $\mathrm{C}(21)-\mathrm{C}(22)-\mathrm{H}(22 \mathrm{~A})$ & 104(3) \\
\hline $\mathrm{C}(21)-\mathrm{C}(22)-\mathrm{H}(22 \mathrm{~B})$ & $113(3)$ \\
\hline $\mathrm{H}(22 \mathrm{~A})-\mathrm{C}(22)-\mathrm{H}(22 \mathrm{~B})$ & $112(4)$ \\
\hline $\mathrm{C}(21)-\mathrm{C}(22)-\mathrm{H}(22 \mathrm{C})$ & $109(3)$ \\
\hline $\mathrm{H}(22 \mathrm{~A})-\mathrm{C}(22)-\mathrm{H}(22 \mathrm{C})$ & $115(4)$ \\
\hline $\mathrm{H}(22 \mathrm{~B})-\mathrm{C}(22)-\mathrm{H}(22 \mathrm{C})$ & $105(4)$ \\
\hline $\mathrm{C}(21)-\mathrm{C}(23)-\mathrm{H}(23 \mathrm{~A})$ & 109(3) \\
\hline $\mathrm{C}(21)-\mathrm{C}(23)-\mathrm{H}(23 \mathrm{~B})$ & $116(3)$ \\
\hline $\mathrm{H}(23 \mathrm{~A})-\mathrm{C}(23)-\mathrm{H}(23 \mathrm{~B})$ & $110(5)$ \\
\hline
\end{tabular}




$\begin{array}{llll}\mathrm{C}(21)-\mathrm{C}(23)-\mathrm{H}(23 \mathrm{C}) & 113(3) & \mathrm{O}(2)-\mathrm{N}(1)-\mathrm{C}(25) & 119.5(4) \\ \mathrm{H}(23 \mathrm{~A})-\mathrm{C}(23)-\mathrm{H}(23 \mathrm{C}) & 103(5) & \mathrm{O}(1)-\mathrm{N}(1)-\mathrm{C}(25) & 118.7(4) \\ \mathrm{H}(23 \mathrm{~B})-\mathrm{C}(23)-\mathrm{H}(23 \mathrm{C}) & 105(4) & \mathrm{N}(1)-\mathrm{C}(25)-\mathrm{Ir}(1) & 117.6(2) \\ \mathrm{C}(21)-\mathrm{C}(24)-\mathrm{H}(24 \mathrm{~A}) & 116(3) & \mathrm{N}(1)-\mathrm{C}(25)-\mathrm{H}(25 \mathrm{~A}) & 98(3) \\ \mathrm{C}(21)-\mathrm{C}(24)-\mathrm{H}(24 \mathrm{~B}) & 111(4) & \mathrm{Ir}(1)-\mathrm{C}(25)-\mathrm{H}(25 \mathrm{~A}) & 104(3) \\ \mathrm{H}(24 \mathrm{~A})-\mathrm{C}(24)-\mathrm{H}(24 \mathrm{~B}) & 107(5) & \mathrm{N}(1)-\mathrm{C}(25)-\mathrm{H}(25 \mathrm{~B}) & 109(2) \\ \mathrm{C}(21)-\mathrm{C}(24)-\mathrm{H}(24 \mathrm{C}) & 107(3) & \mathrm{Ir}(1)-\mathrm{C}(25)-\mathrm{H}(25 \mathrm{~B}) & 110(3) \\ \mathrm{H}(24 \mathrm{~A})-\mathrm{C}(24)-\mathrm{H}(24 \mathrm{C}) & 104(4) & \mathrm{H}(25 \mathrm{~A})-\mathrm{C}(25)-\mathrm{H}(25 \mathrm{~B}) & 118(4) \\ \mathrm{H}(24 \mathrm{~B})-\mathrm{C}(24)-\mathrm{H}(24 \mathrm{C}) & 111(5) & \mathrm{O}(3)-\mathrm{C}(26)-\operatorname{Ir}(1) & 175.3(3) \\ \mathrm{O}(2)-\mathrm{N}(1)-\mathrm{O}(1) & 121.7(4) & & \end{array}$


Table S-12. Torsion angles $\left[{ }^{\circ}\right]$ for 3 .

\begin{tabular}{|c|c|c|c|}
\hline$C(26)-\operatorname{Ir}(1)-P(1)-C(7)$ & $-64.69(17)$ & $\mathrm{C}(5)-\mathrm{C}(6)-\mathrm{C}(8)-\mathrm{P}(2)$ & $-162.0(3)$ \\
\hline $\mathrm{C}(1)-\operatorname{Ir}(1)-\mathrm{P}(1)-\mathrm{C}(7)$ & $26.73(16)$ & $\mathrm{C}(1)-\mathrm{C}(6)-\mathrm{C}(8)-\mathrm{P}(2)$ & $22.4(4)$ \\
\hline $\mathrm{C}(25)-\operatorname{Ir}(1)-\mathrm{P}(1)-\mathrm{C}(7)$ & $-164.47(16)$ & $\mathrm{C}(17)-\mathrm{P}(2)-\mathrm{C}(8)-\mathrm{C}(6)$ & $94.5(3)$ \\
\hline$P(2)-\operatorname{Ir}(1)-P(1)-C(7)$ & $63.51(16)$ & $\mathrm{C}(21)-\mathrm{P}(2)-\mathrm{C}(8)-\mathrm{C}(6)$ & $-150.7(3)$ \\
\hline C(26)--Ir(1)-P(1)-C(13) & $48.67(17)$ & $\operatorname{Ir}(1)-P(2)-C(8)-C(6)$ & $-26.1(3)$ \\
\hline$C(1)-\operatorname{Ir}(1)-P(1)-C(13)$ & $140.09(17)$ & $\mathrm{C}(7)-\mathrm{P}(1)-\mathrm{C}(9)-\mathrm{C}(11)$ & $-165.8(3)$ \\
\hline C(25)--Ir(1)-P(1)-C(13) & $-51.11(17)$ & $\mathrm{C}(13)-\mathrm{P}(1)-\mathrm{C}(9)-\mathrm{C}(11)$ & $83.1(3)$ \\
\hline $\mathrm{P}(2)-\operatorname{Ir}(1)-\mathrm{P}(1)-\mathrm{C}(13)$ & $176.87(15)$ & $\operatorname{Ir}(1)-\mathrm{P}(1)-\mathrm{C}(9)-\mathrm{C}(11)$ & $-56.6(3)$ \\
\hline $\mathrm{C}(26)-\operatorname{Ir}(1)-\mathrm{P}(1)-\mathrm{C}(9)$ & $-176.84(16)$ & $\mathrm{C}(7)-\mathrm{P}(1)-\mathrm{C}(9)-\mathrm{C}(12)$ & $70.9(3)$ \\
\hline $\mathrm{C}(1)-\operatorname{Ir}(1)-\mathrm{P}(1)-\mathrm{C}(9)$ & $-85.42(16)$ & $\mathrm{C}(13)-\mathrm{P}(1)-\mathrm{C}(9)-\mathrm{C}(12)$ & $-40.1(3)$ \\
\hline $\mathrm{C}(25)-\operatorname{Ir}(1)-\mathrm{P}(1)-\mathrm{C}(9)$ & $83.38(16)$ & $\operatorname{Ir}(1)-\mathrm{P}(1)-\mathrm{C}(9)-\mathrm{C}(12)$ & $-179.8(2)$ \\
\hline$P(2)-\operatorname{Ir}(1)-P(1)-C(9)$ & $-48.64(16)$ & $\mathrm{C}(7)-\mathrm{P}(1)-\mathrm{C}(9)-\mathrm{C}(10)$ & $-47.6(3)$ \\
\hline $\mathrm{C}(26)-\operatorname{Ir}(1)-\mathrm{P}(2)-\mathrm{C}(8)$ & $109.16(17)$ & $\mathrm{C}(13)-\mathrm{P}(1)-\mathrm{C}(9)-\mathrm{C}(10)$ & $-158.7(3)$ \\
\hline $\mathrm{C}(1)-\operatorname{Ir}(1)-\mathrm{P}(2)-\mathrm{C}(8)$ & $18.36(16)$ & $\operatorname{Ir}(1)-\mathrm{P}(1)-\mathrm{C}(9)-\mathrm{C}(10)$ & $61.6(3)$ \\
\hline $\mathrm{C}(25)-\operatorname{Ir}(1)-\mathrm{P}(2)-\mathrm{C}(8)$ & $-150.35(17)$ & $\mathrm{C}(7)-\mathrm{P}(1)-\mathrm{C}(13)-\mathrm{C}(14)$ & $77.9(3)$ \\
\hline$P(1)-\operatorname{Ir}(1)-P(2)-C(8)$ & $-18.21(17)$ & $\mathrm{C}(9)-\mathrm{P}(1)-\mathrm{C}(13)-\mathrm{C}(14)$ & $-169.9(3)$ \\
\hline C(26)--Ir(1)-P(2)-C(17) & $-2.11(16)$ & $\operatorname{Ir}(1)-\mathrm{P}(1)-\mathrm{C}(13)-\mathrm{C}(14)$ & $-33.9(3)$ \\
\hline C(1)-Ir(1)-P(2)-C(17) & $-92.91(15)$ & $\mathrm{C}(7)-\mathrm{P}(1)-\mathrm{C}(13)-\mathrm{C}(16)$ & $-40.7(3)$ \\
\hline C(25)--Ir(1)-P(2)-C(17) & $98.38(16)$ & $\mathrm{C}(9)-\mathrm{P}(1)-\mathrm{C}(13)-\mathrm{C}(16)$ & $71.6(3)$ \\
\hline $\mathrm{P}(1)-\operatorname{Ir}(1)-\mathrm{P}(2)-\mathrm{C}(17)$ & $-129.48(14)$ & $\operatorname{Ir}(1)-\mathrm{P}(1)-\mathrm{C}(13)-\mathrm{C}(16)$ & $-152.5(2)$ \\
\hline $\mathrm{C}(26)-\operatorname{Ir}(1)-\mathrm{P}(2)-\mathrm{C}(21)$ & $-138.08(18)$ & $\mathrm{C}(7)-\mathrm{P}(1)-\mathrm{C}(13)-\mathrm{C}(15)$ & $-164.4(3)$ \\
\hline $\mathrm{C}(1)-\operatorname{Ir}(1)-\mathrm{P}(2)-\mathrm{C}(21)$ & $131.12(17)$ & $\mathrm{C}(9)-\mathrm{P}(1)-\mathrm{C}(13)-\mathrm{C}(15)$ & $-52.1(3)$ \\
\hline C(25)-Ir(1)-P(2)-C(21) & $-37.60(18)$ & $\operatorname{Ir}(1)-\mathrm{P}(1)-\mathrm{C}(13)-\mathrm{C}(15)$ & $83.8(3)$ \\
\hline$P(1)-\operatorname{Ir}(1)-P(2)-C(21)$ & $94.54(17)$ & $\mathrm{C}(8)-\mathrm{P}(2)-\mathrm{C}(17)-\mathrm{C}(20)$ & $-166.3(3)$ \\
\hline$C(26)-\operatorname{Ir}(1)-C(1)-C(6)$ & $-109.8(3)$ & $\mathrm{C}(21)-\mathrm{P}(2)-\mathrm{C}(17)-\mathrm{C}(20)$ & $83.4(3)$ \\
\hline $\mathrm{C}(25)-\operatorname{Ir}(1)-\mathrm{C}(1)-\mathrm{C}(6)$ & $75.4(8)$ & $\operatorname{Ir}(1)-P(2)-C(17)-C(20)$ & $-56.7(3)$ \\
\hline$P(1)-\operatorname{Ir}(1)-C(1)-C(6)$ & $156.6(3)$ & $\mathrm{C}(8)-\mathrm{P}(2)-\mathrm{C}(17)-\mathrm{C}(19)$ & $71.5(3)$ \\
\hline $\mathrm{P}(2)-\operatorname{Ir}(1)-\mathrm{C}(1)-\mathrm{C}(6)$ & $-10.5(3)$ & $\mathrm{C}(21)-\mathrm{P}(2)-\mathrm{C}(17)-\mathrm{C}(19)$ & $-38.8(3)$ \\
\hline$C(26)-\operatorname{Ir}(1)-C(1)-C(2)$ & $73.8(3)$ & $\operatorname{Ir}(1)-\mathrm{P}(2)-\mathrm{C}(17)-\mathrm{C}(19)$ & $-178.9(2)$ \\
\hline$C(25)-\operatorname{Ir}(1)-C(1)-C(2)$ & $-101.0(8)$ & $\mathrm{C}(8)-\mathrm{P}(2)-\mathrm{C}(17)-\mathrm{C}(18)$ & $-47.7(3)$ \\
\hline$P(1)-\operatorname{Ir}(1)-C(1)-C(2)$ & $-19.8(2)$ & $\mathrm{C}(21)-\mathrm{P}(2)-\mathrm{C}(17)-\mathrm{C}(18)$ & $-158.0(2)$ \\
\hline $\mathrm{P}(2)-\operatorname{Ir}(1)-\mathrm{C}(1)-\mathrm{C}(2)$ & $173.0(3)$ & $\operatorname{Ir}(1)-\mathrm{P}(2)-\mathrm{C}(17)-\mathrm{C}(18)$ & $61.9(3)$ \\
\hline$C(6)-C(1)-C(2)-C(3)$ & $3.4(5)$ & $\mathrm{C}(8)-\mathrm{P}(2)-\mathrm{C}(21)-\mathrm{C}(23)$ & $-164.7(3)$ \\
\hline $\operatorname{Ir}(1)-C(1)-C(2)-C(3)$ & $180.0(3)$ & $\mathrm{C}(17)-\mathrm{P}(2)-\mathrm{C}(21)-\mathrm{C}(23)$ & $-54.3(3)$ \\
\hline$C(6)-C(1)-C(2)-C(7)$ & $-174.8(3)$ & $\operatorname{Ir}(1)-\mathrm{P}(2)-\mathrm{C}(21)-\mathrm{C}(23)$ & $84.1(3)$ \\
\hline $\operatorname{Ir}(1)-\mathrm{C}(1)-\mathrm{C}(2)-\mathrm{C}(7)$ & $1.8(4)$ & $\mathrm{C}(8)-\mathrm{P}(2)-\mathrm{C}(21)-\mathrm{C}(22)$ & $-41.3(3)$ \\
\hline $\mathrm{C}(1)-\mathrm{C}(2)-\mathrm{C}(3)-\mathrm{C}(4)$ & $-0.6(6)$ & $\mathrm{C}(17)-\mathrm{P}(2)-\mathrm{C}(21)-\mathrm{C}(22)$ & $69.0(3)$ \\
\hline $\mathrm{C}(7)-\mathrm{C}(2)-\mathrm{C}(3)-\mathrm{C}(4)$ & $177.5(4)$ & $\operatorname{Ir}(1)-\mathrm{P}(2)-\mathrm{C}(21)-\mathrm{C}(22)$ & $-152.5(2)$ \\
\hline $\mathrm{C}(2)-\mathrm{C}(3)-\mathrm{C}(4)-\mathrm{C}(5)$ & $-1.7(6)$ & $\mathrm{C}(8)-\mathrm{P}(2)-\mathrm{C}(21)-\mathrm{C}(24)$ & $75.5(3)$ \\
\hline $\mathrm{C}(3)-\mathrm{C}(4)-\mathrm{C}(5)-\mathrm{C}(6)$ & $1.1(6)$ & $\mathrm{C}(17)-\mathrm{P}(2)-\mathrm{C}(21)-\mathrm{C}(24)$ & $-174.1(3)$ \\
\hline$C(4)-C(5)-C(6)-C(1)$ & $1.8(6)$ & $\operatorname{Ir}(1)-\mathrm{P}(2)-\mathrm{C}(21)-\mathrm{C}(24)$ & $-35.7(4)$ \\
\hline $\mathrm{C}(4)-\mathrm{C}(5)-\mathrm{C}(6)-\mathrm{C}(8)$ & $-173.7(4)$ & $\mathrm{O}(2)-\mathrm{N}(1)-\mathrm{C}(25)-\operatorname{Ir}(1)$ & $83.8(4)$ \\
\hline$C(2)-C(1)-C(6)-C(5)$ & $-4.0(5)$ & $\mathrm{O}(1)-\mathrm{N}(1)-\mathrm{C}(25)-\operatorname{Ir}(1)$ & $-95.5(4)$ \\
\hline $\operatorname{Ir}(1)-C(1)-C(6)-C(5)$ & $179.5(3)$ & $\mathrm{C}(26)-\operatorname{Ir}(1)-\mathrm{C}(25)-\mathrm{N}(1)$ & $7.3(3)$ \\
\hline$C(2)-C(1)-C(6)-C(8)$ & 171.6(3) & $\mathrm{C}(1)-\operatorname{Ir}(1)-\mathrm{C}(25)-\mathrm{N}(1)$ & $-178.0(6)$ \\
\hline $\operatorname{Ir}(1)-\mathrm{C}(1)-\mathrm{C}(6)-\mathrm{C}(8)$ & $-4.9(4)$ & $\mathrm{P}(1)-\operatorname{Ir}(1)-\mathrm{C}(25)-\mathrm{N}(1)$ & $102.5(3)$ \\
\hline $\mathrm{C}(3)-\mathrm{C}(2)-\mathrm{C}(7)-\mathrm{P}(1)$ & $-154.5(3)$ & $\mathrm{P}(2)-\operatorname{Ir}(1)-\mathrm{C}(25)-\mathrm{N}(1)$ & $-93.5(3)$ \\
\hline $\mathrm{C}(1)-\mathrm{C}(2)-\mathrm{C}(7)-\mathrm{P}(1)$ & $23.7(4)$ & $\mathrm{C}(1)-\operatorname{Ir}(1)-\mathrm{C}(26)-\mathrm{O}(3)$ & $-8(4)$ \\
\hline C(13)-P(1)-C(7)-C(2) & $-159.9(2)$ & $C(25)-\operatorname{Ir}(1)-C(26)-O(3)$ & 171(4) \\
\hline $\mathrm{C}(9)-\mathrm{P}(1)-\mathrm{C}(7)-\mathrm{C}(2)$ & $84.7(3)$ & $\mathrm{P}(1)-\operatorname{Ir}(1)-\mathrm{C}(26)-\mathrm{O}(3)$ & $73(4)$ \\
\hline $\operatorname{Ir}(1)-\mathrm{P}(1)-\mathrm{C}(7)-\mathrm{C}(2)$ & $-33.5(3)$ & $\mathrm{P}(2)-\operatorname{Ir}(1)-\mathrm{C}(26)-\mathrm{O}(3)$ & $-90(4)$ \\
\hline
\end{tabular}


V. Structural Data for (PCP)IrH(CO) $\left(\mathrm{CNC}_{6} \mathrm{H}_{11}\right)(5)$.



Figure S-4. ORTEP diagrams of 5. Hydrogen atoms omitted for clarity. Thermal ellipsoids are shown at $50 \%$ probability. 
Table S-13. Crystal data and structure refinement for 5 .

Identification code

Empirical formula

Formula weight

Temperature

Wavelength

Crystal system

Space group

Unit cell dimensions

Volume

Z

Density (calculated)

Absorption coefficient

$\mathrm{F}(000)$

Crystal size

Theta range for data collection

Index ranges

Reflections collected

Independent reflections

Completeness to theta $=30.52^{\circ}$

Absorption correction

Max. and min. transmission

Refinement method

Data / restraints / parameters

Goodness-of-fit on $\mathrm{F}^{2}$

Final $\mathrm{R}$ indices [I $>2$ sigma(I)]

$\mathrm{R}$ indices (all data)

Largest diff. peak and hole irh_nm3

C32 H57 Ir N2 O2 P2

755.94

100(2) K

$0.71073 \AA$

Monoclinic

$\mathrm{C} 2 / \mathrm{c}$

$$
\begin{array}{ll}
\mathrm{a}=42.520(2) \AA & \alpha=90^{\circ} . \\
\mathrm{b}=8.4025(4) \AA & \beta=111.569(1)^{\circ} . \\
\mathrm{c}=19.9761(10) \AA & \gamma=90^{\circ} .
\end{array}
$$

6637.2(6) $\AA^{3}$

8

$1.513 \mathrm{Mg} / \mathrm{m}^{3}$

$4.150 \mathrm{~mm}^{-1}$

3088

$0.45 \times 0.30 \times 0.17 \mathrm{~mm}^{3}$

2.05 to $30.52^{\circ}$.

$-48<=\mathrm{h}<=58,-11<=\mathrm{k}<=12,-28<=1<=28$

28407

$9978[\mathrm{R}(\mathrm{int})=0.0219]$

$98.5 \%$

Semi-empirical from equivalents

0.9999 and 0.6211

Full-matrix least-squares on $\mathrm{F}^{2}$

9978 / 1 / 367

1.026

$\mathrm{R} 1=0.0240, \mathrm{wR} 2=0.0586$

$\mathrm{R} 1=0.0268, \mathrm{wR} 2=0.0597$

2.462 and -1.518 e. $\AA^{-3}$ 
Table S-14. Atomic coordinates ( $\left.\times 10^{4}\right)$ and equivalent isotropic displacement parameters $\left(\AA^{2} \times 10^{3}\right)$ for 5 . $U(e q)$ is defined as one third of the trace of the orthogonalized $U^{i j}$ tensor.

\begin{tabular}{|c|c|c|c|c|}
\hline & $\mathrm{x}$ & $\mathrm{y}$ & $\mathrm{z}$ & $\mathrm{U}(\mathrm{eq})$ \\
\hline $\operatorname{Ir}(1)$ & $8863(1)$ & $761(1)$ & 9487(1) & $8(1)$ \\
\hline $\mathrm{P}(1)$ & 9359(1) & $1609(1)$ & $10403(1)$ & $10(1)$ \\
\hline $\mathrm{P}(2)$ & $8516(1)$ & $-185(1)$ & $8354(1)$ & $11(1)$ \\
\hline $\mathrm{C}(1)$ & $9061(1)$ & 2072(2) & 8843(1) & $11(1)$ \\
\hline$C(2)$ & $9387(1)$ & 2736(3) & $9126(1)$ & $13(1)$ \\
\hline$C(3)$ & $9517(1)$ & $3651(3)$ & 8703(1) & $17(1)$ \\
\hline $\mathrm{C}(4)$ & 9331(1) & $3849(3)$ & 7973(1) & $19(1)$ \\
\hline$C(5)$ & $9020(1)$ & $3112(3)$ & $7667(1)$ & $18(1)$ \\
\hline $\mathrm{C}(6)$ & $8885(1)$ & 2239(3) & 8094(1) & $14(1)$ \\
\hline$C(7)$ & 9612(1) & 2294(3) & 9885(1) & $14(1)$ \\
\hline $\mathrm{C}(8)$ & $8548(1)$ & 1425(3) & 7755(1) & $15(1)$ \\
\hline$C(9)$ & $9338(1)$ & $3426(3)$ & $10936(1)$ & $13(1)$ \\
\hline$C(10)$ & $9086(1)$ & $3153(3)$ & $11309(1)$ & $16(1)$ \\
\hline $\mathrm{C}(11)$ & $9676(1)$ & 3953(3) & $11503(1)$ & $21(1)$ \\
\hline$C(12)$ & 9211(1) & 4787(3) & $10381(1)$ & $17(1)$ \\
\hline$C(13)$ & 9649(1) & $83(3)$ & $11028(1)$ & $14(1)$ \\
\hline $\mathrm{C}(14)$ & 9539(1) & $-297(3)$ & 11663(1) & $21(1)$ \\
\hline$C(15)$ & $10024(1)$ & $581(3)$ & $11324(1)$ & $19(1)$ \\
\hline$C(16)$ & 9626(1) & $-1458(3)$ & $10595(1)$ & $19(1)$ \\
\hline$C(17)$ & $8040(1)$ & $-423(3)$ & 8062(1) & $17(1)$ \\
\hline$C(18)$ & 7910(1) & $952(3)$ & 8397(1) & $20(1)$ \\
\hline$C(19)$ & 7941(1) & $-1980(3)$ & $8335(1)$ & $23(1)$ \\
\hline$C(20)$ & $7855(1)$ & $-314(4)$ & $7240(1)$ & $24(1)$ \\
\hline$C(21)$ & $8699(1)$ & $-2016(3)$ & 8081(1) & $15(1)$ \\
\hline $\mathrm{C}(22)$ & $8759(1)$ & $-3335(3)$ & 8653(1) & $19(1)$ \\
\hline$C(23)$ & $8481(1)$ & $-2703(3)$ & 7339(1) & $22(1)$ \\
\hline$C(24)$ & 9042(1) & $-1563(3)$ & 8041(1) & $18(1)$ \\
\hline$C(25)$ & 8693(1) & $-980(3)$ & $10111(1)$ & $14(1)$ \\
\hline $\mathrm{N}(1)$ & $8498(1)$ & $-334(2)$ & $10505(1)$ & $19(1)$ \\
\hline $\mathrm{O}(1)$ & 8196(1) & $-53(3)$ & 10183(1) & $47(1)$ \\
\hline $\mathrm{O}(2)$ & $8639(1)$ & $-43(3)$ & $11153(1)$ & $37(1)$ \\
\hline$C(26)$ & $8555(1)$ & $2470(3)$ & 9577(1) & $12(1)$ \\
\hline $\mathrm{N}(2)$ & $8381(1)$ & $3452(2)$ & 9660(1) & $16(1)$ \\
\hline$C(27)$ & 8151(1) & 4554(3) & 9801(1) & $16(1)$ \\
\hline $\mathrm{C}(28)$ & $8280(1)$ & $5000(3)$ & $10595(1)$ & $22(1)$ \\
\hline$C(29)$ & 8028(1) & 6107(4) & $10756(2)$ & $30(1)$ \\
\hline $\mathrm{C}(30)$ & 7678(1) & $5365(3)$ & $10512(1)$ & $25(1)$ \\
\hline $\mathrm{C}(31)$ & 7554(1) & 4959(3) & 9715(1) & $25(1)$ \\
\hline$C(32)$ & 7798(1) & 3821(3) & 9560(1) & $21(1)$ \\
\hline
\end{tabular}


Table S-15. Bond lengths $[\AA]$ and angles $\left[{ }^{\circ}\right]$ for $\mathbf{5}$.

\begin{tabular}{|c|c|c|c|}
\hline $\operatorname{Ir}(1)-C(26)$ & $1.997(2)$ & $\mathrm{C}(16)-\mathrm{H}(16 \mathrm{C})$ & 0.9800 \\
\hline $\operatorname{Ir}(1)-C(1)$ & $2.090(2)$ & $\mathrm{C}(17)-\mathrm{C}(19)$ & $1.535(3)$ \\
\hline $\operatorname{Ir}(1)-C(25)$ & $2.209(2)$ & $C(17)-C(18)$ & $1.538(3)$ \\
\hline $\operatorname{Ir}(1)-\mathrm{P}(1)$ & $2.3374(5)$ & $C(17)-C(20)$ & $1.542(3)$ \\
\hline $\operatorname{Ir}(1)-\mathrm{P}(2)$ & $2.3399(5)$ & $\mathrm{C}(18)-\mathrm{H}(18 \mathrm{~A})$ & 0.9800 \\
\hline $\operatorname{Ir}(1)-\mathrm{H}(1)$ & $1.574(16)$ & $\mathrm{C}(18)-\mathrm{H}(18 \mathrm{~B})$ & 0.9800 \\
\hline $\mathrm{P}(1)-\mathrm{C}(7)$ & $1.836(2)$ & $\mathrm{C}(18)-\mathrm{H}(18 \mathrm{C})$ & 0.9800 \\
\hline $\mathrm{P}(1)-\mathrm{C}(9)$ & $1.883(2)$ & $\mathrm{C}(19)-\mathrm{H}(19 \mathrm{~A})$ & 0.9800 \\
\hline $\mathrm{P}(1)-\mathrm{C}(13)$ & $1.895(2)$ & $\mathrm{C}(19)-\mathrm{H}(19 \mathrm{~B})$ & 0.9800 \\
\hline $\mathrm{P}(2)-\mathrm{C}(8)$ & $1.844(2)$ & $\mathrm{C}(19)-\mathrm{H}(19 \mathrm{C})$ & 0.9800 \\
\hline $\mathrm{P}(2)-\mathrm{C}(21)$ & $1.892(2)$ & $\mathrm{C}(20)-\mathrm{H}(20 \mathrm{~A})$ & 0.9800 \\
\hline$P(2)-C(17)$ & $1.898(2)$ & $\mathrm{C}(20)-\mathrm{H}(20 \mathrm{~B})$ & 0.9800 \\
\hline $\mathrm{C}(1)-\mathrm{C}(2)$ & $1.406(3)$ & $\mathrm{C}(20)-\mathrm{H}(20 \mathrm{C})$ & 0.9800 \\
\hline$C(1)-C(6)$ & $1.411(3)$ & $C(21)-C(24)$ & $1.537(3)$ \\
\hline$C(2)-C(3)$ & $1.399(3)$ & $\mathrm{C}(21)-\mathrm{C}(23)$ & $1.542(3)$ \\
\hline$C(2)-C(7)$ & $1.511(3)$ & $C(21)-C(22)$ & $1.543(3)$ \\
\hline $\mathrm{C}(3)-\mathrm{C}(4)$ & $1.389(3)$ & $\mathrm{C}(22)-\mathrm{H}(22 \mathrm{~A})$ & 0.9800 \\
\hline $\mathrm{C}(3)-\mathrm{H}(3)$ & 0.9500 & $\mathrm{C}(22)-\mathrm{H}(22 \mathrm{~B})$ & 0.9800 \\
\hline$C(4)-C(5)$ & $1.384(4)$ & $\mathrm{C}(22)-\mathrm{H}(22 \mathrm{C})$ & 0.9800 \\
\hline $\mathrm{C}(4)-\mathrm{H}(4)$ & 0.9500 & $\mathrm{C}(23)-\mathrm{H}(23 \mathrm{~A})$ & 0.9800 \\
\hline$C(5)-C(6)$ & $1.399(3)$ & $\mathrm{C}(23)-\mathrm{H}(23 \mathrm{~B})$ & 0.9800 \\
\hline $\mathrm{C}(5)-\mathrm{H}(5)$ & 0.9500 & $\mathrm{C}(23)-\mathrm{H}(23 \mathrm{C})$ & 0.9800 \\
\hline $\mathrm{C}(6)-\mathrm{C}(8)$ & $1.507(3)$ & $\mathrm{C}(24)-\mathrm{H}(24 \mathrm{~A})$ & 0.9800 \\
\hline $\mathrm{C}(7)-\mathrm{H}(7 \mathrm{~A})$ & 0.9900 & $\mathrm{C}(24)-\mathrm{H}(24 \mathrm{~B})$ & 0.9800 \\
\hline $\mathrm{C}(7)-\mathrm{H}(7 \mathrm{~B})$ & 0.9900 & $\mathrm{C}(24)-\mathrm{H}(24 \mathrm{C})$ & 0.9800 \\
\hline $\mathrm{C}(8)-\mathrm{H}(8 \mathrm{~A})$ & 0.9900 & $\mathrm{C}(25)-\mathrm{N}(1)$ & $1.445(3)$ \\
\hline $\mathrm{C}(8)-\mathrm{H}(8 \mathrm{~B})$ & 0.9900 & $\mathrm{C}(25)-\mathrm{H}(25 \mathrm{~A})$ & 0.9900 \\
\hline$C(9)-C(10)$ & $1.531(3)$ & $\mathrm{C}(25)-\mathrm{H}(25 \mathrm{~B})$ & 0.9900 \\
\hline $\mathrm{C}(9)-\mathrm{C}(11)$ & $1.532(3)$ & $\mathrm{N}(1)-\mathrm{O}(1)$ & $1.229(3)$ \\
\hline$C(9)-C(12)$ & $1.546(3)$ & $\mathrm{N}(1)-\mathrm{O}(2)$ & $1.233(3)$ \\
\hline $\mathrm{C}(10)-\mathrm{H}(10 \mathrm{~A})$ & 0.9800 & $\mathrm{C}(26)-\mathrm{N}(2)$ & $1.160(3)$ \\
\hline $\mathrm{C}(10)-\mathrm{H}(10 \mathrm{~B})$ & 0.9800 & $\mathrm{~N}(2)-\mathrm{C}(27)$ & $1.447(3)$ \\
\hline C(10)-H(10C) & 0.9800 & $\mathrm{C}(27)-\mathrm{C}(28)$ & $1.522(3)$ \\
\hline $\mathrm{C}(11)-\mathrm{H}(11 \mathrm{~A})$ & 0.9800 & $C(27)-C(32)$ & $1.526(3)$ \\
\hline $\mathrm{C}(11)-\mathrm{H}(11 \mathrm{~B})$ & 0.9800 & $\mathrm{C}(27)-\mathrm{H}(27)$ & 1.0000 \\
\hline C(11)-H(11C) & 0.9800 & $C(28)-C(29)$ & $1.540(4)$ \\
\hline $\mathrm{C}(12)-\mathrm{H}(12 \mathrm{~A})$ & 0.9800 & $\mathrm{C}(28)-\mathrm{H}(28 \mathrm{~A})$ & 0.9900 \\
\hline $\mathrm{C}(12)-\mathrm{H}(12 \mathrm{~B})$ & 0.9800 & $\mathrm{C}(28)-\mathrm{H}(28 \mathrm{~B})$ & 0.9900 \\
\hline C(12)-H(12C) & 0.9800 & $C(29)-C(30)$ & $1.519(4)$ \\
\hline$C(13)-C(14)$ & $1.537(3)$ & $\mathrm{C}(29)-\mathrm{H}(29 \mathrm{~A})$ & 0.9900 \\
\hline C(13)-C(16) & $1.540(3)$ & $\mathrm{C}(29)-\mathrm{H}(29 \mathrm{~B})$ & 0.9900 \\
\hline C(13)-C(15) & $1.542(3)$ & $\mathrm{C}(30)-\mathrm{C}(31)$ & $1.521(4)$ \\
\hline $\mathrm{C}(14)-\mathrm{H}(14 \mathrm{~A})$ & 0.9800 & $\mathrm{C}(30)-\mathrm{H}(30 \mathrm{~A})$ & 0.9900 \\
\hline C(14)-H(14B) & 0.9800 & $\mathrm{C}(30)-\mathrm{H}(30 \mathrm{~B})$ & 0.9900 \\
\hline C(14)-H(14C) & 0.9800 & $\mathrm{C}(31)-\mathrm{C}(32)$ & $1.526(3)$ \\
\hline $\mathrm{C}(15)-\mathrm{H}(15 \mathrm{~A})$ & 0.9800 & $\mathrm{C}(31)-\mathrm{H}(31 \mathrm{~A})$ & 0.9900 \\
\hline C(15)-H(15B) & 0.9800 & $\mathrm{C}(31)-\mathrm{H}(31 \mathrm{~B})$ & 0.9900 \\
\hline C(15)-H(15C) & 0.9800 & $\mathrm{C}(32)-\mathrm{H}(32 \mathrm{~A})$ & 0.9900 \\
\hline $\mathrm{C}(16)-\mathrm{H}(16 \mathrm{~A})$ & 0.9800 & $\mathrm{C}(32)-\mathrm{H}(32 \mathrm{~B})$ & 0.9900 \\
\hline $\mathrm{C}(16)-\mathrm{H}(16 \mathrm{~B})$ & 0.9800 & & \\
\hline$C(26)-\operatorname{Ir}(1)-C(1)$ & $95.86(8)$ & $C(25)-\operatorname{Ir}(1)-P(1)$ & $98.55(6)$ \\
\hline$C(26)-\operatorname{Ir}(1)-C(25)$ & $93.61(8)$ & $C(26)-\operatorname{Ir}(1)-P(2)$ & $97.46(6)$ \\
\hline$C(1)-\operatorname{Ir}(1)-C(25)$ & $170.21(8)$ & C(1)-Ir(1)-P(2) & $80.63(6)$ \\
\hline$C(26)-\operatorname{Ir}(1)-P(1)$ & $98.27(6)$ & C(25)-Ir(1)-P(2) & $95.70(6)$ \\
\hline $\mathrm{C}(1)-\operatorname{Ir}(1)-\mathrm{P}(1)$ & $82.55(6)$ & $\mathrm{P}(1)-\operatorname{Ir}(1)-\mathrm{P}(2)$ & $158.004(19)$ \\
\hline
\end{tabular}




\begin{tabular}{|c|c|}
\hline $\mathrm{C}(26)-\operatorname{Ir}(1)-\mathrm{H}(1)$ & $176.7(10)$ \\
\hline $\mathrm{C}(1)-\operatorname{Ir}(1)-\mathrm{H}(1)$ & $86.1(10)$ \\
\hline $\mathrm{C}(25)-\operatorname{Ir}(1)-\mathrm{H}(1)$ & $84.6(10)$ \\
\hline $\mathrm{P}(1)-\operatorname{Ir}(1)-\mathrm{H}(1)$ & $79.3(10)$ \\
\hline $\mathrm{P}(2)-\operatorname{Ir}(1)-\mathrm{H}(1)$ & $85.4(10)$ \\
\hline $\mathrm{C}(7)-\mathrm{P}(1)-\mathrm{C}(9)$ & $102.91(10)$ \\
\hline $\mathrm{C}(7)-\mathrm{P}(1)-\mathrm{C}(13)$ & $102.16(10)$ \\
\hline $\mathrm{C}(9)-\mathrm{P}(1)-\mathrm{C}(13)$ & $109.25(10)$ \\
\hline $\mathrm{C}(7)-\mathrm{P}(1)-\operatorname{Ir}(1)$ & $101.59(7)$ \\
\hline $\mathrm{C}(9)-\mathrm{P}(1)-\operatorname{Ir}(1)$ & $118.24(7)$ \\
\hline $\mathrm{C}(13)-\mathrm{P}(1)-\operatorname{Ir}(1)$ & $119.41(7)$ \\
\hline $\mathrm{C}(8)-\mathrm{P}(2)-\mathrm{C}(21)$ & $105.89(10)$ \\
\hline $\mathrm{C}(8)-\mathrm{P}(2)-\mathrm{C}(17)$ & 101.61(11) \\
\hline $\mathrm{C}(21)-\mathrm{P}(2)-\mathrm{C}(17)$ & $109.25(11)$ \\
\hline $\mathrm{C}(8)-\mathrm{P}(2)-\operatorname{Ir}(1)$ & $102.01(7)$ \\
\hline $\mathrm{C}(21)-\mathrm{P}(2)-\operatorname{Ir}(1)$ & $112.03(7)$ \\
\hline $\mathrm{C}(17)-\mathrm{P}(2)-\operatorname{Ir}(1)$ & $123.73(7)$ \\
\hline $\mathrm{C}(2)-\mathrm{C}(1)-\mathrm{C}(6)$ & $116.52(18)$ \\
\hline $\mathrm{C}(2)-\mathrm{C}(1)-\operatorname{Ir}(1)$ & $121.40(14)$ \\
\hline $\mathrm{C}(6)-\mathrm{C}(1)-\operatorname{Ir}(1)$ & $121.92(16)$ \\
\hline$C(3)-C(2)-C(1)$ & $121.73(19)$ \\
\hline $\mathrm{C}(3)-\mathrm{C}(2)-\mathrm{C}(7)$ & $119.7(2)$ \\
\hline $\mathrm{C}(1)-\mathrm{C}(2)-\mathrm{C}(7)$ & $118.26(18)$ \\
\hline$C(4)-C(3)-C(2)$ & $120.1(2)$ \\
\hline $\mathrm{C}(4)-\mathrm{C}(3)-\mathrm{H}(3)$ & 120.0 \\
\hline $\mathrm{C}(2)-\mathrm{C}(3)-\mathrm{H}(3)$ & 120.0 \\
\hline$C(5)-C(4)-C(3)$ & $119.5(2)$ \\
\hline $\mathrm{C}(5)-\mathrm{C}(4)-\mathrm{H}(4)$ & 120.3 \\
\hline $\mathrm{C}(3)-\mathrm{C}(4)-\mathrm{H}(4)$ & 120.3 \\
\hline$C(4)-C(5)-C(6)$ & $120.4(2)$ \\
\hline $\mathrm{C}(4)-\mathrm{C}(5)-\mathrm{H}(5)$ & 119.8 \\
\hline $\mathrm{C}(6)-\mathrm{C}(5)-\mathrm{H}(5)$ & 119.8 \\
\hline$C(5)-C(6)-C(1)$ & $121.5(2)$ \\
\hline$C(5)-C(6)-C(8)$ & $119.98(19)$ \\
\hline $\mathrm{C}(1)-\mathrm{C}(6)-\mathrm{C}(8)$ & $118.52(19)$ \\
\hline $\mathrm{C}(2)-\mathrm{C}(7)-\mathrm{P}(1)$ & $110.86(15)$ \\
\hline $\mathrm{C}(2)-\mathrm{C}(7)-\mathrm{H}(7 \mathrm{~A})$ & 109.5 \\
\hline $\mathrm{P}(1)-\mathrm{C}(7)-\mathrm{H}(7 \mathrm{~A})$ & 109.5 \\
\hline $\mathrm{C}(2)-\mathrm{C}(7)-\mathrm{H}(7 \mathrm{~B})$ & 109.5 \\
\hline $\mathrm{P}(1)-\mathrm{C}(7)-\mathrm{H}(7 \mathrm{~B})$ & 109.5 \\
\hline $\mathrm{H}(7 \mathrm{~A})-\mathrm{C}(7)-\mathrm{H}(7 \mathrm{~B})$ & 108.1 \\
\hline $\mathrm{C}(6)-\mathrm{C}(8)-\mathrm{P}(2)$ & $108.95(14)$ \\
\hline $\mathrm{C}(6)-\mathrm{C}(8)-\mathrm{H}(8 \mathrm{~A})$ & 109.9 \\
\hline $\mathrm{P}(2)-\mathrm{C}(8)-\mathrm{H}(8 \mathrm{~A})$ & 109.9 \\
\hline $\mathrm{C}(6)-\mathrm{C}(8)-\mathrm{H}(8 \mathrm{~B})$ & 109.9 \\
\hline $\mathrm{P}(2)-\mathrm{C}(8)-\mathrm{H}(8 \mathrm{~B})$ & 109.9 \\
\hline $\mathrm{H}(8 \mathrm{~A})-\mathrm{C}(8)-\mathrm{H}(8 \mathrm{~B})$ & 108.3 \\
\hline $\mathrm{C}(10)-\mathrm{C}(9)-\mathrm{C}(11)$ & $108.54(17)$ \\
\hline $\mathrm{C}(10)-\mathrm{C}(9)-\mathrm{C}(12)$ & $109.63(18)$ \\
\hline $\mathrm{C}(11)-\mathrm{C}(9)-\mathrm{C}(12)$ & $107.67(19)$ \\
\hline $\mathrm{C}(10)-\mathrm{C}(9)-\mathrm{P}(1)$ & $109.94(15)$ \\
\hline $\mathrm{C}(11)-\mathrm{C}(9)-\mathrm{P}(1)$ & $115.19(16)$ \\
\hline $\mathrm{C}(12)-\mathrm{C}(9)-\mathrm{P}(1)$ & $105.73(14)$ \\
\hline $\mathrm{C}(9)-\mathrm{C}(10)-\mathrm{H}(10 \mathrm{~A})$ & 109.5 \\
\hline $\mathrm{C}(9)-\mathrm{C}(10)-\mathrm{H}(10 \mathrm{~B})$ & 109.5 \\
\hline $\mathrm{H}(10 \mathrm{~A})-\mathrm{C}(10)-\mathrm{H}(10 \mathrm{~B})$ & 109.5 \\
\hline $\mathrm{C}(9)-\mathrm{C}(10)-\mathrm{H}(10 \mathrm{C})$ & 109.5 \\
\hline$(10 \mathrm{~A})-\mathrm{C}(10)-\mathrm{H}(10 \mathrm{C})$ & 109.5 \\
\hline
\end{tabular}

\begin{tabular}{|c|c|}
\hline $\mathrm{H}(10 \mathrm{~B})-\mathrm{C}(10)-\mathrm{H}(10 \mathrm{C})$ & 109.5 \\
\hline C(9)-C(11)-H(11A) & 109.5 \\
\hline $\mathrm{C}(9)-\mathrm{C}(11)-\mathrm{H}(11 \mathrm{~B})$ & 109.5 \\
\hline $\mathrm{H}(11 \mathrm{~A})-\mathrm{C}(11)-\mathrm{H}(11 \mathrm{~B})$ & 109.5 \\
\hline $\mathrm{C}(9)-\mathrm{C}(11)-\mathrm{H}(11 \mathrm{C})$ & 109.5 \\
\hline $\mathrm{H}(11 \mathrm{~A})-\mathrm{C}(11)-\mathrm{H}(11 \mathrm{C})$ & 109.5 \\
\hline $\mathrm{H}(11 \mathrm{~B})-\mathrm{C}(11)-\mathrm{H}(11 \mathrm{C})$ & 109.5 \\
\hline $\mathrm{C}(9)-\mathrm{C}(12)-\mathrm{H}(12 \mathrm{~A})$ & 109.5 \\
\hline $\mathrm{C}(9)-\mathrm{C}(12)-\mathrm{H}(12 \mathrm{~B})$ & 109.5 \\
\hline $\mathrm{H}(12 \mathrm{~A})-\mathrm{C}(12)-\mathrm{H}(12 \mathrm{~B})$ & 109.5 \\
\hline $\mathrm{C}(9)-\mathrm{C}(12)-\mathrm{H}(12 \mathrm{C})$ & 109.5 \\
\hline $\mathrm{H}(12 \mathrm{~A})-\mathrm{C}(12)-\mathrm{H}(12 \mathrm{C})$ & 109.5 \\
\hline $\mathrm{H}(12 \mathrm{~B})-\mathrm{C}(12)-\mathrm{H}(12 \mathrm{C})$ & 109.5 \\
\hline $\mathrm{C}(14)-\mathrm{C}(13)-\mathrm{C}(16)$ & $108.2(2)$ \\
\hline $\mathrm{C}(14)-\mathrm{C}(13)-\mathrm{C}(15)$ & 109.01(18) \\
\hline$C(16)-C(13)-C(15)$ & $106.63(19)$ \\
\hline $\mathrm{C}(14)-\mathrm{C}(13)-\mathrm{P}(1)$ & $111.36(16)$ \\
\hline $\mathrm{C}(16)-\mathrm{C}(13)-\mathrm{P}(1)$ & $107.85(14)$ \\
\hline $\mathrm{C}(15)-\mathrm{C}(13)-\mathrm{P}(1)$ & $113.56(15)$ \\
\hline $\mathrm{C}(13)-\mathrm{C}(14)-\mathrm{H}(14 \mathrm{~A})$ & 109.5 \\
\hline $\mathrm{C}(13)-\mathrm{C}(14)-\mathrm{H}(14 \mathrm{~B})$ & 109.5 \\
\hline $\mathrm{H}(14 \mathrm{~A})-\mathrm{C}(14)-\mathrm{H}(14 \mathrm{~B})$ & 109.5 \\
\hline $\mathrm{C}(13)-\mathrm{C}(14)-\mathrm{H}(14 \mathrm{C})$ & 109.5 \\
\hline $\mathrm{H}(14 \mathrm{~A})-\mathrm{C}(14)-\mathrm{H}(14 \mathrm{C})$ & 109.5 \\
\hline $\mathrm{H}(14 \mathrm{~B})-\mathrm{C}(14)-\mathrm{H}(14 \mathrm{C})$ & 109.5 \\
\hline $\mathrm{C}(13)-\mathrm{C}(15)-\mathrm{H}(15 \mathrm{~A})$ & 109.5 \\
\hline $\mathrm{C}(13)-\mathrm{C}(15)-\mathrm{H}(15 \mathrm{~B})$ & 109.5 \\
\hline $\mathrm{H}(15 \mathrm{~A})-\mathrm{C}(15)-\mathrm{H}(15 \mathrm{~B})$ & 109.5 \\
\hline $\mathrm{C}(13)-\mathrm{C}(15)-\mathrm{H}(15 \mathrm{C})$ & 109.5 \\
\hline $\mathrm{H}(15 \mathrm{~A})-\mathrm{C}(15)-\mathrm{H}(15 \mathrm{C})$ & 109.5 \\
\hline $\mathrm{H}(15 \mathrm{~B})-\mathrm{C}(15)-\mathrm{H}(15 \mathrm{C})$ & 109.5 \\
\hline $\mathrm{C}(13)-\mathrm{C}(16)-\mathrm{H}(16 \mathrm{~A})$ & 109.5 \\
\hline $\mathrm{C}(13)-\mathrm{C}(16)-\mathrm{H}(16 \mathrm{~B})$ & 109.5 \\
\hline $\mathrm{H}(16 \mathrm{~A})-\mathrm{C}(16)-\mathrm{H}(16 \mathrm{~B})$ & 109.5 \\
\hline $\mathrm{C}(13)-\mathrm{C}(16)-\mathrm{H}(16 \mathrm{C})$ & 109.5 \\
\hline $\mathrm{H}(16 \mathrm{~A})-\mathrm{C}(16)-\mathrm{H}(16 \mathrm{C})$ & 109.5 \\
\hline $\mathrm{H}(16 \mathrm{~B})-\mathrm{C}(16)-\mathrm{H}(16 \mathrm{C})$ & 109.5 \\
\hline C(19)-C(17)-C(18) & $107.2(2)$ \\
\hline C(19)-C(17)-C(20) & $109.2(2)$ \\
\hline $\mathrm{C}(18)-\mathrm{C}(17)-\mathrm{C}(20)$ & $107.0(2)$ \\
\hline $\mathrm{C}(19)-\mathrm{C}(17)-\mathrm{P}(2)$ & $112.39(16)$ \\
\hline $\mathrm{C}(18)-\mathrm{C}(17)-\mathrm{P}(2)$ & $107.58(16)$ \\
\hline $\mathrm{C}(20)-\mathrm{C}(17)-\mathrm{P}(2)$ & $113.08(17)$ \\
\hline $\mathrm{C}(17)-\mathrm{C}(18)-\mathrm{H}(18 \mathrm{~A})$ & 109.5 \\
\hline $\mathrm{C}(17)-\mathrm{C}(18)-\mathrm{H}(18 \mathrm{~B})$ & 109.5 \\
\hline $\mathrm{H}(18 \mathrm{~A})-\mathrm{C}(18)-\mathrm{H}(18 \mathrm{~B})$ & 109.5 \\
\hline $\mathrm{C}(17)-\mathrm{C}(18)-\mathrm{H}(18 \mathrm{C})$ & 109.5 \\
\hline $\mathrm{H}(18 \mathrm{~A})-\mathrm{C}(18)-\mathrm{H}(18 \mathrm{C})$ & 109.5 \\
\hline $\mathrm{H}(18 \mathrm{~B})-\mathrm{C}(18)-\mathrm{H}(18 \mathrm{C})$ & 109.5 \\
\hline $\mathrm{C}(17)-\mathrm{C}(19)-\mathrm{H}(19 \mathrm{~A})$ & 109.5 \\
\hline C(17)-C(19)-H(19B) & 109.5 \\
\hline $\mathrm{H}(19 \mathrm{~A})-\mathrm{C}(19)-\mathrm{H}(19 \mathrm{~B})$ & 109.5 \\
\hline $\mathrm{C}(17)-\mathrm{C}(19)-\mathrm{H}(19 \mathrm{C})$ & 109.5 \\
\hline $\mathrm{H}(19 \mathrm{~A})-\mathrm{C}(19)-\mathrm{H}(19 \mathrm{C})$ & 109.5 \\
\hline $\mathrm{H}(19 \mathrm{~B})-\mathrm{C}(19)-\mathrm{H}(19 \mathrm{C})$ & 109.5 \\
\hline $\mathrm{C}(17)-\mathrm{C}(20)-\mathrm{H}(20 \mathrm{~A})$ & 109.5 \\
\hline $\mathrm{C}(17)-\mathrm{C}(20)-\mathrm{H}(20 \mathrm{~B})$ & 109.5 \\
\hline $\mathrm{H}(20 \mathrm{~A})-\mathrm{C}(20)-\mathrm{H}(20 \mathrm{~B})$ & 109.5 \\
\hline
\end{tabular}




\begin{tabular}{|c|c|c|c|}
\hline$C(17)-C(20)-H(20 C)$ & 109.5 & $C(26)-N(2)-C(27)$ & $174.1(2)$ \\
\hline $\mathrm{H}(20 \mathrm{~A})-\mathrm{C}(20)-\mathrm{H}(20 \mathrm{C})$ & 109.5 & $\mathrm{~N}(2)-\mathrm{C}(27)-\mathrm{C}(28)$ & $110.45(19)$ \\
\hline $\mathrm{H}(20 \mathrm{~B})-\mathrm{C}(20)-\mathrm{H}(20 \mathrm{C})$ & 109.5 & $\mathrm{~N}(2)-\mathrm{C}(27)-\mathrm{C}(32)$ & $109.58(19)$ \\
\hline $\mathrm{C}(24)-\mathrm{C}(21)-\mathrm{C}(23)$ & $106.87(18)$ & $\mathrm{C}(28)-\mathrm{C}(27)-\mathrm{C}(32)$ & $111.46(19)$ \\
\hline $\mathrm{C}(24)-\mathrm{C}(21)-\mathrm{C}(22)$ & $108.33(19)$ & $\mathrm{N}(2)-\mathrm{C}(27)-\mathrm{H}(27)$ & 108.4 \\
\hline $\mathrm{C}(23)-\mathrm{C}(21)-\mathrm{C}(22)$ & 108.63(19) & $\mathrm{C}(28)-\mathrm{C}(27)-\mathrm{H}(27)$ & 108.4 \\
\hline $\mathrm{C}(24)-\mathrm{C}(21)-\mathrm{P}(2)$ & $108.13(15)$ & $\mathrm{C}(32)-\mathrm{C}(27)-\mathrm{H}(27)$ & 108.4 \\
\hline $\mathrm{C}(23)-\mathrm{C}(21)-\mathrm{P}(2)$ & $114.55(16)$ & $\mathrm{C}(27)-\mathrm{C}(28)-\mathrm{C}(29)$ & $110.6(2)$ \\
\hline $\mathrm{C}(22)-\mathrm{C}(21)-\mathrm{P}(2)$ & $110.13(14)$ & $\mathrm{C}(27)-\mathrm{C}(28)-\mathrm{H}(28 \mathrm{~A})$ & 109.5 \\
\hline $\mathrm{C}(21)-\mathrm{C}(22)-\mathrm{H}(22 \mathrm{~A})$ & 109.5 & $\mathrm{C}(29)-\mathrm{C}(28)-\mathrm{H}(28 \mathrm{~A})$ & 109.5 \\
\hline $\mathrm{C}(21)-\mathrm{C}(22)-\mathrm{H}(22 \mathrm{~B})$ & 109.5 & $\mathrm{C}(27)-\mathrm{C}(28)-\mathrm{H}(28 \mathrm{~B})$ & 109.5 \\
\hline $\mathrm{H}(22 \mathrm{~A})-\mathrm{C}(22)-\mathrm{H}(22 \mathrm{~B})$ & 109.5 & $\mathrm{C}(29)-\mathrm{C}(28)-\mathrm{H}(28 \mathrm{~B})$ & 109.5 \\
\hline $\mathrm{C}(21)-\mathrm{C}(22)-\mathrm{H}(22 \mathrm{C})$ & 109.5 & $\mathrm{H}(28 \mathrm{~A})-\mathrm{C}(28)-\mathrm{H}(28 \mathrm{~B})$ & 108.1 \\
\hline $\mathrm{H}(22 \mathrm{~A})-\mathrm{C}(22)-\mathrm{H}(22 \mathrm{C})$ & 109.5 & $\mathrm{C}(30)-\mathrm{C}(29)-\mathrm{C}(28)$ & $111.2(2)$ \\
\hline $\mathrm{H}(22 \mathrm{~B})-\mathrm{C}(22)-\mathrm{H}(22 \mathrm{C})$ & 109.5 & $\mathrm{C}(30)-\mathrm{C}(29)-\mathrm{H}(29 \mathrm{~A})$ & 109.4 \\
\hline $\mathrm{C}(21)-\mathrm{C}(23)-\mathrm{H}(23 \mathrm{~A})$ & 109.5 & $\mathrm{C}(28)-\mathrm{C}(29)-\mathrm{H}(29 \mathrm{~A})$ & 109.4 \\
\hline $\mathrm{C}(21)-\mathrm{C}(23)-\mathrm{H}(23 \mathrm{~B})$ & 109.5 & $\mathrm{C}(30)-\mathrm{C}(29)-\mathrm{H}(29 \mathrm{~B})$ & 109.4 \\
\hline $\mathrm{H}(23 \mathrm{~A})-\mathrm{C}(23)-\mathrm{H}(23 \mathrm{~B})$ & 109.5 & $\mathrm{C}(28)-\mathrm{C}(29)-\mathrm{H}(29 \mathrm{~B})$ & 109.4 \\
\hline $\mathrm{C}(21)-\mathrm{C}(23)-\mathrm{H}(23 \mathrm{C})$ & 109.5 & $\mathrm{H}(29 \mathrm{~A})-\mathrm{C}(29)-\mathrm{H}(29 \mathrm{~B})$ & 108.0 \\
\hline $\mathrm{H}(23 \mathrm{~A})-\mathrm{C}(23)-\mathrm{H}(23 \mathrm{C})$ & 109.5 & $\mathrm{C}(29)-\mathrm{C}(30)-\mathrm{C}(31)$ & $110.5(2)$ \\
\hline $\mathrm{H}(23 \mathrm{~B})-\mathrm{C}(23)-\mathrm{H}(23 \mathrm{C})$ & 109.5 & $\mathrm{C}(29)-\mathrm{C}(30)-\mathrm{H}(30 \mathrm{~A})$ & 109.6 \\
\hline $\mathrm{C}(21)-\mathrm{C}(24)-\mathrm{H}(24 \mathrm{~A})$ & 109.5 & $\mathrm{C}(31)-\mathrm{C}(30)-\mathrm{H}(30 \mathrm{~A})$ & 109.6 \\
\hline $\mathrm{C}(21)-\mathrm{C}(24)-\mathrm{H}(24 \mathrm{~B})$ & 109.5 & $\mathrm{C}(29)-\mathrm{C}(30)-\mathrm{H}(30 \mathrm{~B})$ & 109.6 \\
\hline $\mathrm{H}(24 \mathrm{~A})-\mathrm{C}(24)-\mathrm{H}(24 \mathrm{~B})$ & 109.5 & $\mathrm{C}(31)-\mathrm{C}(30)-\mathrm{H}(30 \mathrm{~B})$ & 109.6 \\
\hline $\mathrm{C}(21)-\mathrm{C}(24)-\mathrm{H}(24 \mathrm{C})$ & 109.5 & $\mathrm{H}(30 \mathrm{~A})-\mathrm{C}(30)-\mathrm{H}(30 \mathrm{~B})$ & 108.1 \\
\hline $\mathrm{H}(24 \mathrm{~A})-\mathrm{C}(24)-\mathrm{H}(24 \mathrm{C})$ & 109.5 & $\mathrm{C}(30)-\mathrm{C}(31)-\mathrm{C}(32)$ & $110.6(2)$ \\
\hline $\mathrm{H}(24 \mathrm{~B})-\mathrm{C}(24)-\mathrm{H}(24 \mathrm{C})$ & 109.5 & $\mathrm{C}(30)-\mathrm{C}(31)-\mathrm{H}(31 \mathrm{~A})$ & 109.5 \\
\hline $\mathrm{N}(1)-\mathrm{C}(25)-\operatorname{Ir}(1)$ & $115.62(15)$ & $\mathrm{C}(32)-\mathrm{C}(31)-\mathrm{H}(31 \mathrm{~A})$ & 109.5 \\
\hline $\mathrm{N}(1)-\mathrm{C}(25)-\mathrm{H}(25 \mathrm{~A})$ & 108.4 & $\mathrm{C}(30)-\mathrm{C}(31)-\mathrm{H}(31 \mathrm{~B})$ & 109.5 \\
\hline $\operatorname{Ir}(1)-\mathrm{C}(25)-\mathrm{H}(25 \mathrm{~A})$ & 108.4 & $\mathrm{C}(32)-\mathrm{C}(31)-\mathrm{H}(31 \mathrm{~B})$ & 109.5 \\
\hline $\mathrm{N}(1)-\mathrm{C}(25)-\mathrm{H}(25 \mathrm{~B})$ & 108.4 & $\mathrm{H}(31 \mathrm{~A})-\mathrm{C}(31)-\mathrm{H}(31 \mathrm{~B})$ & 108.1 \\
\hline $\mathrm{Ir}(1)-\mathrm{C}(25)-\mathrm{H}(25 \mathrm{~B})$ & 108.4 & $\mathrm{C}(31)-\mathrm{C}(32)-\mathrm{C}(27)$ & $110.3(2)$ \\
\hline $\mathrm{H}(25 \mathrm{~A})-\mathrm{C}(25)-\mathrm{H}(25 \mathrm{~B})$ & 107.4 & $\mathrm{C}(31)-\mathrm{C}(32)-\mathrm{H}(32 \mathrm{~A})$ & 109.6 \\
\hline $\mathrm{O}(1)-\mathrm{N}(1)-\mathrm{O}(2)$ & $121.5(2)$ & $\mathrm{C}(27)-\mathrm{C}(32)-\mathrm{H}(32 \mathrm{~A})$ & 109.6 \\
\hline $\mathrm{O}(1)-\mathrm{N}(1)-\mathrm{C}(25)$ & $119.1(2)$ & $\mathrm{C}(31)-\mathrm{C}(32)-\mathrm{H}(32 \mathrm{~B})$ & 109.6 \\
\hline $\mathrm{O}(2)-\mathrm{N}(1)-\mathrm{C}(25)$ & $119.3(2)$ & $\mathrm{C}(27)-\mathrm{C}(32)-\mathrm{H}(32 \mathrm{~B})$ & 109.6 \\
\hline $\mathrm{N}(2)-\mathrm{C}(26)-\operatorname{Ir}(1)$ & $177.19(17)$ & & \\
\hline $\mathrm{H}(32 \mathrm{~A})-\mathrm{C}(32)-\mathrm{H}(32 \mathrm{~B})$ & 108.1 & & \\
\hline
\end{tabular}


Table S-16. Torsion angles $\left[{ }^{\circ}\right]$ for 5.

\begin{tabular}{|c|c|c|c|}
\hline$\overline{C(26)-\operatorname{Ir}(1)-P(1)-C(7)}$ & $-110.27(10)$ & $\operatorname{Ir}(1)-\mathrm{P}(2)-\mathrm{C}(8)-\mathrm{C}(6)$ & $28.22(16)$ \\
\hline$C(1)-\operatorname{Ir}(1)-P(1)-C(7)$ & $-15.39(9)$ & $\mathrm{C}(7)-\mathrm{P}(1)-\mathrm{C}(9)-\mathrm{C}(10)$ & $170.63(15)$ \\
\hline C(25)-Ir(1)-P(1)-C(7) & $154.78(10)$ & $\mathrm{C}(13)-\mathrm{P}(1)-\mathrm{C}(9)-\mathrm{C}(10)$ & $-81.37(17)$ \\
\hline$P(2)-\operatorname{Ir}(1)-P(1)-C(7)$ & $24.96(10)$ & $\operatorname{Ir}(1)-\mathrm{P}(1)-\mathrm{C}(9)-\mathrm{C}(10)$ & $59.71(16)$ \\
\hline$C(26)-\operatorname{Ir}(1)-P(1)-C(9)$ & $1.39(10)$ & $\mathrm{C}(7)-\mathrm{P}(1)-\mathrm{C}(9)-\mathrm{C}(11)$ & $-66.38(18)$ \\
\hline$C(1)-\operatorname{Ir}(1)-P(1)-C(9)$ & $96.27(9)$ & $\mathrm{C}(13)-\mathrm{P}(1)-\mathrm{C}(9)-\mathrm{C}(11)$ & $41.62(19)$ \\
\hline C(25)-Ir(1)-P(1)-C(9) & $-93.56(10)$ & $\operatorname{Ir}(1)-\mathrm{P}(1)-\mathrm{C}(9)-\mathrm{C}(11)$ & $-177.30(14)$ \\
\hline$P(2)-\operatorname{Ir}(1)-P(1)-C(9)$ & $136.62(8)$ & $\mathrm{C}(7)-\mathrm{P}(1)-\mathrm{C}(9)-\mathrm{C}(12)$ & $52.37(16)$ \\
\hline C(26)-Ir(1)-P(1)-C(13) & $138.47(10)$ & $\mathrm{C}(13)-\mathrm{P}(1)-\mathrm{C}(9)-\mathrm{C}(12)$ & $160.37(15)$ \\
\hline $\mathrm{C}(1)-\operatorname{Ir}(1)-\mathrm{P}(1)-\mathrm{C}(13)$ & $-126.64(10)$ & $\operatorname{Ir}(1)-\mathrm{P}(1)-\mathrm{C}(9)-\mathrm{C}(12)$ & $-58.55(16)$ \\
\hline C(25)-Ir(1)-P(1)-C(13) & $43.53(10)$ & $\mathrm{C}(7)-\mathrm{P}(1)-\mathrm{C}(13)-\mathrm{C}(14)$ & $163.04(17)$ \\
\hline $\mathrm{P}(2)-\operatorname{Ir}(1)-\mathrm{P}(1)-\mathrm{C}(13)$ & $-86.30(10)$ & $\mathrm{C}(9)-\mathrm{P}(1)-\mathrm{C}(13)-\mathrm{C}(14)$ & $54.53(19)$ \\
\hline$C(26)-\operatorname{Ir}(1)-P(2)-C(8)$ & $72.66(10)$ & $\operatorname{Ir}(1)-\mathrm{P}(1)-\mathrm{C}(13)-\mathrm{C}(14)$ & $-86.02(17)$ \\
\hline $\mathrm{C}(1)-\operatorname{Ir}(1)-\mathrm{P}(2)-\mathrm{C}(8)$ & $-22.09(10)$ & $\mathrm{C}(7)-\mathrm{P}(1)-\mathrm{C}(13)-\mathrm{C}(16)$ & $-78.41(17)$ \\
\hline C(25)-Ir(1)-P(2)-C(8) & $167.08(10)$ & $\mathrm{C}(9)-\mathrm{P}(1)-\mathrm{C}(13)-\mathrm{C}(16)$ & $173.09(15)$ \\
\hline$P(1)-\operatorname{Ir}(1)-P(2)-C(8)$ & $-62.68(10)$ & $\operatorname{Ir}(1)-\mathrm{P}(1)-\mathrm{C}(13)-\mathrm{C}(16)$ & $32.54(18)$ \\
\hline$C(26)-\operatorname{Ir}(1)-P(2)-C(21)$ & $-174.50(10)$ & $\mathrm{C}(7)-\mathrm{P}(1)-\mathrm{C}(13)-\mathrm{C}(15)$ & $39.52(18)$ \\
\hline $\mathrm{C}(1)-\operatorname{Ir}(1)-\mathrm{P}(2)-\mathrm{C}(21)$ & $90.75(10)$ & $\mathrm{C}(9)-\mathrm{P}(1)-\mathrm{C}(13)-\mathrm{C}(15)$ & $-68.98(18)$ \\
\hline C(25)-Ir(1)-P(2)-C(21) & $-80.09(10)$ & $\operatorname{Ir}(1)-\mathrm{P}(1)-\mathrm{C}(13)-\mathrm{C}(15)$ & $150.47(14)$ \\
\hline $\mathrm{P}(1)-\operatorname{Ir}(1)-\mathrm{P}(2)-\mathrm{C}(21)$ & $50.16(10)$ & $\mathrm{C}(8)-\mathrm{P}(2)-\mathrm{C}(17)-\mathrm{C}(19)$ & 164.91(16) \\
\hline C(26)-Ir(1)-P(2)-C(17) & $-40.25(11)$ & $\mathrm{C}(21)-\mathrm{P}(2)-\mathrm{C}(17)-\mathrm{C}(19)$ & $53.33(18)$ \\
\hline $\mathrm{C}(1)-\operatorname{Ir}(1)-\mathrm{P}(2)-\mathrm{C}(17)$ & $-135.00(11)$ & $\operatorname{Ir}(1)-\mathrm{P}(2)-\mathrm{C}(17)-\mathrm{C}(19)$ & $-81.98(17)$ \\
\hline C(25)-Ir(1)-P(2)-C(17) & $54.16(11)$ & $\mathrm{C}(8)-\mathrm{P}(2)-\mathrm{C}(17)-\mathrm{C}(18)$ & $-77.27(17)$ \\
\hline $\mathrm{P}(1)-\operatorname{Ir}(1)-\mathrm{P}(2)-\mathrm{C}(17)$ & $-175.59(10)$ & $\mathrm{C}(21)-\mathrm{P}(2)-\mathrm{C}(17)-\mathrm{C}(18)$ & $171.15(15)$ \\
\hline$C(26)-\operatorname{Ir}(1)-C(1)-C(2)$ & $104.22(17)$ & $\operatorname{Ir}(1)-\mathrm{P}(2)-\mathrm{C}(17)-\mathrm{C}(18)$ & $35.85(19)$ \\
\hline$C(25)-\operatorname{Ir}(1)-C(1)-C(2)$ & $-90.5(5)$ & $\mathrm{C}(8)-\mathrm{P}(2)-\mathrm{C}(17)-\mathrm{C}(20)$ & $40.7(2)$ \\
\hline$P(1)-\operatorname{Ir}(1)-C(1)-C(2)$ & $6.62(16)$ & $\mathrm{C}(21)-\mathrm{P}(2)-\mathrm{C}(17)-\mathrm{C}(20)$ & $-70.9(2)$ \\
\hline $\mathrm{P}(2)-\operatorname{Ir}(1)-\mathrm{C}(1)-\mathrm{C}(2)$ & $-159.16(17)$ & $\operatorname{Ir}(1)-P(2)-C(17)-C(20)$ & $153.82(15)$ \\
\hline$C(26)-\operatorname{Ir}(1)-C(1)-C(6)$ & $-80.52(18)$ & $\mathrm{C}(8)-\mathrm{P}(2)-\mathrm{C}(21)-\mathrm{C}(24)$ & $49.19(16)$ \\
\hline$C(25)-\operatorname{Ir}(1)-C(1)-C(6)$ & $84.8(5)$ & $\mathrm{C}(17)-\mathrm{P}(2)-\mathrm{C}(21)-\mathrm{C}(24)$ & $157.92(14)$ \\
\hline$P(1)-\operatorname{Ir}(1)-C(1)-C(6)$ & $-178.12(17)$ & $\operatorname{Ir}(1)-\mathrm{P}(2)-\mathrm{C}(21)-\mathrm{C}(24)$ & $-61.21(15)$ \\
\hline$P(2)-\operatorname{Ir}(1)-C(1)-C(6)$ & $16.10(16)$ & $\mathrm{C}(8)-\mathrm{P}(2)-\mathrm{C}(21)-\mathrm{C}(23)$ & $-69.84(19)$ \\
\hline$C(6)-C(1)-C(2)-C(3)$ & $6.3(3)$ & $\mathrm{C}(17)-\mathrm{P}(2)-\mathrm{C}(21)-\mathrm{C}(23)$ & $38.88(19)$ \\
\hline $\operatorname{Ir}(1)-\mathrm{C}(1)-\mathrm{C}(2)-\mathrm{C}(3)$ & $-178.23(16)$ & $\operatorname{Ir}(1)-\mathrm{P}(2)-\mathrm{C}(21)-\mathrm{C}(23)$ & $179.76(14)$ \\
\hline$C(6)-C(1)-C(2)-C(7)$ & $-167.26(19)$ & $\mathrm{C}(8)-\mathrm{P}(2)-\mathrm{C}(21)-\mathrm{C}(22)$ & $167.39(16)$ \\
\hline $\operatorname{Ir}(1)-C(1)-C(2)-C(7)$ & $8.2(3)$ & $\mathrm{C}(17)-\mathrm{P}(2)-\mathrm{C}(21)-\mathrm{C}(22)$ & $-83.89(17)$ \\
\hline $\mathrm{C}(1)-\mathrm{C}(2)-\mathrm{C}(3)-\mathrm{C}(4)$ & $-3.8(3)$ & $\operatorname{Ir}(1)-\mathrm{P}(2)-\mathrm{C}(21)-\mathrm{C}(22)$ & $56.98(17)$ \\
\hline$C(7)-C(2)-C(3)-C(4)$ & $169.7(2)$ & $\mathrm{C}(26)-\operatorname{Ir}(1)-\mathrm{C}(25)-\mathrm{N}(1)$ & $-13.52(17)$ \\
\hline$C(2)-C(3)-C(4)-C(5)$ & $-1.1(4)$ & $\mathrm{C}(1)-\operatorname{Ir}(1)-\mathrm{C}(25)-\mathrm{N}(1)$ & $-179(3)$ \\
\hline$C(3)-C(4)-C(5)-C(6)$ & $3.2(4)$ & $\mathrm{P}(1)-\operatorname{Ir}(1)-\mathrm{C}(25)-\mathrm{N}(1)$ & $85.41(16)$ \\
\hline $\mathrm{C}(4)-\mathrm{C}(5)-\mathrm{C}(6)-\mathrm{C}(1)$ & $-0.5(3)$ & $\mathrm{P}(2)-\operatorname{Ir}(1)-\mathrm{C}(25)-\mathrm{N}(1)$ & $-111.39(16)$ \\
\hline$C(4)-C(5)-C(6)-C(8)$ & $-179.3(2)$ & $\operatorname{Ir}(1)-\mathrm{C}(25)-\mathrm{N}(1)-\mathrm{O}(1)$ & $80.0(3)$ \\
\hline$C(2)-C(1)-C(6)-C(5)$ & $-4.2(3)$ & $\operatorname{Ir}(1)-\mathrm{C}(25)-\mathrm{N}(1)-\mathrm{O}(2)$ & $-98.3(2)$ \\
\hline $\operatorname{Ir}(1)-C(1)-C(6)-C(5)$ & $-179.63(17)$ & $\mathrm{C}(1)-\operatorname{Ir}(1)-\mathrm{C}(26)-\mathrm{N}(2)$ & $-132(4)$ \\
\hline $\mathrm{C}(2)-\mathrm{C}(1)-\mathrm{C}(6)-\mathrm{C}(8)$ & 174.69(19) & $\mathrm{C}(25)-\operatorname{Ir}(1)-\mathrm{C}(26)-\mathrm{N}(2)$ & $50(4)$ \\
\hline $\operatorname{Ir}(1)-\mathrm{C}(1)-\mathrm{C}(6)-\mathrm{C}(8)$ & $-0.8(3)$ & $\mathrm{P}(1)-\operatorname{Ir}(1)-\mathrm{C}(26)-\mathrm{N}(2)$ & $-49(4)$ \\
\hline $\mathrm{C}(3)-\mathrm{C}(2)-\mathrm{C}(7)-\mathrm{P}(1)$ & $163.90(17)$ & $\mathrm{P}(2)-\operatorname{Ir}(1)-\mathrm{C}(26)-\mathrm{N}(2)$ & $147(4)$ \\
\hline $\mathrm{C}(1)-\mathrm{C}(2)-\mathrm{C}(7)-\mathrm{P}(1)$ & $-22.4(2)$ & $\operatorname{Ir}(1)-\mathrm{C}(26)-\mathrm{N}(2)-\mathrm{C}(27)$ & $-53(5)$ \\
\hline $\mathrm{C}(9)-\mathrm{P}(1)-\mathrm{C}(7)-\mathrm{C}(2)$ & $-99.13(16)$ & $\mathrm{C}(26)-\mathrm{N}(2)-\mathrm{C}(27)-\mathrm{C}(28)$ & $72(2)$ \\
\hline C(13)-P(1)-C(7)-C(2) & $147.58(15)$ & $\mathrm{C}(26)-\mathrm{N}(2)-\mathrm{C}(27)-\mathrm{C}(32)$ & $-51(2)$ \\
\hline $\operatorname{Ir}(1)-\mathrm{P}(1)-\mathrm{C}(7)-\mathrm{C}(2)$ & $23.73(16)$ & $\mathrm{N}(2)-\mathrm{C}(27)-\mathrm{C}(28)-\mathrm{C}(29)$ & $-177.2(2)$ \\
\hline$C(5)-C(6)-C(8)-P(2)$ & $158.60(17)$ & $\mathrm{C}(32)-\mathrm{C}(27)-\mathrm{C}(28)-\mathrm{C}(29)$ & $-55.1(3)$ \\
\hline $\mathrm{C}(1)-\mathrm{C}(6)-\mathrm{C}(8)-\mathrm{P}(2)$ & $-20.3(2)$ & $\mathrm{C}(27)-\mathrm{C}(28)-\mathrm{C}(29)-\mathrm{C}(30)$ & $55.2(3)$ \\
\hline $\mathrm{C}(21)-\mathrm{P}(2)-\mathrm{C}(8)-\mathrm{C}(6)$ & $-89.13(16)$ & $\mathrm{C}(28)-\mathrm{C}(29)-\mathrm{C}(30)-\mathrm{C}(31)$ & $-56.7(3)$ \\
\hline C(17)-P(2)-C(8)-C(6) & $156.77(15)$ & $\mathrm{N}(2)-\mathrm{C}(27)-\mathrm{C}(32)-\mathrm{C}(31)$ & 179.22(19) \\
\hline
\end{tabular}

